\title{
Population Viability and Resource Competition on North Brother Island: Conservation implications for tuatara (Sphenodon punctatus) and Duvaucel's Gecko (Hoplodactylus duvaucelii)
}

\author{
Joanna Wilson
}

A thesis submitted as partial fulfilment of the requirements for the degree of Master of Science in Conservation Biology

Victoria University of Wellington 


\section{Abstract}

Population viability for small, isolated populations is determined by many factors, particularly demographic stochasticity. Coexistence of communities is promoted through resource partitioning, particularly if species share similar niche requirements. Demographic characteristics, long-term trends and patterns of partitioning were investigated for two reptile species: tuatara (Sphenodon punctatus) and Duvaucel's gecko (Hoplodactylus duvaucelii), using mark recapture techniques on North Brother Island, New Zealand. Capture time and location were recorded as well as snout-vent length, mass and sex of individuals. Adult population size, sex ratio, survival and recapture probability for both species were estimated.

Intervention will be needed to prevent population collapse for tuatara, as the population is male-biased (3.24 males: 1 female), with sub-adults exhibiting a stronger bias (4.1 males: 1 female). The total population size is estimated at 390-437 adults, with high adult survival (95\%). The Duvaucel's gecko population is stable enough to be harvested for translocation, as the population was estimated at 583-677 adults, with an even sex ratio. Adult survival was high (92\%) and longevity is at least $43-50$ years. Patterns in partitioning suggest tuatara are excluding Duvaucel's gecko as tuatara occupy vegetated areas and few animals were caught at the same time in the same place as a member of the other species $(\sim 10 \%)$. Long-term site fidelity appears to occur in both species as the majority of animals were captured previously within $10 \mathrm{~m}$ (tuatara) or 15m (Duvaucel's gecko) of their 2008 location, and travelled less than $2 \mathrm{~m}$ per year on average.

Tuatara show an overall decline in body condition since 1957, which is more rapid in females, and may be related to intraspecific interactions and density-dependent effects. 
Gecko body condition is not declining, suggesting no negative effects at the population level are occurring as a result of competitive exclusion. This study indicates that characteristics that have implications for population viability have the capacity to differ, even for species with similar niche requirements occupying the same habitat, and supports the considerable value of long-term monitoring. 


\section{Acknowledgements}

Thanks Nicky for being a great supervisor and reading my tuatara chapter at least 8 times without complaining! Thankfully the rest went a lot faster. Without Nicky's help I would have been even more confused, and more frequently, than I was. If I was ever stuck Nicky was there to give me advice and was very patient at explaining things to me, even when I was being particularly dense.

Thanks to Peter Martin, Jennifer Moore, Kimberly Miller, Sue Keall and Nicky Nelson for giving up their nights to walk along cliff edges as my field assistants. Jen, Nicky and Pete also managed to keep us in fresh fish for the week, which was a tasty addition to our field rations of chocolate and fruit toast.

The historical data I used was generously provided by Sue Keall, which she and many people had been involved in collecting over the last 50 years. Jo Hoare also provided me with the original graphs from her study on body condition of tuatara on North Brother Island. She saved me many hours of data entry and calculations and for that I am very grateful!

Throughout my work, many people have provided assistance and comments on my manuscripts. Firstly, Shirley Pledger assisted me in interpreting the results from my models. Secondly, to the Hatchet group of 2009 for their helpful comments. And finally Mel Duncan and Hilary Cresko, who went through the whole Masters experience with me and had the dubious pleasure of reading all my stuff over and over again. Also Mel helped me understand my statistics, which took a few explanations to sink in and Hilary 
helped me out with my site fidelity measurements. Thanks so much guys! Couldn't have done it without you.

I would also like to thank Dallas zoo, Toledo Zoo and St Louis Zoo for providing the funding for this study. Without your generous support this work would not have taken place. Thanks also to the School of Biological Sciences at Victoria and the Allan Wilson Centre for their support and encouragement.

Thanks to the Department of Conservation (Permit NM-23655-RES), Victoria University Animal Ethics Committee (\#2006R12) and Te Atiawa Manawhenua ki te Tau Ihu for granting me permission to work on North Brother Island.

Finally, thanks have to go to my parents Fay and Geoff Wilson for keeping me fed and housed while I did my thesis. You may have had absolutely no idea what I was talking about most of the time but hopefully this makes a nice addition to your bookcase. 


\section{Table of Contents}

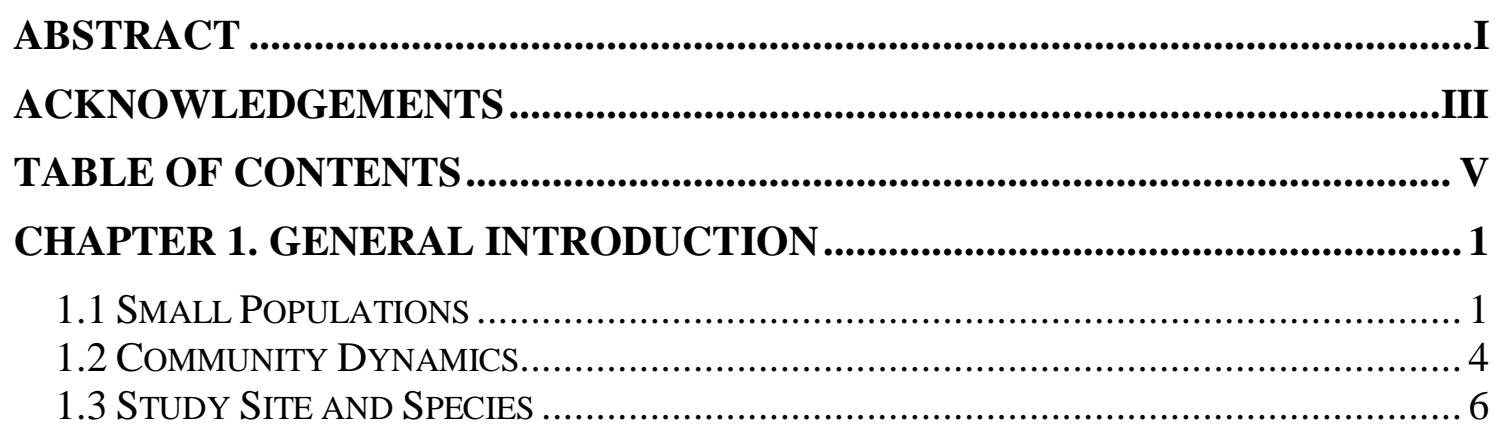

CHAPTER 2: SEX BIAS IN TUATARA (SPHENODON PUNCTATUS) ON

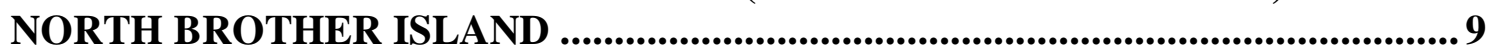

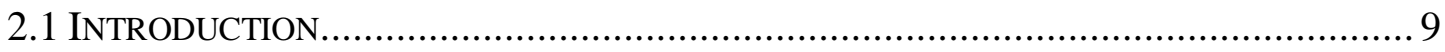

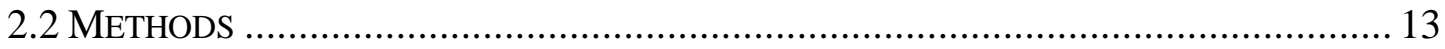

2.2.1 Field Site Description ....................................................................... 13

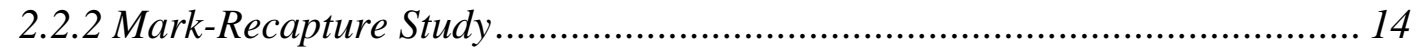

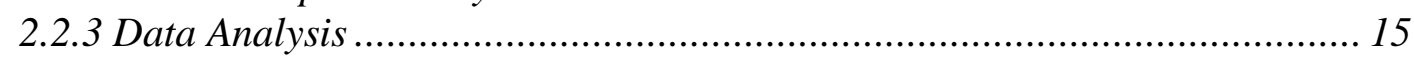

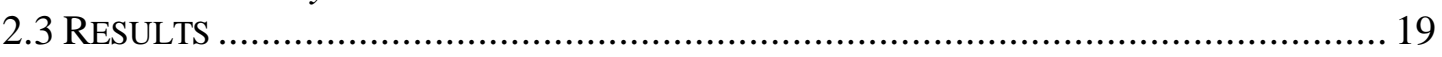

2.3.1 Recruitment, size, mass, and body condition........................................... 19

2.3.2 Estimates of Population Size ..................................................................... 21

2.3.3 Estimates of Sex Ratio ...................................................................... 23

2.3.4 Survival and Recapture Rates .............................................................. 24

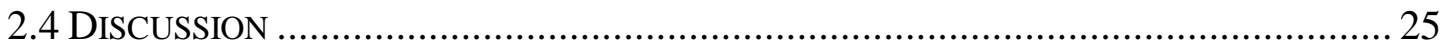

2.4.1 Population Characteristics ………………………………………….... 25

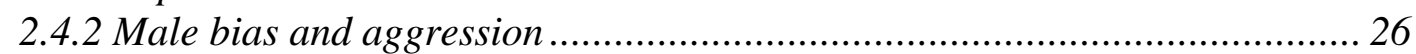

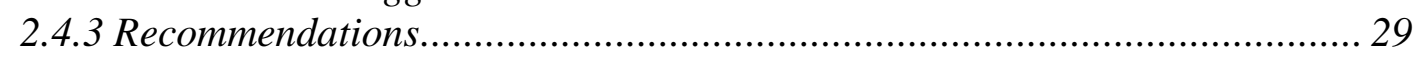

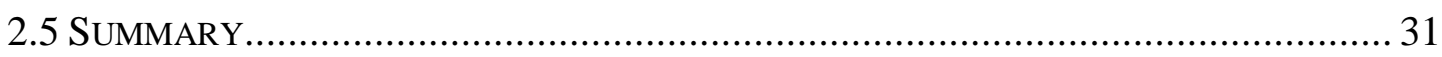

CHAPTER 3: POPULATION CHARACTERISTICS OF DUVAUCEL'S GECKO HOPLODACTYLUS DUVAUCELII ON NORTH BROTHER ISLAND.................. 33

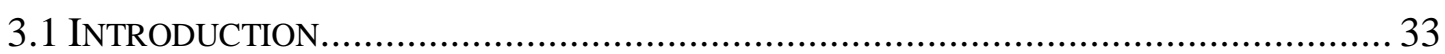

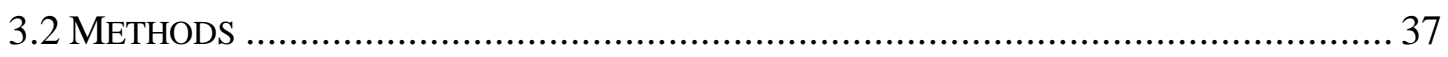

3.2.1 Field Site Description................................................................................... 37

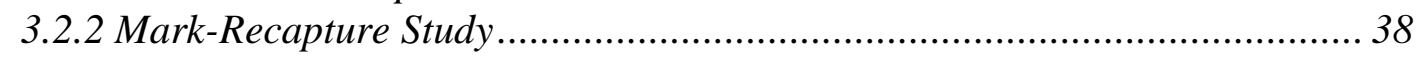

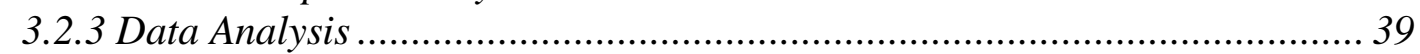

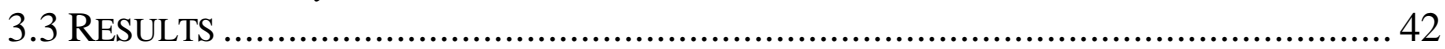

3.3.1 Descriptive Statistics of Captured Individuals........................................... 42

3.3.2 Estimates of Population Size and Sex Ratio …………………………….... 43

3.3.3 Estimates of Survival ............................................................................. 45

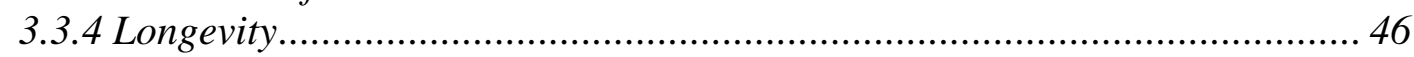

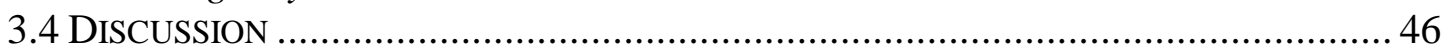

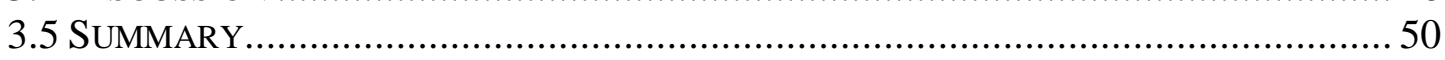

CHAPTER 4: POTENTIAL FOR RESOURCE COMPETITION ..........................51

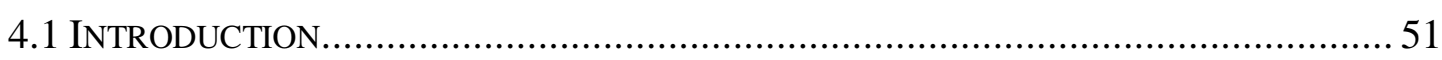

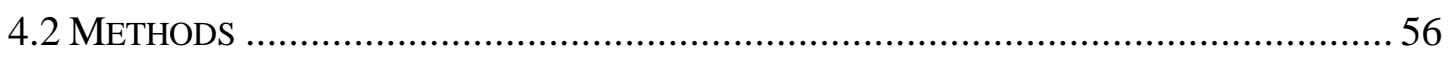

4.2.1 Field Site Description ............................................................................ 56 


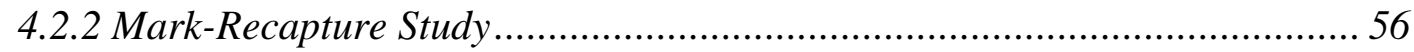

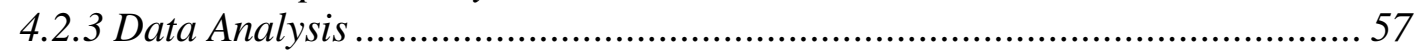

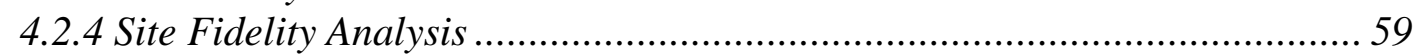

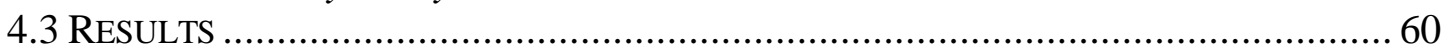

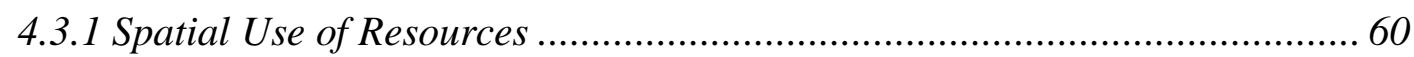

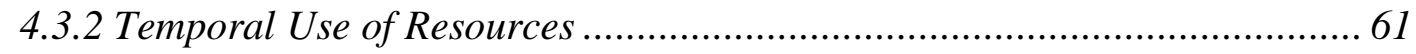

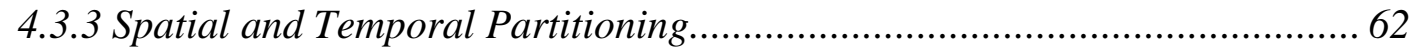

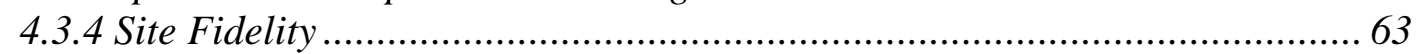

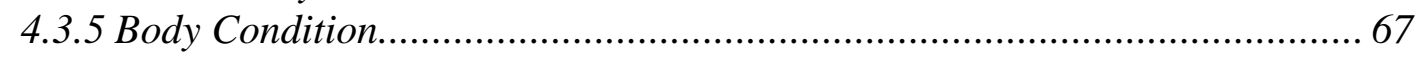

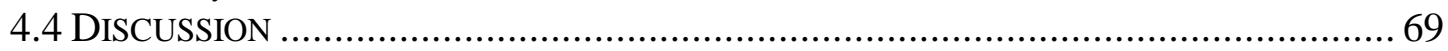

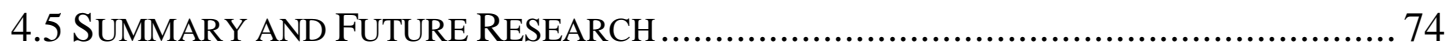

CHAPTER 5: SYNTHESIS OF RESULTS, RECOMMENDATIONS AND

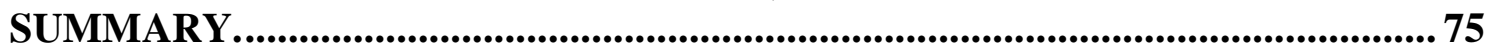

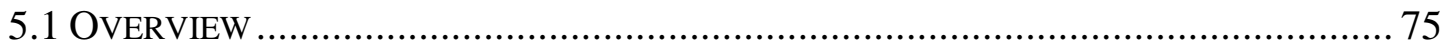

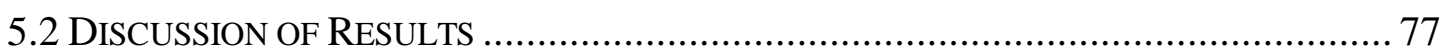

5.3 CONSERVATION ISSUES AND RECOMMENDATIONS FOR SPHENODON PUNCTATUS ON

NORTH BROTHER ISLAND ................................................................................ 80

5.4 CONSERVATION ISSUES AND RECOMMENDATIONS FOR HOPLODACTYLUS

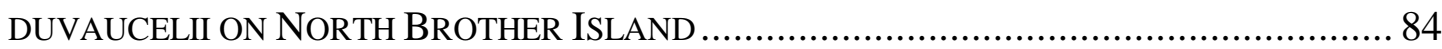

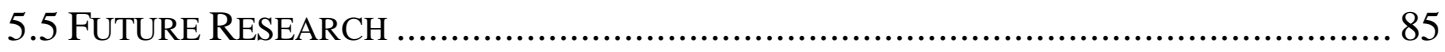

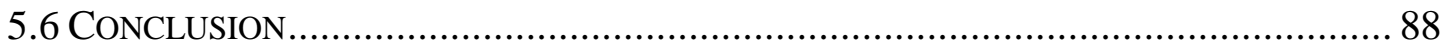

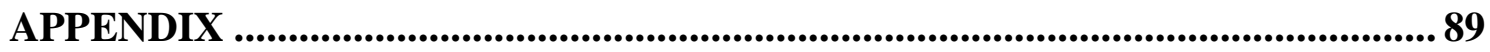

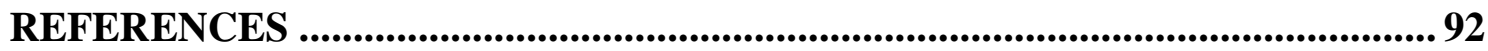




\section{Chapter 1. General Introduction}

\subsection{Small Populations}

Species are vulnerable to extinction due to a number of factors, many of which are anthropogenically sourced, including overexploitation, pollution and habitat modification (Lande 1998). One of the most important factors in species extinction in the past has been the introduction of exotic species (Lande 1998). Carnivorous mammals in particular have been a problem in many island nations and have led to the decline in range and population numbers of many species. In New Zealand, many species have suffered range contractions due to the introduction of rats, cats and mustelids. Due to the financial and practical difficulties involved in complete eradication, conservation efforts have been largely limited to fenced mainland reserves and offshore islands (Towns \& Broome 2003). These isolated populations are often small and have long-term population viability concerns.

In addition to anthropogenic influences, Shaffer (1981) identified four factors that affect population viability. These are demographic stochasticity, environmental stochasticity, natural catastrophe and genetic stochasticity. While all of these factors contribute to population viability, the impacts of each differ depending on the species and population under examination.

Demographic stochasticity arises from the natural variation in demographic characteristics affecting population size and growth, such as reproductive success, sex ratios and survival (Boyce et al. 2006; Lande 1998). Demographic stochasticity is very important in small populations, where variation in individual survival and reproductive 
rates have a greater impact than they would in a large population (Lande 1993). In a very small population the loss of a single breeding female may drastically reduce recruitment into the population. For example, the population of black rhinoceros (Diceros bicornis) in the Ngorongoro Crater was severely reduced by poachers and now numbers approximately 13-15 individuals, with potentially only 5 animals contributing to reproduction (Moehlman et al. 1996). The death of a breeding female due to poaching in 1995 would have impacted on the population's ability to grow and persist long-tem. Even in a large population, a skewed sex ratio may reduce the effective population size to a smaller number of individuals that contribute to reproduction.

Environmental stochasticity arises from natural variation in the environment over time (Shaffer 1981) and can affect a population of any size (Lande 1993). This variation includes changes in habitat and community structure, which can result in distribution changes, lower recruitment and changes in food availability. For example, the fecundity and population size of several ungulate species is related to climatic conditions influencing food quality and availability (Sæther 1997). Environmental variation as a result of global climate change is becoming of increasing concern. Skewed sex ratios may result for species with temperature-dependent sex determination, if females cannot make behavioural changes to alter nesting conditions in response to temperature, or migration is unable to occur in response to climate change (Janzen 1994).

Natural catastrophes are rare events in time that include floods, fire, disease and droughts (Shaffer 1981). Although these events are infrequent, they can have a major effect on a population, dramatically reducing population numbers, regardless of the initial population size. A population crash of wolf numbers in the Isle Royale National 
Park, Michigan, was attributed to a canine parvovirus outbreak (Peterson et al. 1998). Invasions by exotic species may also be considered catastrophes. Following the introduction of Nile perch (Lates nilotica) to Lake Victoria, Africa, many species have become extinct or declined drastically, which has had detrimental cascading effects throughout the lake community (Goldschmidt et al. 1993).

Genetic stochasticity is the change in gene frequencies arising from allele fixation, deleterious gene mutations and inbreeding depression (Lande 1998). A reduction in quantitative genetic variation from these factors can reduce a population's ability to adapt and persist long-term in a changing environment (Lande 1995). High levels of inbreeding depression in small populations can quickly lead to extinction, whereas moderately deleterious mutations can build up in a population over long periods of time, causing a slow erosion of fitness (Lande 1995). Demographic and genetic stochasticity, which can depress population size or growth, may be mitigated by immigration from other populations (Shaffer 1981). However, if the population is isolated, by being on an island or in an enclosed reserve, immigration may be impossible without human intervention. This may lead to increased genetic drift and inbreeding depression in an isolated population. An island population of black-footed rock wallaby (Petrogale lateralis) had low genetic variation and exhibited inbreeding depression in the form of reduced fecundity, skewed sex ratios and fluctuating asymmetry (Eldridge et al. 1999). If a population is small these effects can lead to extinction vortices, where genetic and demographic factors feedback to further reduce the population (Caughley 1994).

I investigated the demography of two reptile populations: the tuatara (S. punctatus, revised from S. guntheri by Hay et al. 2010) and Duvaucel's gecko (Hoplodactylus 
duvaucelii) on North Brother Island, New Zealand. Both species are of conservation interest and previous studies have revealed potential viability issues for the tuatara population. The populations of $S$. punctatus and $H$. duvaucelii are small and vulnerable to the effects of demographic and genetic stochasticity. While genetic and demographic stochasticity operate at the population level, environmental stochasticity and catastrophes occur on a community level, affecting all species in a particular location. Interspecific interactions, such as competition, partitioning and confrontation, also affect how each population reacts to community level processes.

\subsection{Community Dynamics}

Understanding how a species reacts to and interacts with other species in its environment can provide information that may aid in situ conservation and provide baseline data to assist in evaluating translocation efforts. Stable coexistence, where species densities do not show long-term trends and populations can recover from low densities (Chesson 2000), is promoted through environmental variation and partitioning of resources. This is particularly important for conservation estate where there are often multiple species of conservation importance that need to be maintained in the community. Coexistence is influenced strongly by interspecific interactions, such as competition, which could limit available habitat or displace individuals from more favourable habitats.

Competition can be either resource competition, where species compete to obtain or consume the resource, or interference competition, where confrontation between species occurs over the resource (Kronfeld-Schor \& Dayan 2003). Resource partitioning, traditionally through habitat, time or food (Toft 1985), is thought to reduce both forms 
of competition. Patterns of resource partitioning are determined by a combination of species physiological constraints and interspecific interactions (Toft 1985). Therefore if two species have similar physiological constraints and requirements the partitioning observed may be attributed to interspecific interactions, including competition.

Spatial partitioning can occur via interference competition, where one species excludes another or avoidance behaviour occurs, or through exploitative competition, which is more evident at the microhabitat scale or in sessile organisms (Schoener 1983). Species of bromeliad-occupying mosquito larvae partition space to avoid agonistic interactions (Gilbert et al. 2008). Food can be partitioned through either form of competition. Access to the resource could be denied by the presence of another species or one species may out-compete the other in gaining access to the resource. In the case of temporal partitioning interference competition and exploitative competition may act in tandem, with one form of competition generating the temporal partitioning and the other occurring as a result of it (Kronfeld-Schor \& Dayan 1999).

Although the general term competition is used when two individuals (or species) have a negative effect on each other, competitive asymmetry may arise when one species is a superior competitor to another (Connell 1983; Schoener 1983). Larger animals are generally more superior competitors than smaller ones, but other factors that can cause asymmetry include recruitment ability, differences in feeding parameters and physiological tolerances (Schoener 1983). Connell (1983) suggests that in relatively spatially stable species, competition occurs mainly between neighbours, regardless of species and when this occurs asymmetry is more likely to depend on individual size or age rather than species. 
One could assume that if individuals of one species are more competitive than those of another species, they would eventually out-compete and eliminate the opposition (Connell 1983), as was demonstrated by Gause in his initial experiments with paramecium (Gordon 2000). However, if the superior competitor has high intraspecific competition it may self-limit its population to the point that the inferior competitor is not excluded (Connell 1983). Even if interspecific competition is higher than intraspecific competition, environmental variation may allow the inferior competitor to persist, especially if the usually inferior competitor is better at exploiting certain environmental conditions (Connell 1983).

\subsection{Study Site and Species}

North Brother is a 3.9ha island located in the Cook Strait, north-west of Wellington at $41^{\circ} 06^{\prime} \mathrm{S}, 174^{\circ} 26^{\prime} \mathrm{E}$ (Anon). A lighthouse was built on the island in 1877 and a human presence remained on the island until 1990, when the lighthouse was fully automated (Anon). Much of the island is steep cliff, with much of the upper area occupied by buildings and concreted areas associated with the lighthouse. North Brother Island is home to several endemic reptile species - the tuatara Sphenodon punctatus, gecko species Hoplodactylus duvaucelii and Hoplodactylus maculatus and skink species Oligosoma lineoocellatum and Oligosoma polychroma (Thompson et al. 1992). The flora is dominated by Coprosma repens (taupata), Disphyma australe (horokaka), Hebe elliptica and Salicornia australis (Gillam 1960).

Tuatara occurred on North Brother Island prior to the construction of the lighthouse (Buller 1877; Newman 1878). However, many S. punctatus were either killed during 
lighthouse construction or removed from the island as scientific specimens and curiosities (Newman 1878), resulting in a small population. Currently, the population is at relatively high density and thought to be at carrying capacity (Hoare et al. 2006). A male-bias is evident in the adult population as males outnumber females 1.7: 1 (Nelson et al. 2002b) but the operational sex ratio may be as extreme as 15 males: 1 female in any year (Mitchell et al. 2009). The population has previously been harvested for eggs (1989-91 and 2000-01) and 38 animals in total were taken to establish three new populations in 1995 and 1998.

Hoplodactylus duvaucelii is extinct on the mainland and currently occurs on several offshore islands, with populations split into two geographic groups: Cook Strait and off the North Island's northern coast (Thompson et al. 1992). Translocations from North Brother Island have occurred to nearby Mana Island in the past and there is potential for future translocations from this population.

Both tuatara and Duvaucel's gecko are nocturnal reptiles. They have been observed to overlap spatially and have similar dietary requirements. In addition, Duvaucel's gecko are thought to show strong site fidelity (Thompson et al. 1992) and tuatara are known to be territorial (Moore et al. 2009). There is potential for competition between the two species, although competitive interactions may be in favour of tuatara due to their larger size.

I aimed to determine the current population statuses and long-term trends of $S$. punctatus and H. duvaucelii. I also aimed to determine if spatial and temporal partitioning is occurring between the two species on North Brother Island. The thesis is 
in the form of self-contained manuscripts, with each chapter prepared for separate publication. Consequently, there is some repetition among chapters, particularly in the methodology sections. References for all chapters are located at the end of the thesis, after the appendix. In chapter two I investigate the population structure and characteristics of tuatara on North Brother Island and explore the male sex ratio bias in this population. In chapter three I investigate the population structure and characteristics of $H$. duvaucelii on North Brother Island and investigate the potential for future translocations. In chapter four I investigate the potential for interspecific competition between the two species by investigating spatial and temporal overlap. I also collate long-term data to evaluate site fidelity and body condition trends in both species over the past 50 years to investigate long-term trends on North Brother Island. In chapter five I integrate the results of the three data chapters and make recommendations for conservation management and future research of tuatara and Duvaucel's gecko on North Brother Island. 


\section{Chapter 2: Sex Bias in Tuatara (Sphenodon punctatus) on}

\section{North Brother Island}

\subsection{Introduction}

Small populations are especially vulnerable to the effects of demographic stochasticity (Shaffer 1981), such as variability in reproductive success, sex ratios and individual survival (Boyce et al. 2006; Lande 1998). Fisher (1930) states that natural selection will favour an even sex ratio through equal parental investment in both sexes. However, populations of many species are known to deviate from this even ratio and are biased towards one sex. Biases in sex ratio can arise at any life stage, through sex determination, birth/hatching, differential juvenile and adult survival, or migration. Under Fishers (1930) theory, any biases in population sex ratio should be short-term fluctuations in a population, with parents producing more of the more vulnerable sex to compensate for biased mortality during the parental care period. Sustained biased sex ratios are therefore of concern, especially when the bias is male.

Aside from skewing the operational (breeding) sex ratio, large biases in the number of males can lead to higher male resource acquisition to the detriment of females and increased harassment towards females (Rankin \& Kokko 2007). Le Galliard et al (2005) found increased aggression against females in male-biased populations of the common lizard Lacerta vivipara. An increase in aggression by males toward females can cause increased female mortality and reduced fecundity, which can lower their overall lifetime reproductive success (Le Galliard et al. 2008). If the bias is prolonged then the situation 
can develop into an extinction vortex where the male bias is exacerbated through a feedback loop, as seen in experiments using L. vivipara (Le Galliard et al. 2005).

Changes in demography, including sex ratios, can be influenced by the environment. Climate change affects species in many ways, including changes to range and migration patterns observed in European birds (Thomas \& Lennon 1999) and butterflies (Parmesan et al. 1999; Sparks et al. 2005). The timing and success of reproduction caused the decline of populations of pied flycatcher Ficedula hypoleuca due to food supply peaking prior to breeding with the earlier arrival of spring (Both et al. 2006). Species with temperature-dependent sex determination (TSD) that produce nests with all male, all female or mixed sex offspring, depending on nest temperature, are particularly vulnerable to the effects of climate change on sex ratios (Janzen 1994). With warming predictions for New Zealand ranging from $0.7-5.1^{\circ} \mathrm{C}$ by 2090 (Mullan et al. 2008), this could potentially have a large impact on the tuatara (Sphenodon), an endemic reptile order with TSD. An unusual form of TSD is seen in tuatara, where males are produced at higher nest temperatures than females (Mitchell et al. 2006).

Tuatara were once widespread through both the North and South Islands of New Zealand (Worthy \& Holdaway 1995), but were lost from the mainland in the mid to late 1800's (Newman 1878) and are now restricted to offshore islands and reserves. A decrease in Sphenodon remains in the sub fossil record where kiore (Rattus exulans) remains are present suggests that tuatara became less common with the arrival of Pacific Islanders approximately 1000 years ago (Worthy 1998; Worthy \& Holdaway 1995). 
The tuatara on North Brother Island were first described in 1877 as species Sphenodon guntheri on the basis of morphology and colouring (Buller 1877). Although classified internationally as vulnerable (IUCN 2009) and nationally as endangered in New Zealand, the species was considered to be stable (Hitchmough et al. 2007). The North Brother Island tuatara exhibit low heterozygosity compared with other tuatara populations (Daugherty et al. 1990; Hay et al. 2010; MacAvoy et al. 2007), likely due to a founder effect after the last glaciation. Recently, the North Brother Island tuatara status as a species has been reconsidered and $S$. guntheri is now considered to be a genetically important group of S. punctatus, and will hereafter be referred to as the North Brother Island population of S. punctatus (Hay et al. 2010).

Sex determination in this population occurs around an estimated pivotal temperature of $21.57^{\circ} \mathrm{C}$, with a transitional range of $1-4^{\circ} \mathrm{C}$ where both sexes are produced (Mitchell et al. 2006). This makes tuatara particularly vulnerable to climate warming, as increases in nest temperatures are likely to lead to increased numbers of male offspring produced if adult females do not respond behaviourally to an increase in temperature by nesting in different locations. Predictions based on projected climate change for the region suggest a decrease in the number of female hatchlings produced at even the most conservative warming estimations (Mitchell et al. 2008). At the higher temperature increases predicted for the region all offspring will be male at the current nest depths, of $100 \mathrm{~mm}$ or less, by the mid 2080's (Mitchell et al. 2008).

Mitchell et al. (2009) modelled population viability for the North Brother Island tuatara over 2000 years at varying levels of male bias in hatchling sex ratio and inbreeding level. This small population was found to be fairly robust with all modelled populations 
surviving for 2000 years where $60-70 \%$ of hatchlings were male, and including inbreeding depression. In the absence of inbreeding depression the population could withstand $75 \%$ of hatchlings being male. The population growth rate became negative when hatchlings were $80 \%$ male regardless of population size (Mitchell et al. 2009). Although there is no evidence of inbreeding depression on North Brother Island, ideally the male bias should not exceed $70 \%$. Once the North Brother population reaches $80 \%$ male hatchlings, management intervention will be required.

A population census in 2000 found 473 individuals on North Brother Island of which approximately $60 \%$ of individuals were indentified as male (Mitchell et al. 2009). Using mark-recapture analyses, the sex ratio for the adult population on North Brother Island was also estimated as 63\% male (Nelson et al. 2002b). Data from 1988 - 1997 suggest that the bias has not significantly changed over the course of the decade (Nelson et al. 2002b). However, demographic changes over time may not become apparent for many years, due to long generational times of approximately 40-50 years (Miller et al. 2009) and the long gap between hatching and researchers ability to visually determine sex at maturity. Tuatara are long-lived, with the longest capture histories for this population indicating life spans of at least 61 years (Nelson et al. 2002b) although 100 years is considered likely for tuatara. The species is sexually dimorphic; males are longer and heavier than females (Dawbin 1982). Male body condition is also known to be higher than females, but both sexes have declining body condition, with females showing a faster decline (Hoare et al. 2006).

I investigated the current status of the S. punctatus population on North Brother Island, including population size, sex ratio, body condition and survival to evaluate if any 
changes have occurred in this population over the last decade that might threaten its long-term survival.

\subsection{Methods}

\subsubsection{Field Site Description}

North Brother Island is a steep, rocky island of about 3.9ha, located in the Cook Strait, New Zealand. It is roughly conical in shape and rises to $75 \mathrm{~m}$ above sea level (Gaston \& Scofield 1995). The island has been the site of large-scale human modification. In 1877 a lighthouse was constructed at the peak of the island (Anon). The island has several man-made structures and concreted areas that were used in the construction and servicing of the lighthouse in the past. The majority of these are around the summit of the island, including two houses, a generator shed, a helipad and old water tanks. At each end of the island there are also concreted areas with sheds and decommissioned cranes used for the loading and unloading of boats. A railway line runs down the north face from the lighthouse. The vegetation is all under $2 \mathrm{~m}$ in height and is mainly ground cover. The vegetation is typical of coastal ecosystems of the Marlborough Sounds region and is mostly native, for example Coprosma repens (taupata) and Disphyma australe (horokaka) (Gillam 1960), as ongoing weed control has largely eradicated exotic weeds. Much of the island is exposed rock, with shallow soils on the north and south faces. 


\subsubsection{Mark-Recapture Study}

A mark-recapture study was conducted over four nights from 26/11/2008 - 30/11/2008 Tuatara were captured at the same time as Duvaucel's gecko (see Chapter 3). Two teams of two went out at night starting at 10pm and finishing at 4am, covering the search area of approximately 1 ha twice. The area surveyed was approximately $45 \%$ of the estimated total tuatara habitat. Tuatara were captured by hand each night, placed in a cloth bag, and brought to the old lighthouse keeper's house for processing. Reflector pegs unique to each bag were left at the removal point. The time of capture and the location of each animal were recorded. Each individual was given a temporary unique number for identification and this was written on both sides of the animal in non-toxic black permanent marker. This mark would remain for the entire trip. Once marked, individuals were measured and weighed with mass, snout-vent length (SVL), tail length and any tail regeneration recorded. Sex of individuals was determined by secondary sexual characteristics, with individuals that were unable to be assigned to a particular sex considered juveniles. Females had their abdomens palpitated by hand to check for the presence of eggs. Any previous identification through toe clip or PIT tag (microchip) was also recorded. All tuatara were added to the records for this population, which date back to 1957 . All tuatara caught without any existing permanent identification were PIT tagged for future ease of identification. Once processed all individuals were returned to their capture location by the end of each capture session. Recaptures over the following nights were recorded using identifying numbers that could be clearly observed. If the observer could not see the number clearly, the animal was captured to confirm the identity of the individual but was not measured again. Equal effort was placed on capturing new animals and recording those already marked. 


\subsubsection{Data Analysis}

The data were analysed using SPSS Statistics (version 17.0) and Microsoft Excel 2000. Body condition for 2008 was calculated using the same formula as Hoare et al (2006) (logmass/logSVL). Modelling was carried out using MARK (version 5.1). Females in the North Brother Island population are considered mature from an SVL of $163 \mathrm{~mm}$ (Cree et al. 1991) and for modelling purposes all animals below this point were considered juveniles unless their sex could be indentified definitively. Juveniles were excluded from the modelling as they are known to be harder to detect using current search methods and only a small number were captured (Dawbin 1982). MARK ranks models according to AICc, which is an adjusted AIC (Akaike's Information Criterion) score used to account for any biases resulting from small sample sizes (Burnham \& Anderson 2002). AICc differences are used to estimate the relative Kullback-Liebler (K-L) distance between the approximating model and the unknown reality (Burnham \& Anderson 2002). The smaller $\triangle \mathrm{AICc}$ is, the more substantial the support for the model is, with scores $>10$ indicating essentially no support and 0-2 indicating substantial support for the model being the best model (Burnham \& Anderson 2002).

\subsubsection{Population size}

Six models were generated using Huggins closed captures in MARK to estimate population size: $M(t), M(b)$ and $M(t b)$, with and without an effect of sex on capture (Table 2.1) There are four main assumptions for using a closed capture method. These are that the population is closed (i.e. no births, deaths, immigration or emigration), animals do not lose their marks, marks are recorded correctly, and that each animal has a constant and equal capture probability. The first assumption is considered valid as births and deaths are unlikely during the 4-night study period and the study site is an 
island. Migration into and out of the study area is unlikely as the species involved is highly territorial and animals do not move far (Gillingham et al. 1995). The second and third assumptions are generally assumed to be correct. The marker pen does not fade over the course of the study and it is assumed that recording is accurate. The final assumption is difficult to fulfil as individual heterogeneity, or an influence of sex or life stage may result in different catchability. This can be accounted for by model selection and by not including juveniles in the analyses.

Table 2.1 A description of the models used for analysis in MARK and their parameters.

\begin{tabular}{ll}
\hline Model & Description \\
\hline $\mathrm{M}(\mathrm{t})$ & $\begin{array}{l}\text { Model accounts for differences in capture probabilities among } \\
\text { capture occasions, for example due to weather, capture effort etc. } \\
\text { Recapture rates are considered to be the same as initial capture rates } \\
(\mathrm{p}) .\end{array}$ \\
$\mathrm{M}(\mathrm{b})$ & $\begin{array}{l}\text { Model accounts for differences in capture }(\mathrm{p}) \text { and recapture }(\mathrm{c}) \\
\text { probabilities based on behavioural responses to capture. Individuals } \\
\text { may exhibit capture shyness }(\mathrm{p}>\mathrm{c}) \text { or capture happiness }(\mathrm{p}<\mathrm{c}) \\
\text { following initial capture. }\end{array}$ \\
& $\begin{array}{l}\text { Model accounts for both temporal and behavioural effects. } \\
\mathrm{M}(\mathrm{tb})\end{array}$ \\
& Model accounts for differences in capture probability between sexes. \\
\hline
\end{tabular}

The population estimates from the best fitting models determined by $\triangle \mathrm{AICc}$ were extrapolated to include all potential habitat on the island, including the estimated 55\% of habitat that was not searched. The estimates do not include juveniles as they were excluded from the modelling.

\subsubsection{Sex Ratio}

Sex ratios were calculated from actual capture numbers as well as population estimates from the highest three ranking models for the survey area for males and females. Sex ratios were not calculated for the extrapolated population estimates for the whole island. 
A $\chi^{2}$ test was performed to determine if the calculated sex ratios were significantly different from a 50:50 ratio. A sex ratio was also calculated for the unmarked individuals captured, which have recruited into the catchable population since 2000/01. Only individuals whose sex could be identified were included, but this included 4 subadults that were considered likely female but were under the $163 \mathrm{~mm}$ SVL threshold used for adult females in the previous analyses. Three individuals that were toe clipped, but could not be identified accurately due to additional toe loss, were excluded from analyses.

\subsubsection{Survival and Recapture}

Long term records of individual captures dating back to 1957 (Table 2.2) were analysed to estimate survival and recapture probability using the recapture models in the program MARK. Only adult individuals that had been definitively sexed during the period 19572008 were included in analyses. Sixteen models were performed to obtain survival (Phi) and recapture probability (p) estimates. Survival and recapture probability could vary according to time (t) or be constant (.). A sex effect (*sex) was included to determine if the parameters differed between males and females. 
Table 2.2 Trip dates, adult captures and the number of capture occasions per trip for all mark-recapture trips from 1957-2008. *nights not consecutive

\begin{tabular}{clccc}
\hline Trip \# & Trip Date & $\begin{array}{c}\text { \# Adults } \\
\text { Captured }\end{array}$ & Sex ratio M:F & Capture Nights \\
\hline 1 & August 1957 & 24 & $0.60: 1$ & 1 \\
2 & January 1988 & 109 & $2.03: 1$ & 3 \\
3 & December 1988 & 35 & $1.33: 1$ & 3 \\
4 & November 1989 & 47 & $0.96: 1$ & 3 \\
5 & October 1990 & 53 & $1.65: 1$ & $7 *$ \\
6 & November 1990 & 119 & $1.59: 1$ & 3 \\
7 & November 1991 & 108 & $1.30: 1$ & 3 \\
8 & November 1993 & 188 & $2.48: 1$ & 5 \\
9 & November 1994 & 207 & $1.92: 1$ & 3 \\
10 & November 1995 & 36 & $1.40: 1$ & 1 \\
11 & March 1996 & 237 & $2.16: 1$ & 5 \\
12 & February 1997 & 237 & $2.00: 1$ & 5 \\
13 & December 1997 & 196 & $2.02: 1$ & 5 \\
14 & October - December 2000 & 356 & $1.72: 1$ & $4-6$ wks* \\
15 & November - December 2001 & 265 & $1.60: 1$ & $4-6$ wks* \\
16 & March 2005 & 146 & $2.84: 1$ & 5 \\
17 & November 2008 & 140 & $3.24: 1$ & 4 \\
\hline
\end{tabular}

Open population models, where births, deaths and migration are occurring, have six main assumptions. The first two assumptions are that on each sampling occasion each animal in the population has the same probability of capture, and every marked animal has the same chance of survival from one sampling occasion to the next. These assumptions are considered to be met in the adult population. Juveniles, which may have different rates of detection and survival, were excluded from the analyses. Differences in survival and capture rates between males and females were accounted for by including a sex effect in the models. The assumption that marks are not lost or overlooked is generally considered to be met as individuals are identified through distinct toe clip patterns or PIT tags. However, it is known that at least five individuals whose records show they have not been captured previously are potentially listed as new captures due to natural toe loss. The assumption that all samples are instantaneous and animals released immediately is difficult to meet, as animals may spend up to 2 hours away from the capture site during processing. However, given the length of time 
between trips, the sampling can be considered to be relatively instantaneous. The assumptions that emigration from the sample area is permanent and that each animal's fate is independent from other animals in the population are also considered to be met.

\subsection{Results}

\subsubsection{Recruitment, size, mass, and body condition.}

A total of 149 tuatara (107 males; 33 females; 9 juveniles) were captured during the four night survey. Thirty-one previously unrecorded individuals were found, six of which were juveniles of indeterminable sex. Caution is necessary however as five of these new individuals may in fact be on the existing record but are no longer identifiable due to natural toe loss. Recruitment is occurring as juveniles were captured, but no hatchlings were observed. Nesting behaviour by one female was observed on the north face. Males averaged an SVL of $204.0 \mathrm{~mm} \pm 2.1 \mathrm{~mm}$ with a mean mass of $286.7 \mathrm{~g} \pm 8.6 \mathrm{~g}$ (Figure 2.1). Females had an average SVL of $187.0 \mathrm{~mm} \pm 2.8 \mathrm{~mm}$ with a mean mass of $202.6 \mathrm{~g} \pm 8.6 \mathrm{~g}$ (Figure 2.1). Mean body condition (logmass/logSVL) for males in this study was $1.055 \pm 0.002$; mean female body condition from 2008 was $1.012 \pm 0.001$. Condition fluctuates, but is still declining for both sexes, with lower scores than in all previous years (Figure 2.2). 


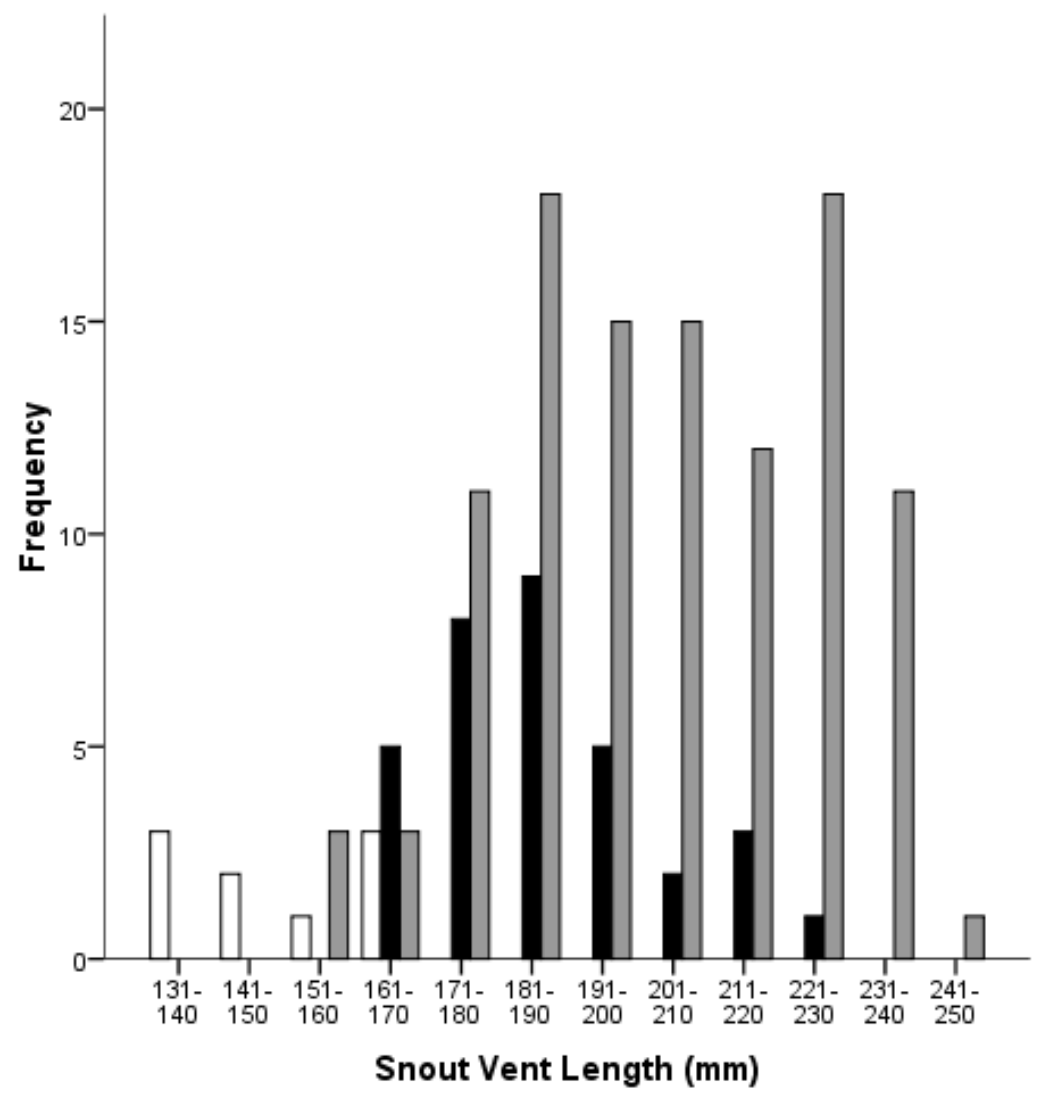

Figure 2.1 The distribution of tuatara according to sex and size class. $\mathrm{N}=149 ; 9$ juveniles ( $\square)$, 33 females( $\square$ ) and 107 males ( $\square$ ).

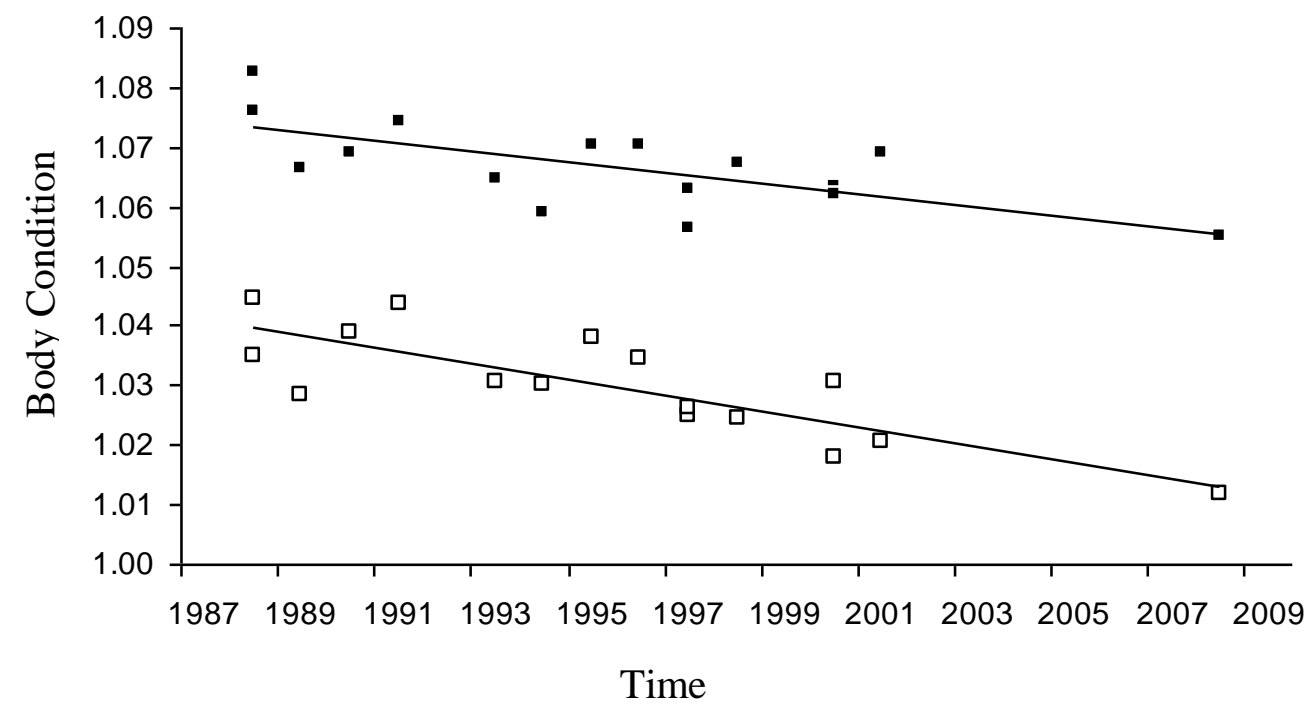

Figure 2.2 Trend of body condition (log mass/log SVL) in adult male (•) and adult female ( $($ ) tuatara over 20 years. Adapted from Hoare et al. (2006), using their data pre2008. Female condition continues to decrease at a faster rate than males. 


\subsubsection{Estimates of Population Size}

The data are insufficient to fit models with multiple factors due to low numbers of captures and recaptures (Table 2.3). For example, Models $M(t b)$ with and without sex effects contained improbable population estimates in the thousands, with standard errors and confidence intervals that were unrealistic. The top two models were those that accounted for differences between initial capture and recapture probabilities $(\mathrm{M}(\mathrm{b})$; Table 2.4). The third ranked model accounting for differences in time with no sex effect will also be discussed as this has been the top model for prior trips (Nelson et al. 2002b), and because reptile activity is known to be influenced by temperature and weather conditions. Model M(b) with no sex effect shows capture shyness for all individuals, as recapture rates (c) were lower than capture rates (p) (Figure 2.3). Population size for the study area using this model was calculated at 178 individuals. Model M(b) with a sex effect showed both males and females exhibiting capture shyness, as recapture rates (c) were lower than capture rates (p), but the effect was stronger in females (Figure 2.3). Population size for the study area using this model was calculated at 179 individuals. Model M(t) with no sex effect showed very similar capture rates (p) over all nights (Figure 2.3). Population size for the study area using this model was calculated at 198 individuals.

Table 2.3 Number of captures and recaptures of tuatara each night for all four nights of the study in November 2008.

\begin{tabular}{lcc}
\hline Date & New Captures & Recaptures \\
\hline $27 / 11 / 2008$ & 60 & - \\
$28 / 11 / 2008$ & 47 & 11 \\
$29 / 11 / 2008$ & 20 & 28 \\
$30 / 11 / 2008$ & 22 & 34 \\
\hline
\end{tabular}


Table 2.4 Models used for population size and sex ratio estimation in order of ranking, with the top ranking model first.

\begin{tabular}{llllll}
\hline Model & AAICc & AICc Weight & $\begin{array}{l}\text { Model } \\
\text { Likelihood }\end{array}$ & $\begin{array}{l}\text { No. } \\
\text { Parameters }\end{array}$ & Deviance \\
\hline M(b) no sex effect & 0.0000 & 0.46889 & 1.0000 & 2 & 994.9335 \\
M(b) sex effect & 0.2653 & 0.41064 & 0.8758 & 2 & 995.1988 \\
M(t) no sex effect & 3.6124 & 0.07703 & 0.1643 & 4 & 994.4954 \\
M(tb) no sex effect & 5.0492 & 0.03755 & 0.0801 & 6 & 991.8524 \\
M(t) sex effect & 8.8814 & 0.00553 & 0.0118 & 8 & 991.5751 \\
M(tb) sex effect & 14.3992 & 0.00035 & 0.0007 & 12 & 988.7839 \\
\hline
\end{tabular}

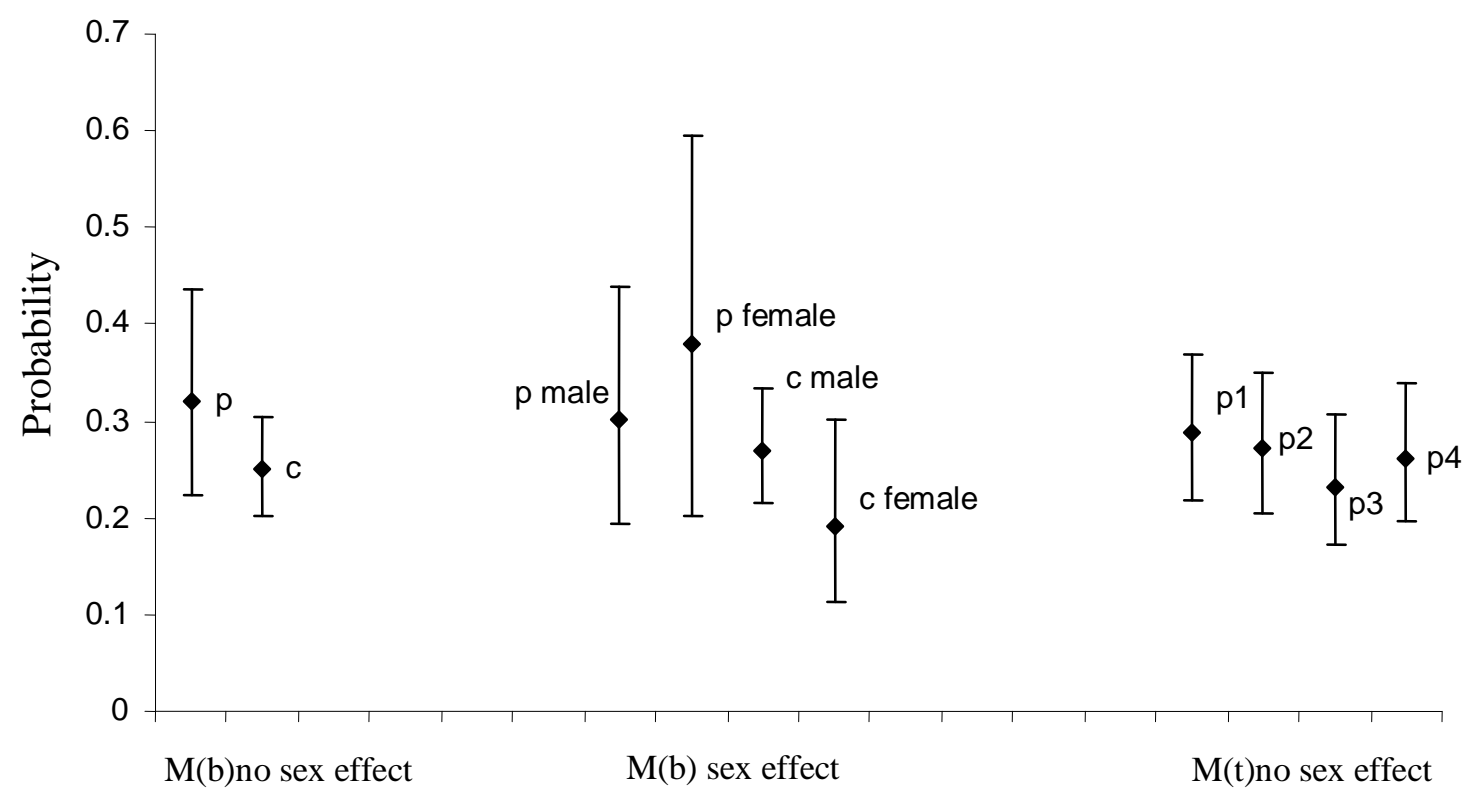

Model

Figure 2.3 The output parameter estimates for models $M(b)$ with and without a sex effect and model $M(t)$ without a sex effect. For both $M(b)$ models, 'p' indicates initial capture rate, ' $c$ ' indicates recapture rate. For model $\mathrm{M}(\mathrm{t})$, ' $\mathrm{p}$ ' indicates capture rate over sessions 1 to 4 , including recaptures on each occasion. At probability 0 there is no chance of capture, at 1 there is a $100 \%$ chance if capture.

Population estimates were extrapolated to estimate the adult population size for the entire island, using the three models from Figure 3. Population estimates for the island range from 390 to 437 adults. 


\subsubsection{Estimates of Sex Ratio}

Male and female estimates from each model demonstrated a significant bias towards males $(\mathrm{p}<0.0001$; Table 2.5; Figure 2.4). The sex ratio of the recruiting population was also male biased. Once juveniles of indeterminable sex had been excluded there was a total of 6 female ( 1 new in 2005, 5 new in 2008) and 27 male captures ( 8 new in 2005, 19 new in 2008), that is, a sex ratio of 4.5 males: 1 female, or $81.8 \%$ males.

Table 2.5 Summary of sex ratios and associated $\chi^{2}$ values evaluating deviation from a $1: 1$ ratio for the actual group of captures, the population estimates for the study area produced by the top three ranking models and the recruiting population

\begin{tabular}{lcccccc}
\hline & $\mathrm{N}$ & Sex Ratio M:F & $\%$ Male & $\chi^{2}$ value & DF & P-value \\
\hline Actual captures & 140 & $3.24: 1$ & 76.4 & 39.114 & 1 & $<0.0001$ \\
M(b) no sex effect & 178 & $3.24: 1$ & 76.4 & 49.640 & 1 & $<0.0001$ \\
M(b) sex effect & 179 & $3.59: 1$ & 78.2 & 56.989 & 1 & $<0.0001$ \\
M(t) no sex effect & 198 & $3.21: 1$ & 76.2 & 54.626 & 1 & $<0.0001$ \\
Recruiting population & 33 & $4.50: 1$ & 81.8 & 13.364 & 1 & 0.0003 \\
\hline
\end{tabular}

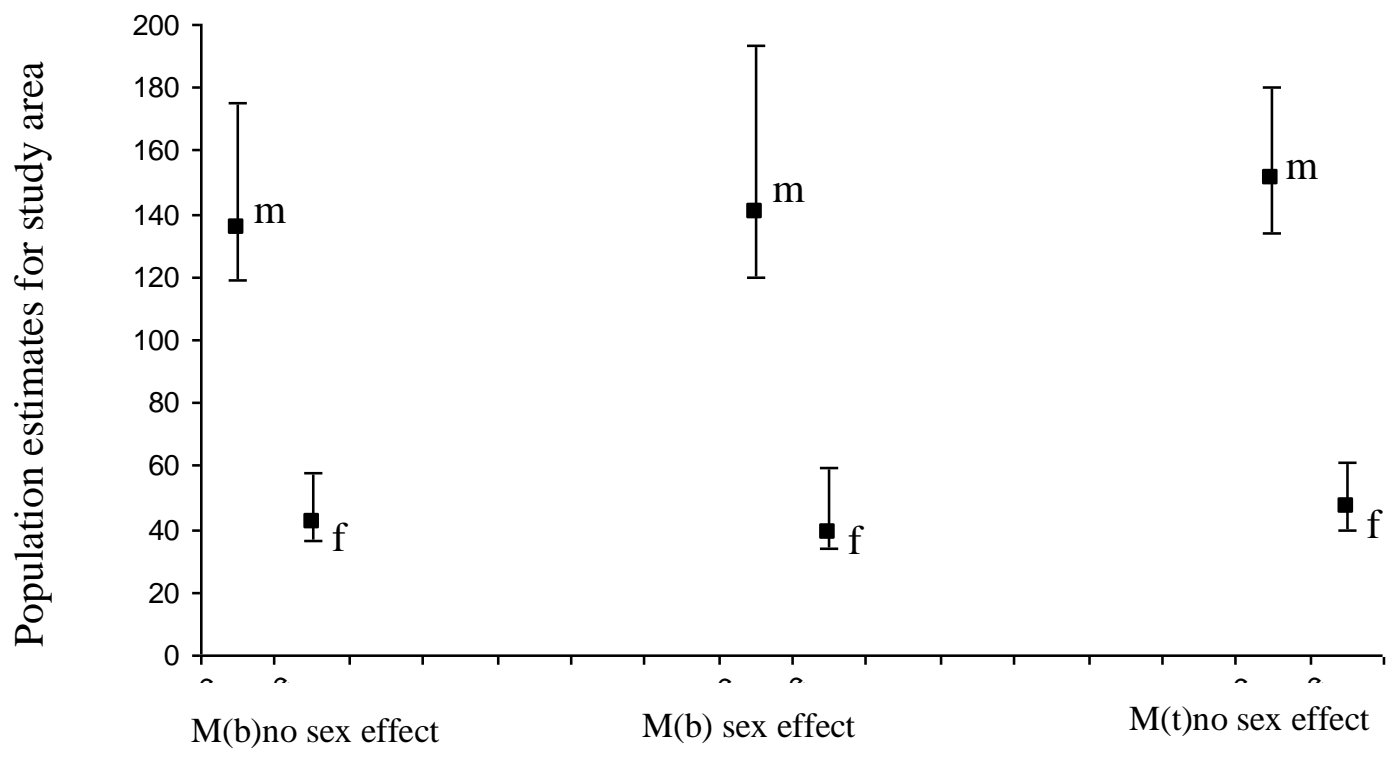

Model

Figure 2.4 Estimates of numbers of males (m) and females (f) from models $\mathrm{M}(\mathrm{b})$ with a sex effect, $M(b)$ without a sex effect and $M(t)$ without a sex effect, with $95 \%$ confidence intervals. Males greatly outnumber females. 


\subsubsection{Survival and Recapture Rates}

For the two highest ranking models, survival and recapture varied with time. The top model showed a difference in recapture rates between males and females. The best fitting model was Phi(t)p(t*sex), with a $\triangle \mathrm{AICc}$ of 0.00 and model likelihood 1.00, followed by Phi(t)p(t) with a $\triangle \mathrm{AICc}$ of 6.89 and model likelihood of 0.03 . All other models were $>10 \Delta \mathrm{AICc}$.

Survival was not constant over the period 1957-2008 but was affected by variation among trips, ranging from 0.60 to 1.00 . The low survival estimates obtained were due to the low capture numbers on the trips preceding the survival period, for example, trips 5 and 10 (Table 2.2). These trips did not involve full mark-recapture studies, but were for other purposes, such as translocation, where marked animals were recorded when captured but this was not the main objective of the trip. When these two survival estimates are removed Phi averages $\sim 0.95$ over the whole period. There was no effect of sex on survival, indicating males and females have an equal likelihood of surviving between trips.

Recapture probability was also affected by variation among trips, ranging from 0.07 -

0.94. The amount of time spent searching on each trip affected the recapture probabilities, for example, recapture probability was $\sim 0.93$ for both sexes for trip 14 when captures were recorded over a two month period; for trip 10 recapture probability was $\sim 0.08$ for both sexes when searching was conducted over only one night. The model indicated a difference between the sexes in recapture probabilities. An effort was made to catch every individual on the island during trip 14 and trip 10 was for translocation purposes, which could have influenced which animals were captured. 
When the recapture probabilities for the two extremes (trip 10 and 14) were removed, females averaged a recapture probability of 0.41 ; males averaged 0.49 across the whole period 1957-2008.

\subsection{Discussion}

\subsubsection{Population Characteristics}

The population of $390-437$ adults is male biased with a sex ratio of 3.24 males: 1 female. There are more males entering the breeding population with the sex ratio of the recruiting population 4.1 males: 1 female. Adult survival was high at $\sim 95 \%$ and similar to past estimates (Nelson et al. 2002b), with no difference in survival between the sexes. Recruitment is occurring and although few juveniles were found it is known that they are harder to detect than adults by current search methods (Dawbin 1982). Inclusion of juveniles in MARK analyses lowers overall survival rate. However this could be due to the known low detection rate rather than mortality. Pike et al (2008) found that juvenile survival estimates for squamates and turtles were high and in some cases comparative with conspecific adults when modelled from population data.

The best models for estimating population size were both based around differences in capture and recapture behaviour. For previous trips models with differences in time had been chosen as the overall best model (Nelson et al. 2002b), and temperature and weather conditions are known to affect reptile activity. Time based models are also influenced by search effort and time spent searching. Over the survey period in 2008 the weather conditions were fairly consistent - cool, breezy and little cloud, with no rain. As the same teams covered the same ground each night and were out for approximately 
the same time each night variation between nights would have been minimal. These factors would have less influence on the model selection, causing $\mathrm{M}(\mathrm{t})$ to be lower down the model ranking than would be expected from previous results. Our results could indicate that variation over time such as weather conditions that are associated with reptile activity are masking behavioural trends related to capture.

This study was limited by running mark-recapture studies for two species at the same time in 2008. Equal focus was put on capturing each species, but this meant that the study area was smaller than previous trips and the total area was only covered twice per night. Only one third of the estimated total tuatara population was captured over four nights. Although many individuals would have been located outside of the study area, there is likely a portion of the population that is uncatchable, which did not emerge from their burrows at all over the four night study. This could reduce capture numbers and affect results, including sex ratios and population size estimates.

\subsubsection{Male bias and aggression}

The male bias has apparently increased in the last decade since Nelson et al. (2002b) and Mitchell et al. (2009) obtained their data. The bias in the adult sex ratio likely arises prior to individuals reaching adult status, which is supported by the strong male bias seen in individuals recruiting into the breeding population. Due to the long delay between hatching and researchers ability to visually identify individual sex, the "recruiting population" (new captures in 2005/2008) were approximately 15 - 30 years of age according to the growth curve of Mitchell et al. (2009). Although this could 
potentially indicate that more than $80 \%$ of hatchlings for this group were male, differential juvenile mortality cannot be discounted (Mitchell et al. 2009).

Differential juvenile mortality is not uncommon and has been observed in several species, including captive tuatara. In a small captive juvenile tuatara population, Gruber (2007) observed significantly higher mortality for females from natural nests than males between hatching and five years. Nazca boobies (Sula granti) were found to have an even sex ratio at the end of the parental care period, but juvenile cohorts returning to the colony to breed were male biased (Maness et al. 2007). A bias in juvenile mortality may be occurring separately or in conjunction with a bias in the primary sex ratio at sex determination. A study on American alligator populations found that although hatchlings were female biased, the adult population was male biased, indicating high juvenile female mortality (Lance et al. 2000).

It can be difficult to determine if juvenile mortality is actually occurring, due to cryptic animals or lack of remains found. Juvenile mortality may be the result of resource constraints, aggression or predation. Aggression was considered likely in Gruber's (2007) study group, with all individuals from the male dominated natural nest group showing tail loss and aggressive actions observed. Aggression is more likely at higher densities, where individuals cannot easily avoid confrontation.

The male bias may be caused at sex determination. Currently nest sites are located on the northern slope of North Brother Island, where tuatara are most abundant and the gradient is less steep. The soil on the island is poor and nests are shallow, currently ranging from $5-25 \mathrm{~cm}$ (Mitchell et al. 2009), limited by soil depth. Models suggest 
that in current climatic conditions nests of depths less than 50mm produce all males, with mixed nests at 100mm and all female at greater depths (Mitchell et al. 2008). Under climate change predictions soil temperatures will increase, producing male dominated nests that will play a large role in influencing future ratios.

Due to the isolated nature of this population, response to climate by migrating to more suitable areas is not possible without human intervention. Under maximum climate change predictions females would have to change the timing of nesting to produce offspring of both sexes. Although individual nesting plasticity has been observed in several species it is unlikely that this will offset the effects of climate change due to the large time shifts that would need to occur to produce adaptive sex ratios (an estimated 60 days for painted turtles Chrysemys picta (Schwanz \& Janzen 2008); 90 days for tuatara (Mitchell et al. 2009)). Shifts in nesting times may not necessarily be beneficial either. For Trachemys scripta elegans, the red-eared slider turtle, the longer nesting season due to warmer weather has lead to multiple nestings. There has been an increase in hatchling numbers, but the timing of sex determination has resulted in male dominated nests (Tucker et al. 2008).

As well as having a male bias in the tuatara population on North Brother Island, Hoare et al. (2006) revealed a long-term decline in body condition, which was more pronounced in females than males (see Figure 2.2). The general decline may be attributed to resource constraints but the faster rate of decline in female condition could potentially be caused by male aggression. Male aggression in a male-biased population leading to stress, injury or death has been witnessed in several species. Adult female common lizards Lacerta vivipara had an increased number of mating scars and lower 
fecundity in a male-biased population compared with a female-biased population in captivity (Le Galliard et al. 2005); female feral sheep Ovis aries in a male-biased population were subject to high male harassment and often sustained fatal injuries from repeated mating attempts and aggression (Reale et al. 1996). It is possible that aggressive actions towards females are reducing female fitness on North Brother Island, resulting in a lower body condition. It is known that fecundity in this population is lower than other populations, with females producing a clutch every 9 years instead of 3-5 (Mitchell et al. 2009), but whether this is the result of aggression, resource acquisition, or an environmental factor is currently unknown.

\subsubsection{Recommendations}

Regardless of the origin of the bias, it appears that human intervention will be necessary. Counter measures should be taken to increase the number of female hatchlings and reduce any potential causes for differential mortality. Removal of males to reduce the bias may reduce aggression towards females, but further research on behaviour would need to be undertaken to confirm that this is occurring before drastic changes to the population structure are undertaken.

Mitchell et al. (2008) suggest shading nest sites following oviposition. This strategy has been used to lower the temperatures of sea turtles nests in Malaysia to non-lethal limits (van de Merwe et al. 2006). While a good idea in theory, the shallow soil and exposed nature of the island may mean any structures located at current nesting sites would be easily damaged and need to be replaced often. Oviposition timing may differ between females, leading to a prolonged human presence on the island each year, even though most of the female population do not breed each year. This strategy would require 
constant yearly visits, which will be time and resource consuming for an uncertain outcome.

Mitchell et al. (2009) suggest regular direct interventions by removing eggs and incubating them in a controlled environment to produce all females. This intervention would need to be ongoing as male hatchlings are expected to increase to $100 \%$ by 2080 as air temperatures increase (Mitchell et al. 2008). This option would guarantee female hatchlings and raising females separately in captivity before release (headstarting) may counter any sex bias in juvenile mortality. As well as technical issues around egg harvesting and incubation, biosecurity concerns would need to be addressed. Animals would need to be in excellent health for translocation and the risk of animals contracting disease or mites would need to be minimised. Although this has been done before, it may not be feasible long-term as intervention would need to be ongoing. Returning animals to North Brother Island may also cause problems as this species is territorial and space may not be available for the translocated animals.

The population appears to be approximately 390 - 440 adults, which is comparable with the 2000/2001 population census data of Mitchell et al. (2009). Although the population size appears stable, body condition is still declining in both sexes, with females experiencing a faster decline (Hoare et al. 2006). Hoare et al. (2006) identified that the population was likely at carrying capacity as tuatara showed competitive release through increases in size and weight following translocation to other islands (Nelson et al. 2002a). If the population is at carrying capacity then adding more individuals to the population, regardless of sex, is likely to increase the pressure on the limited resources of North Brother Island. Increasing numbers of tuatara on the island could increase the 
loss of body condition, resulting in reduced survival, resilience and fecundity in this population. It could also negatively impact on other reptile species in the community. Hoare et al (2006) recommend restoration of man-made areas to increase vegetation cover and food resources to reduce the effects of any competition. This could also potentially reduce any juvenile female mortality if it is associated with lack of resource availability.

Enhancing the recently created populations on the other islands may be the best way to ensure the survival of genetically distinct North Brother Island S. punctatus. The islands of the translocated populations are larger with a wider variety of habitats that can support many more tuatara, with a wider range of nesting sites. Along with biosecurity issues, genetic variation will need to be taken into account in selecting individuals for translocation.

\subsection{Summary}

The effects of climate change are likely to increase the current male bias in the $S$. punctatus population of North Brother Island, regardless of the current cause. This population needs to have intervention put in place to ensure long-term viability. All management options will need to take into consideration that the population is likely at carrying capacity and that removal or addition of individuals to the island will result in biosecurity concerns. Future studies should include mark-recapture techniques to provide more population data towards understanding long-term trends, as well as monitoring the sex ratio and body condition in this population. Future research directions could include investigating male aggression, resource acquisition and 
juvenile mortality to further knowledge of how these factors affect sex ratios and body condition in this population. 


\section{Chapter 3: Population Characteristics of Duvaucel's Gecko}

\section{Hoplodactylus duvaucelii on North Brother Island}

\subsection{Introduction}

Long-term studies enable us to investigate temporal fluctuations and trends that are not apparent in short-term studies (Blossey 1999). Few studies track individuals in a population over long periods of time, but these studies can provide important data on longevity, survival and temporal fluctuations in population demography such as size, sex ratio and age structure (Blaustein et al. 1994; Wooller et al. 1992). They can also provide insight on population responses to catastrophic events (Young 1994). Such information is important for informing management programs and making decisions regarding species conservation such as the need for human intervention or whether a population can be used as a translocation source, especially for long lived species (Moore et al. 2007).

Translocations involve the removal of individuals from a source population. If too many animals are removed this can have negative effects on the source population such as increased inbreeding and increased vulnerability to demographic stochasticity, traits often already present in small or isolated populations (Lande 1998). However, if too few animals are used for a founding population, the new population will face the same issues. Limiting impacts on the source population means that the population can be used to harvest individuals for subsequent translocation efforts (Dimond \& Armstrong 2007). For example, the New Zealand North Island Robin (Petroica longipes) population on Tiritiri Matangi is the most accessible population of this species and is used to provide 
founders for translocations. Monitoring and modeling have revealed that 30 individuals every 3 years can be taken sustainably without having a negative affect on the source population (Dimond \& Armstrong 2007).

Long-term population studies can help to evaluate the status of translocated populations, by providing baseline data from which natural variation, and therefore success, could be evaluated (Balazs \& Chaloupka 2004; Blaustein et al. 1994). Life history characteristics, such as survival rates, longevity, age structure, population densities and recruitment are all important in determining the success of a translocation (Dodd \& Seigel 1991), and estimating the time it will take until translocated populations become self sustainable. Translocations of New Zealand's long-lived, slow reproducing species, may not be successfully established until decades after the initial translocations (Towns $\&$ Ferreira 2001). For example, translocation may not be considered successful until the population is self-sustainable and fully comprised of locally-born animals, which for Cyclodina skinks translocated to Korapuki Island is a minimum of 16 years, and likely longer (Towns \& Ferreira 2001). Without any information for comparison, resources may be wasted on a population that does not need intervention, or the population could become extinct in the absence of good long-term data (Blaustein et al. 1994). There are several species of New Zealand reptiles that are being translocated to extend their range, including the Duvaucel's Gecko (Hoplodactylus duvaucelii). For some species, there is little known about their natural history and long-term data is rare.

The Duvaucel's gecko is a nocturnal gecko endemic to New Zealand, known to utilise a range of terrestrial and arboreal habitats (Hoare et al. 2007). Duvaucel's geckos are active at low temperatures with records of body temperatures at $8^{\circ} \mathrm{C}$ in individuals 
foraging during winter (Barwick 1982) and are long-lived, with a life span of at least 36 years (Thompson et al. 1992). Evidence in the sub-fossil record indicates that the former range of $H$. duvaucelii extended over much of New Zealand with bones of similar size and shape to H. duvaucelii present throughout both the North and South Islands of New Zealand, including sub-alpine areas (Worthy 1987, 1998; Worthy \& Holdaway 1995). The species is now found only on offshore islands and the loss of range has been attributed to the presence of rats. The sub-fossil record indicates that $H$. duvaucelii became less prevalent with the arrival of kiore (Rattus exulans) approximately 1000 years ago (Worthy 1998). Modern studies support this, showing that rats displace geckos and reduce survivorship of smaller (and therefore younger) individuals (Hoare et al. 2007).

Two main geographical groups exist for this species; one is off the northern coast of the North Island and the other is in the Cook Strait. The most studied populations are those on the Poor Knights Islands (Whitaker 1968) and the Mercury group (Hoare et al. 2007; Van Winkel 2008) in the north, and the population on North Brother Island in the south (Barwick 1982; Thompson et al. 1992). Hoplodactylus duvaucelii can reach lengths of up to $160 \mathrm{~mm}$ snout-vent length (SVL) and a mass of $118 \mathrm{~g}$ in the Poor Knights Island group (Whitaker 1968). However, individuals in the population on North Brother Island are smaller and weigh less, with maximum snout-vent length (SVL) recorded of $120 \mathrm{~mm}$ and a maximum recorded mass of 49g (Barwick 1982). Barwick (1982) examined fourteen male and sixteen female geckos from the North Brother population in the Cook Strait to assess size and age at maturity. He found that males appeared to mature at a SVL of $98 \mathrm{~mm}$ and females at a SVL of $95 \mathrm{~mm}$. From this data he estimated that $H$. duvaucelii reach maturity at around seven years of age (Barwick 1982). Data from Cree 
(1994) taken from the northern group indicate that the minimum SVL at maturity is 110mm for females. Hoplodactylus duvaucelii are viviparous with females capable of producing 1-2 young at a time. Barwick (1982) estimated that the gestation period was 7-8 months, whereas Cree (1994) suggested that gestation may in fact be at least a year and that females may only produce offspring every second year.

Although considered lower risk for extinction (IUCN 2009), H. duvaucelii is still of conservation interest. The Department of Conservation (DoC) lists the species as sparse, with a human induced loss of range (Hitchmough et al. 2007). The population on North Brother Island is one of several in the Cook Strait, but there is no scope for migration and genetic exchange between populations without human intervention. The species is being re-established on other islands, including Mana Island in the south (Flannagan 2000), and Tiritiri Matangi and Motuora Islands in the north (Van Winkel 2008) where rats have been eradicated. The population on North Brother Island has been used as a translocation source for the southern region, with translocations of a total of 40 animals undertaken in 1997 and 1998, for release on Mana Island. Other pest free islands listed for potential translocations include the Chetwode Islands and Motuara Island in the Marlborough Sounds (Millar \& Gaze 1997). Removal of large numbers of individuals from the source population could potentially impact negatively on the source population on North Brother Island. Accurate and up to date information is necessary to ensure that effects on the North Brother Island population are minimal.

Few studies have been done on this species and long-term patterns of survival and longevity are not well documented, with the last estimate of longevity (36 years) produced by Thompson et al. (1992). The population of $H$. duvaucelii on North Brother 
Island, Cook Strait, has been subject to several mark-recapture surveys going back as far as 1957, but this data has not been analysed. Using new and historical data, I investigated population characteristics of Duvaucel's gecko on North Brother Island including current population size, sex ratio, survival and longevity. This information will provide baseline data for this population, as well as evaluating the potential for future translocations.

\subsection{Methods}

\subsubsection{Field Site Description}

North Brother Island is a steep, rocky island rising to $75 \mathrm{~m}$ above sea level (Gaston \& Scofield 1995) located in Cook Strait, New Zealand. At 3.9ha (Millar \& Gaze 1997) the island is small, and large areas have been modified due to the construction and continuing maintenance of the lighthouse. Concrete platforms are located at the northern and southern points of the island with a railway track crossing the northern face from the sea to the lighthouse. Other structures that remain intact and in use include several buildings that currently serve as temporary living quarters and a generator shed, but there are also several disused water tanks and sheds. The flora is largely native (due to weed control) and is dominated by Coprosma repens (taupata), Disphyma australe (horokaka), Hebe elliptica and Salicornia australis (Gillam 1960). The majority of plants were growing as groundcover, with the exception of around the main buildings where they reach $1-2 \mathrm{~m}$ in height. 


\subsubsection{Mark-Recapture Study}

The mark-recapture study of $H$. duvaucelii was conducted over four nights from 26/11/2008 - 30/11/2008 at the same time as S. punctatus (Chapter 2). Two teams of two went out at night starting at 10pm and finishing at 4am, covering the same search area of approximately 1 ha twice each night. Search area was based on existing paths and areas that were safe to search. Geckos were placed in small cloth bags and placed in a backpack. Reflector pegs unique to each bag were left at the removal point so that animals could be released in the same location after processing. The time and location of each capture were recorded, along with the bag number. Each individual was given a temporary unique identifying number, which was written in metallic silver (xylene free) pen at the base of the tail. The numbers were visible for the duration of the study. Once marked, individuals were measured for snout-vent length (SVL), tail length and tail regeneration by the same person each night. Each animal was also weighed using a pesola spring balance and had their sex identified using secondary sexual characteristics. The number of mites on each animal was roughly counted in multiples of five to estimate mite numbers. Any identifying toe clips were recorded and animals that could be identified had their measurements added to the long-term records held for this population. Individuals without a history were not added to the long-term records unless they could be identified by natural toe losses; no individuals were permanently marked. Once processed all individuals were returned to their capture location. Recaptures were recorded visually in the field as identifying numbers could be clearly seen, and the animal released immediately. If the observer was unsure about the number the animal was captured and its identity was confirmed back at the field centre. Searchers placed equal effort on captures and recaptures. 


\subsubsection{Data Analysis}

The raw data was analysed using SPSS (version 17.0). Summary statistics for the sample as a whole were produced. Modelling was carried out using MARK (version 5.1). Juveniles were excluded from all modelling due to low capture rates. Models are ranked according to an adjusted form of Akaike's Information Criterion (AICc), which accounts for any biases resulting from small sample sizes (Burnham \& Anderson 2002). AICc differences are used to estimate the relative Kullback-Liebler distance between the model used and reality, which is unknown (Burnham \& Anderson 2002). A smaller $\triangle \mathrm{AICc}$ indicates stronger support for the model, with scores 0-2 indicating substantial support for the model used being the best model (Burnham \& Anderson 2002).

\subsubsection{Population size and Sex Ratio}

Data were analysed in MARK to produce models that provided an estimate of population size. Six models were generated using Huggins closed captures models $M(t), M(b)$, and $M(t b)$ with and without an effect of sex (Table 3.1)

Table 3.1 Models used to estimate population parameters of interest including N-hat (population size). Adding a sex effect accounts for differences between males and females for each parameter.

\begin{tabular}{ll}
\hline Model & Description \\
\hline $\mathrm{M}(\mathrm{t})$ & $\begin{array}{l}\text { Model accounts for differences in the parameters between capture } \\
\text { occasions such as weather, capture effort etc. }\end{array}$ \\
$\mathrm{M}(\mathrm{b})$ & $\begin{array}{l}\text { Model accounts for differences in capture and recapture likelihood by } \\
\text { behaviour such as trap shy }(\mathrm{p}>\mathrm{c}) \text { or trap happy }(\mathrm{p}<\mathrm{c}) \text { behaviour. }\end{array}$ \\
$\mathrm{M}(\mathrm{tb})$ & $\begin{array}{l}\text { Model accounts for both time and behaviour differences in } \\
\text { parameters. }\end{array}$ \\
+ Sex Effect & Model accounts for differences in capture probability between sexes. \\
\hline
\end{tabular}


The assumptions for using a closed capture method are that the population is closed (no births, deaths, migration), animals do not lose their marks, marks are recorded correctly, and each animal has a constant and equal capture probability. The first assumption is considered valid as births and deaths are unlikely during the 4-night study period and individuals have been observed in the past to remain in a similar area long-term (Thompson et al. 1992). The second and third assumptions are generally assumed to be correct. The marker pen does not fade over the course of the study and it is assumed that recording is accurate. The final assumption is difficult to fulfil as individual heterogeneity, such as sex, life stage or behaviour may result in different catchability. These factors are accounted for in model selection by excluding juveniles and modelling for behavioural and sex effects.

The population estimates from the best models were extrapolated to include all potential habitat on the island, with an estimated $65 \%$ of habitat unsearched. The population estimates do not include juveniles as they were excluded from the modelling.

Sex ratios were calculated from actual capture numbers and population estimates for the study area calculated from the best models. Sex ratios were not calculated for the extrapolated population estimates for the whole island. A $\chi^{2}$ test was performed to determine if the calculated sex ratios were significantly different from a 1:1 ratio.

\subsubsection{Survival and Recapture}

Long-term records are kept for H. duvaucelii dating back to 1957 (Table 3.2). The number of individuals on record is currently 1066. Individuals caught during the 2008 trip were not marked and only existing marks and new individuals with natural toe loss 
were recorded. Twelve new individuals were registered, although some of these are likely to have had an existing record but due to subsequent toe loss could not be indentified. Only adult individuals of identifiable sex were used. Sixteen models were run in MARK under the recaptures model type to gain survival (Phi) and recapture probability (p) estimates. Survival and recapture probability could change over time (t), stay constant (.) and differ between males and females (*sex).

The recaptures model type produces open population models where the population is presumed to be experiencing births, deaths and migration. There are several assumptions for this type of model. Firstly, at each sampling occasion each animal in the population has the same probability of capture and that every marked animal has the same chance of survival from one sampling occasion to the next. These assumptions are assumed to be met through model type and exclusion of juveniles, which may have different rates of detection and survival to adults. Marks must also not be lost or overlooked. Individuals are identified through toe clip patterns and natural toe loss may lead to individuals being misidentified, especially over long study periods. Individuals are identified as best as possible, however there may be a few individuals whose records show they have not been caught when in fact toe loss has led to new identification marks for the animal. The assumption that all samples are instantaneous and animals are released immediately is also difficult to meet, as animals spent up to 2 hours away from their capture site, but due to the long intervals between trips this should not influence the results. As the population is on an island and individuals have previously shown site fidelity (Thompson et al. 1992), the assumption that emigration from the sample area is permanent is assumed to be met. It is also assumed that each animal's fate is independent from other animals in the population. 
Table 3.2 Trip dates, adult captures used in analyses and the number of capture occasions per trip for all mark-recapture trips from 1957-2008. *Only includes animals with permanent ID as no new permanent marks were made.

\begin{tabular}{clcc}
\hline Trip \# & Trip Date & \# Adults & Capture Nights \\
\hline 1 & August 1957 & 62 & unknown \\
2 & May 1958 & 88 & 4 \\
3 & August 1959 & 65 & 5 \\
4 & January 1988 & 19 & 3 \\
5 & November 1994 & 10 & 1 \\
6 & December 1997 & 6 & 4 \\
7 & February 1999 & 339 & 5 \\
8 & February 2000 & 335 & 5 \\
9 & January 2001 & 313 & 6 \\
10 & November 2008 & $79 *$ & 4 \\
\hline
\end{tabular}

\subsection{Results}

\subsubsection{Descriptive Statistics of Captured Individuals}

A total of 136 individuals were captured during the study. Of these 67 were female, 54 were male and 15 were juveniles whose sex could not be identified due to a lack of secondary sexual characteristics. Large adults made up the bulk of the captures (Figure 3.1). Adult length (SVL) and mass ( $\mathrm{g}$ ) did not differ between the sexes (t-test, $\mathrm{p}=0.5$ ). Average adult SVL was $108.55 \mathrm{~mm} \pm 0.64 \mathrm{~mm}(\mathrm{SE})$ and average adult mass $30.70 \mathrm{~g} \pm$ $0.56 \mathrm{~g}$ (SE). Recruitment is occurring as individuals were found in all size classes (Figure 3.1). 


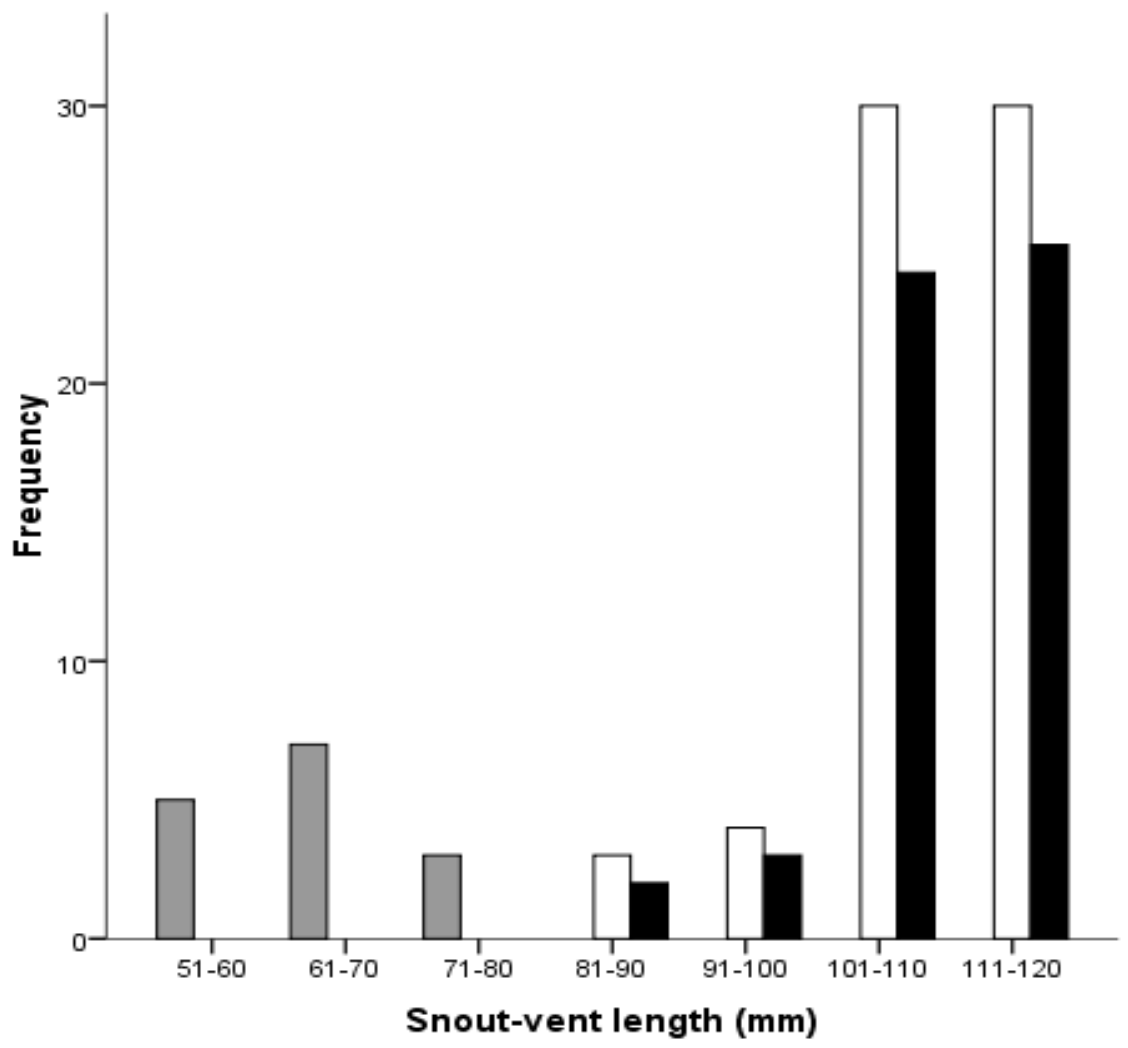

Figure 3.1 The frequency of individuals in each size class according to sex. Juveniles form their own category as their sex is undeterminable. $N=136 ; 15$ juveniles $(\square), 67$ females ( $\square$ ) and 54 males ( $\mathbf{a})$.

\subsubsection{Estimates of Population Size and Sex Ratio}

The data are insufficient to fit models with multiple factors due to low numbers of captures and recaptures (Table 3.3). The top model, $\mathrm{M}(\mathrm{b})$ without a sex effect, accounted for differences between initial capture and recapture probabilities (Table 3.4). Capture rates (p) and recapture rates (c) overlapped (Figure 3.2). Population size for the study area was calculated at 204 adults. Model M(t) with no sex effect showed very similar capture rates (p) over all nights (Figure 3.2). Population size for the study area was calculated at 237 adults. 
Table 3.3 Number of captures and recaptures of $H$. duvaucelii each night for all four nights of the study in November 2008.

\begin{tabular}{lcc}
\hline Date & New Captures & Recaptures \\
\hline $27 / 11 / 2008$ & 43 & - \\
$28 / 11 / 2008$ & 41 & 8 \\
$29 / 11 / 2008$ & 30 & 16 \\
$30 / 11 / 2008$ & 22 & 13 \\
\hline
\end{tabular}

Table 3.4 Models used for population size and sex ratio estimation in order of ranking, with the top ranking model first.

\begin{tabular}{llllcc}
\hline Model & $\begin{array}{l}\text { Delta } \\
\text { AICc }\end{array}$ & $\begin{array}{l}\text { AICc } \\
\text { Weight }\end{array}$ & $\begin{array}{l}\text { Model } \\
\text { Likelihood }\end{array}$ & $\begin{array}{c}\text { Number of } \\
\text { Parameters }\end{array}$ & Deviance \\
\hline M(b) no sex effect & 0.0000 & 0.62553 & 1.0000 & 2 & 803.1472 \\
M(t) no sex effect & 2.2383 & 0.20427 & 0.3266 & 4 & 801.3270 \\
M(b) sex effect & 3.8986 & 0.08906 & 0.1424 & 4 & 802.9873 \\
M(tb) no sex effect & 5.5139 & 0.03971 & 0.0635 & 6 & 800.5100 \\
M(t) sex effect & 5.8113 & 0.03422 & 0.0547 & 8 & 796.6804 \\
M(tb) sex effect & 8.9282 & 0.00720 & 0.0115 & 12 & 791.4380 \\
\hline
\end{tabular}

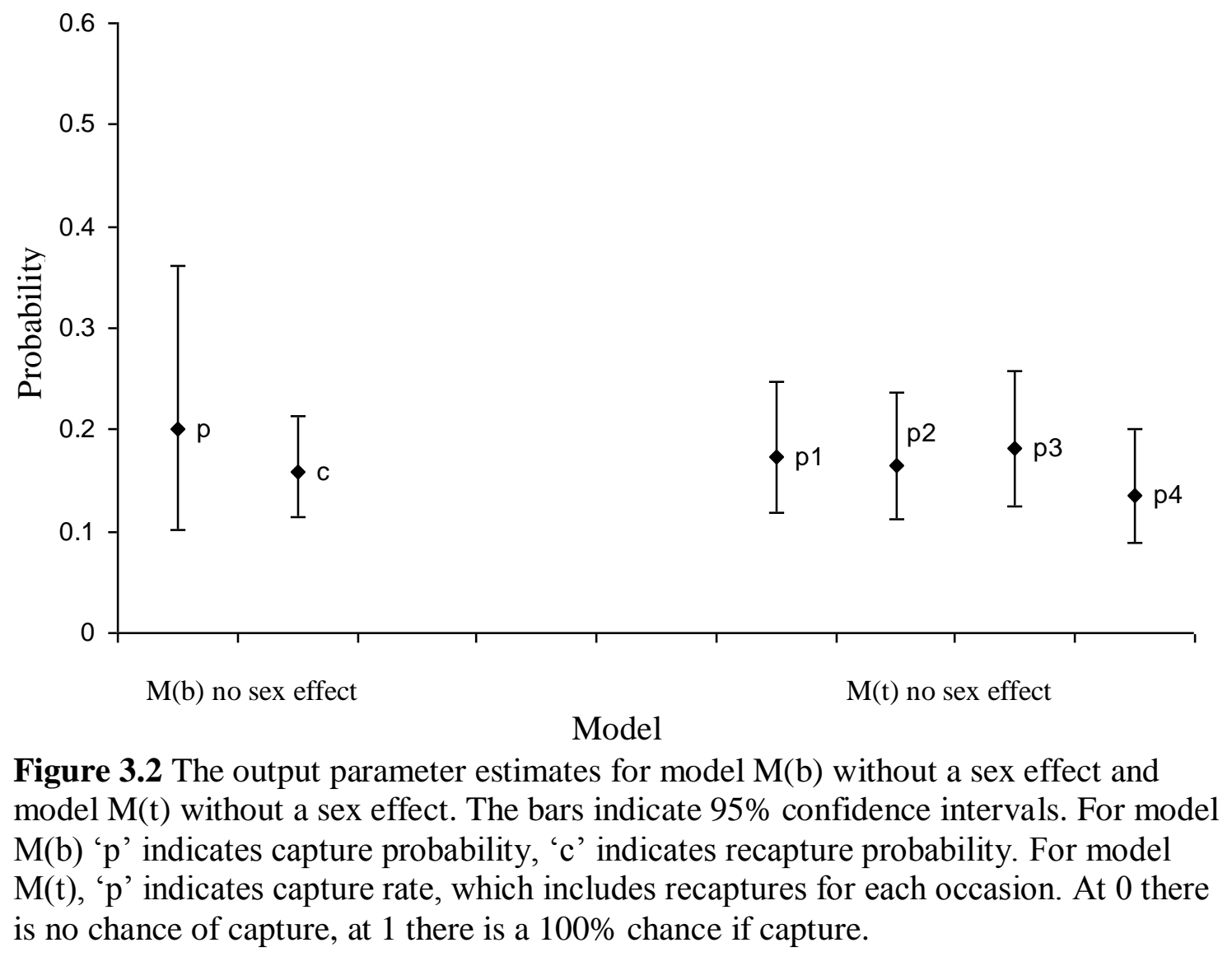


Population estimates from models $M(b)$ without a sex effect and $M(t)$ without a sex effect were extrapolated to estimate the population size for the entire island. Population estimates for the island range from 583-677 adults. Juveniles are not included in these estimates due to low capture rates.

The sex ratio of the population in the study area, and estimated through the models, was 1 male: 1.24 females, which is not significantly different from 1:1 (Figure 3.3). The proportion of each sex in the population is therefore considered to be roughly equal.

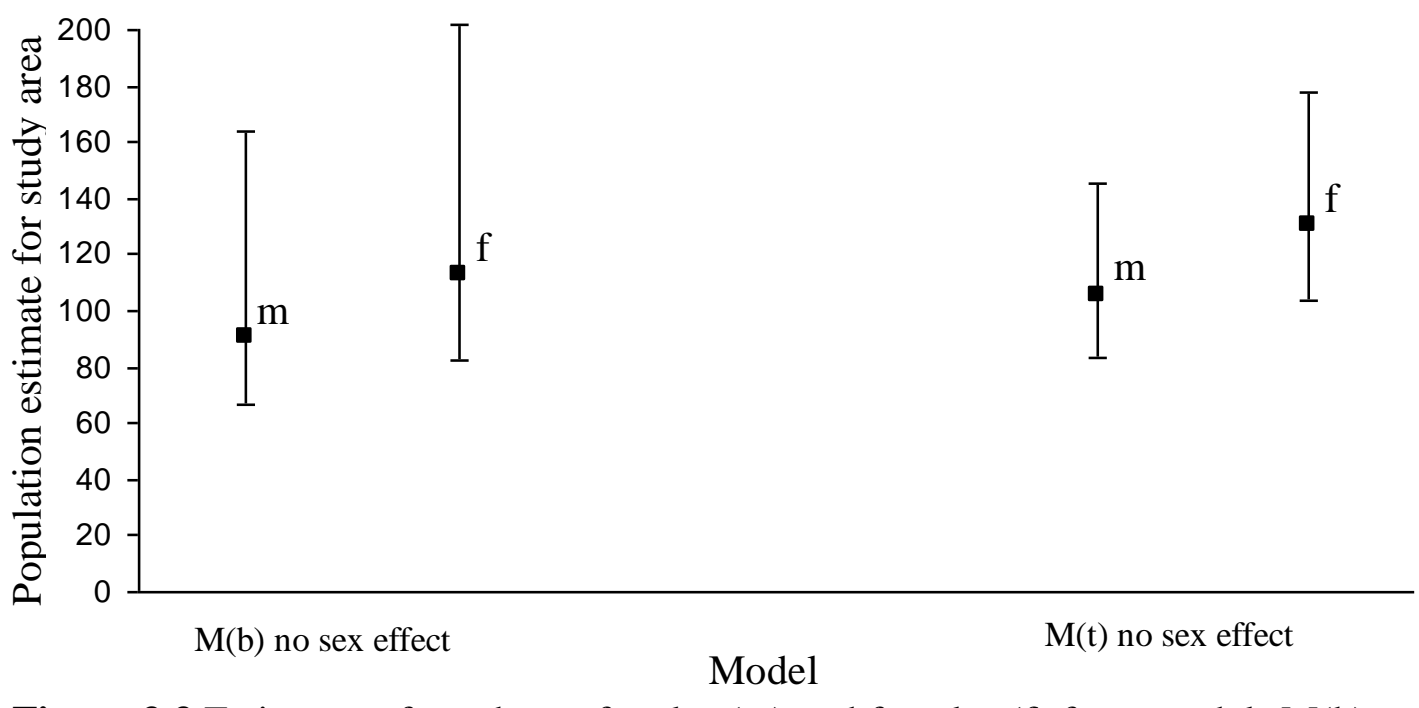

Figure 3.3 Estimates of numbers of males ( $\mathrm{m}$ ) and females (f) from models $\mathrm{M}(\mathrm{b})$ without a sex effect and $\mathrm{M}(\mathrm{t})$ without a sex effect with $95 \%$ confidence intervals.

\subsubsection{Estimates of Survival}

The top two models Phi(.)p(t) and Phi(.*sex)p(t) were within $2 \Delta \mathrm{AICc}$ and are considered as the best models for the data. Survival (Phi) is $\sim 92 \%$ for the adult population, regardless of sex, for both models. Variation among trips was clearly considered the main driver for $\mathrm{p}$ (recapture) ranging from 0.081 to 0.496 in each model, 
with little variation between the best models. Low recapture rates can be an artefact of the data rather than a true representation due to lower search time or effort and capture of low numbers of previously marked individuals. The latter occurs at both trips 4 and 6 . Twenty individuals were caught on trip 4, only one of which was previously marked. These individuals were deliberately selected for their large size (Thompson et al. 1992) and so were not a random sample. On trip 6, only nine individuals were caught, with four previously marked, resulting in a low recapture probability. Trip 2 also has a low recapture rate, however this may be due to a smaller proportion of the population having been previously marked on this occasion. Errors occurred for recapture probability in trip 5 for both models due to the absence of capture of previously marked individuals on this occasion, and hence no recapture rates were able to be estimated.

\subsubsection{Longevity}

Two individuals that were initially captured in 1958 were re-captured in 2001. One of the individuals was a juvenile male in 1958. The other was a mature female measuring $111 \mathrm{~mm}$ SVL in 1958. In 2001 her SVL was recorded as $113 \mathrm{~mm}$, indicating that she was fully grown when originally caught. Adding the seven years that it takes to reach maturity in this species (Barwick 1982) to the 43 years between captures produces a minimum longevity of 50 years for this female.

\subsection{Discussion}

The population is characterised by high survival ( 0.92), an even sex ratio, a high proportion of large individuals and low recapture probabilities. The majority of individuals in the sample were large adults (101-120mm) of both sexes. This may be 
due to a lower detection rate for smaller individuals or there may be few juveniles in the population due to mortality or low reproduction. Hoplodactylus duvaucelii on North Brother Island remain smaller than their northern counterparts, but average SVL from 2008 was similar to previous records for North Brother Island (Barwick 1982). This population may be close to carrying capacity as the seven recaptured individuals from the forty translocated to Mana Island gained weight, and sub-adults grew rapidly in the year following translocation (Jones 2000), presumably as a result of less competition for resources.

Low capture rates for the 2008 trip may be due to the study design where $H$. duvaucelii were captured at the same time as tuatara S. punctatus (Chapter 2). Although equal effort was placed on catching both species, tuatara are larger and perhaps more visible to searchers than $H$. duvaucelii and searchers may have disturbed or overlooked $H$. duvaucelii while securing a tuatara. However, low capture rates for the population $(<0.5)$ indicate that only a small proportion of the population were sampled. All searching is done around vegetation to avoid breaking the brittle taupata and damaging smaller plants. Hoplodactylus duvaucelii may be present under the vegetation but remain unseen due to this method. Juveniles have lower detection rates than adults in several reptile species (Pike et al. 2008). This is known to be true of tuatara (Dawbin 1982), whose juveniles are larger than those of H. duvaucelii. According to Pike et al. (2008), viviparous squamate species have a higher survival rate than oviparous species, with juvenile survival similar to adult survival rates overall. Given that the adult survival rate for $H$. duvaucelii is 0.92 , juvenile survival could also be high, but this could not be accurately estimated due to low capture probabilities. 
Many of the captured animals exhibited tail loss, indicating that either intra- or interspecific aggression, or attempted predation is occurring in this population. Although tail regeneration suggests that attacks are occurring on H. duvaucelii, the high survival rate indicates that attacks do not necessarily result in fatalities. Aside from tuatara, there are no natural predators on the island as the majority of birds on North Brother Island are seabirds (Gaston \& Scofield 1995) that are not known to consume lizards. Juvenile mortality may be occurring if adult $H$. duvaucelii or tuatara prey upon the young. Although the diets of both species consist primarily of insects (Barwick 1982; Walls 1981), they have also been known to consume lizards. Barwick (1982) observed lizard rib bones and two small humeri in the stomach of a mature female $H$. duvaucelii on North Brother Island. He attributed them to a juvenile common gecko Hoplodactylus maculatus. Duvaucel's gecko were also observed to eat juvenile goldstriped geckos Hoplodactylus chrysosireticus on Mana Island (Flannagan 2000). Lizard and bird remains together comprised only $4 \%$ of tuatara diet on Stephens Island (Walls 1981), but the reptile community could potentially be a more utilised food group on the resource limited North Brother Island. Despite the high number of $H$. duvaucelii exhibiting tail loss, survival is similar to that of tuatara on the island (95\%; see Chapter 2), who are not subject to predation as adults, suggesting that intraspecific competition may be a contributing factor in tail loss. Translocated $H$. duvaucelii from North Brother to Mana Island exhibited no tail loss at one year after release, where densities are low and predators (including tuatara) are not present (Jones 2000). This suggests that either tuatara attacks or density-dependent competition are responsible for tail loss on North Brother Island. 
Previous measures of longevity in $H$. duvaucelii identified an individual as being at least 36 years old (Thompson et al. 1992). Continued monitoring of this population has resulted in longevity being identified as at least 43-50 years for two individuals. New Zealand geckos live longer than geckos in other areas of the world, likely due to their slow reproduction cycle (Cree 1994). Several Australian geckos have lifespans of only 2-3 years (Read 1999), while others reach at least 9 years (Kitchener et al. 1988). Ten Hoplodactylus maculatus, common geckos, on Motunau Island in North Canterbury had an estimated longevity of 36 years in 1997 (Bannock et al. 1999), which was extended to 42 years for one individual in 2005 (Lettink \& Whitaker 2006). Lettink \& Whitaker (2006) believed that 42 years was the longest longevity for a free-living gecko population globally, and I have been unable to find any evidence of another gecko of any species reaching the estimated 50 years identified for $H$. duvaucelii. However, it is difficult to estimate age of geckos without long-term mark-recapture techniques due to growth patterns (Lettink \& Whitaker 2006) and few studies are conducted over decades. Other reptiles, such as sea turtles and tuatara, are estimated to live for over 100 years, and it may be that $H$. duvaucelii also has a more extreme longevity than currently thought.

Updating species knowledge is important and there are few opportunities to follow populations over long periods as on North Brother Island. The population of $H$. duvaucelii on North Brother Island comprises an estimated 580-680 adults over the whole island. Barwick's initial estimate of population size on the island was 750 animals/ha (Barwick 1982), which he considered to be a very rough estimate, and this estimation was used as a guide for use of the population as a translocation source (Flannagan 2000). While an estimated total of 580 adults is not as large as Barwick's 
estimate, the population is relatively large, with a roughly equal sex ratio, and removal of some animals for translocation may be appropriate, provided monitoring of the source population is continued. Animals removed for translocation purposes should be unmarked, so that longevity studies on this population can continue.

Monitoring should be continued on this population to provide further information about longevity and population fluctuations over time. Ideally, long-term studies should follow a population for several population turnovers as apparent stability of a population in numbers may simply be a reflection of lifespan and survival, especially in long-lived individuals (Blaustein et al. 1994). If longevity in H. duvaucelii exceeds fifty years then monitoring any population for more than one turnover would be difficult financially and in terms of resources available. Because of this, the 50 years of data already held makes this population a valuable resource for future studies on longevity, long-term trends and the effects of translocation on a population.

\subsection{Summary}

The population of Duvaucel's gecko on North Brother Island appears to be stable, with an equal sex ratio and high survival. Monitoring should be continued on this island, as long-term data is valuable in understanding the natural history of a species. Future studies should include mark-recapture techniques to provide more population data towards understanding long-term trends in this population, including longevity, as well as providing baseline data for translocated populations. Future research directions could include investigating density-dependence following removal of animals for translocation, site fidelity and interspecific interactions with S. punctatus on North Brother Island. 


\section{Chapter 4: Potential for Resource Competition}

\subsection{Introduction}

Coexistence of species in a habitat is promoted through environmental variation and partitioning of resources. Patterns of partitioning are determined by a combination of species physiological constraints and interspecific interactions (Toft 1985). Species with similar niche requirements will not be able to coexist without some form of partitioning occurring. Where partitioning does not occur, confrontation over resources can lead to direct mortality in competing species (Kitchen et al. 1999).

Resources in a community have traditionally been partitioned into three categories habitat, food and time (Toft 1985). Toft (1985), suggests that reptiles and amphibian mainly partition resources spatially. Spatial partitioning allows species to separate themselves physically and in doing so avoid confrontations over other resources, such as food. Partitioning food items, such as prey species by type or size, allows species to coexist in an area where prey may be scarce. For example, many snakes partition by prey type (Luiselli 2006). A study of five elapid snakes in Australia revealed prey partitioning, with two species preying solely on lizard species, and another primarily on squamate eggs (Goodyear \& Pianka 2008). Temporal partitioning allows species to utilise the same space and food items without confrontation, provided the food resource renews itself between time periods. Temporal partitioning is the most understudied of the three categories, but has been observed among bat species (Adams \& Thibault 2006).

Resource partitioning is thought to aid species coexistence by reducing overlap in resource use (resource competition), either by consumption (food) or presence 
(space/time), or by avoiding confrontation (interference competition) (Kronfeld-Schor \& Dayan 2003; Schoener 1983). Interference competition is the active prevention of individuals accessing resources (Schoener 1983), which can take the form of the dominant species excluding the submissive species, causing behavioral changes, or direct mortality (Kitchen et al. 1999; Kronfeld-Schor \& Dayan 1999; Ziv et al. 1993). For example, there were behavioural changes in spatial and temporal avoidance of wolves by coyotes following recolonisation of wolves in Montana, USA (Arjo \& Pletscher 1999). Similar changes were also observed in Yellowstone National Park, USA, where initially high encounters between wolves and coyotes, immediately following wolf reintroduction, decreased over time (Merkle et al. 2009).

Islands generally have fewer species than comparable areas on the continental mainland; the number of species decreases with increasing distance from the mainland (Macarthur \& Wilson 1963). Although there are fewer species, islands may have much higher densities of animals than their mainland counterparts. For herpetofaunal communities, island biomass is, on average, about seven times greater than it is for that of similar communities on corresponding mainland sites (Rodda \& Dean-Bradley 2002). Niche shifts may also occur, with an island population exploiting resources differently to those on the mainland, including spatial expansion or utilising a wider range of food resources due to decreased competition (MacArthur et al. 1972). Because of high densities and niche shifts, ecologically similar species may competitively exclude one another (MacArthur et al. 1972), especially as resources on an island, such as space and food, are limited. 
New Zealand has many offshore islands with unusually high reptile diversity and biomass (Towns et al. 1990). For example, on 10ha Middle Island, in the Mercury group, there are 10 native reptile species (Towns et al. 1985), compared to all of Great Britain, which only has six native reptile species (Reading 1997). Islands that are free of introduced mammalian predators exhibit higher densities and diversity than the mainland and islands that been invaded by rats (Towns et al. 1985). For example, mainland New Zealand only has 12 widespread species out of 38 lizard species present on offshore islands (Towns et al. 1985). The reptile community on Middle Island has been observed to partition microhabitat, with skink species showing little overlap between rocky shore platforms, boulder beaches and open shrub areas (Towns et al. 1985). The Poor Knights Islands have 8 reptile species, which also appear to partition microhabitat (Whitaker 1968). Despite knowing that partitioning occurs, the mechanisms driving patterns of partitioning are not well understood.

North Brother Island is a small 3.9ha island that has never been invaded by rats, with a community of 5 reptile species. Two of these species potentially compete - Duvaucel's gecko Hoplodactylus duvaucelii and tuatara Sphenodon punctatus. On such a small depauperate island, mechanisms driving co-existence of competitors warrant further investigation. Duvaucel's gecko is a large, nocturnal habitat generalist of up to $120 \mathrm{~mm}$ snout-vent length (SVL) (Barwick 1982). Tuatara on North Brother Island are known to grow up to $246 \mathrm{~mm} \mathrm{SVL}$ for males and $213 \mathrm{~mm}$ for females (Thompson et al. 1992). Duvaucel's gecko exhibit aggressive and predatory behaviour with other gecko species of the same genera (H. maculatus (Barwick 1982); H. chrysosireticus (Flannagan 2000). The stomach contents of $H$. duvaucelii specimens from North Brother Island revealed plant remains, seeds, insects (both nymphs and adults) and small lizard bones (Barwick 
1982), but the study was limited by sampling predominantly in winter. The majority of remains were Orthoptera nymphs, (Barwick 1982). Barwick suggested that $H$. duvaucelii prey were more sedentary insects and nymphs, as no moths were found. Sphenodon punctatus diet on nearby Stephens Island consisted mainly of insects (54\%) and other invertebrates (20\%) with only $4 \%$ of their diet consisting of reptile or bird species (Walls 1981). It is reasonable to assume that tuatara and Duvaucel's geckos on North Brother Island have similar feeding preferences, for those species that occur on North Brother Island. There is also the possibility of $S$. punctatus preying upon $H$. duvaucelii.

If dietary overlap is occurring, then partitioning along the spatial or temporal niche axis should be evident. Spatial partitioning through interference competition is evident in territorial species, such as tuatara, when individuals actively defend their space from intruders (Schoener 1983), but this is more likely to generate intraspecific competition. Both $S$. punctatus and $H$. duvaucelii are nocturnal, but could potentially have different activity periods during the night. If $H$. duvaucelii are being preyed upon by $S$. punctatus then $H$. duvaucelii should avoid areas with tuatara through either spatial, or temporal partitioning, where they co-occur.

Competitive asymmetry may arise when one species is a superior competitor to another (Connell 1983; Schoener 1983). Larger animals are generally more superior competitors than smaller ones, but other factors that can cause asymmetry include recruitment ability, differences in feeding parameters and physiological tolerances (Schoener 1983). Tuatara and Duvaucel's gecko both have low reproductive rates (Cree 1994) and have similar feeding (Barwick 1982; Walls 1981) preferences. Because of these similarities, 
the larger tuatara could potentially be displacing $H$. duvaucelii from areas with greater food resources, which are assumed to be heavily vegetated areas (Hoare et al. 2006).

I investigated competition between $S$. punctatus and $H$. duvaucelii on North Brother Island by evaluating spatial and temporal resource partitioning. Site fidelity and long term body condition trends for both species were also investigated. I hypothesise interference competition is occurring if $H$. duvaucelii avoid tuatara by using lower resource areas and/or have activity periods outside of those of tuatara. Alternatively, if the expected differences in spatial location and temporal activity are not evident, $H$. duvaucelii and S. punctatus may not be in direct competition with each other. Diet analyses were excluded from this study.

If interference competition is occurring and if individuals on North Brother Island remain in the same vicinity throughout most of their lives, they are likely to be competing with the same neighbours. Connell (1983) suggests that in relatively spatially stable species, such as plants and marine organisms, competition occurs mainly between neighbours, regardless of species. I hypothesise that long-term close neighbours will avoid agonistic interactions and partitioning will be evident in grid squares where $S$. punctatus and $H$. duvaucelii both occur, if site fidelity is evident. Alternatively, if site fidelity is not evident, patterns of partitioning where both species occur may not be evident, or are unrelated to site fidelity.

I also hypothesise that if interspecific competition is the main driver in resource acquisition, both species should exhibit the same trend in body condition. However, if 
differences in trend do exist, then intra-specific competition may play a more dominant role in determining body condition.

\subsection{Methods}

\subsubsection{Field Site Description}

North Brother Island is a steep, rocky island rising to $75 \mathrm{~m}$ above sea level (Gaston \& Scofield 1995) located in Cook Strait, New Zealand. The island is small at 3.9ha (Millar \& Gaze 1997), and large areas have been modified due to the construction and continuing maintenance of the lighthouse. Concrete platforms are located at the northern and southern points of the island with a railway track crossing the northern face from the sea to the lighthouse. The majority of buildings are around the summit of the island, and include several buildings that currently serve as temporary living quarters and a generator shed, as well as disused water tanks and sheds. Due to weed control programs the flora is largely native, dominated by Coprosma repens (taupata), Disphyma australe (horokaka), Hebe elliptica and Salicornia australis (Gillam 1960).

\subsubsection{Mark-Recapture Study}

A mark-recapture study was conducted over four nights from $26^{\text {th }}-30^{\text {th }}$ November 2008. Tuatara and Duvaucel's gecko were both captured. Each night, two teams of two went out from approximately $10 \mathrm{pm}$ to $4 \mathrm{am}$, covering the search area of approximately 1ha twice. Animals were captured by hand and placed in individual cloth bags. Reflector pegs unique to each bag were left at the removal point. The time of capture and the location of each animal were recorded. Animals were then taken to the former 
lighthouse keeper's house for processing. Each individual was given a temporary unique number for identification and this was written in non-toxic permanent marker on both sides of tuatara and on the base of the tail of geckos. These marks would remain on the animal for the length of the trip. Once marked, individuals were measured and weighed with mass, snout-vent length (SVL), tail length and any tail regeneration recorded. For both species sex of individuals was determined by secondary sexual characteristics, with individuals that were unable to be assigned to a particular sex considered juveniles. Male H. duvaucelii are determined by hemipenal sacs and large cloacal spurs; male $S$. punctatus are identified by crest development and large heads. Breeding size for adult Duvaucel's gecko is considered to be $95 \mathrm{~mm}$ SVL for females and 98mm SVL (Barwick 1982); for tuatara breeding size is considered 163mm SVL for both sexes in this population (Cree et al. 1991). Any previous identification through toe clip or PIT tag (microchip) was also recorded, with capture data added to long term records of capture for both species. Once processed all individuals were returned to their capture location by the end of each capture session. Recaptures over the following nights were recorded using identifying numbers that could be clearly observed. If the observer could not see the number clearly, the animal was captured to confirm the identity of the individual but was not measured again and was immediately released. Time and location of the recaptures were recorded for the first time an animal was seen each night, regardless of whether the animal was seen again. Equal effort was placed on capturing new animals and recording those already marked of both species.

\subsubsection{Data Analysis}

All data were analysed using Microsoft Excel 2000 and SPSS (version 17.0). Body condition was calculated using $\log (\operatorname{mass}) / \log (\mathrm{SVL})$ as in Hoare et al. (2006) and data 
for S. punctatus from 1957-2001 from Hoare et al. (2006) were used. Cumulative rainfall for the two months prior to, but not including, the month of the study period was plotted with body condition over time to look for patterns explaining any fluctuations in body condition. For analysing spatial overlap each grid square on the 2008 map (Appendix), of approximately $14 \mathrm{~m}^{2}$, was considered a separate location and classified as vegetated, open (dirt or low ground cover vegetation) or concrete.

To analyse temporal overlap, the time of first capture for each individual recorded in the field was separated into fourteen groups (Table 4.1). Only captures for the first day were used in analysis to minimise the potential influence of human disturbance affecting animal activity on subsequent nights. For the locations where $H$. duvaucelii and $S$. punctatus occurred together, time and day were graphed by location to see if temporal partitioning was occurring.

Table 4.1 Partitioning of time into half hour groups over the search period. Animals in category 1 were captured opportunistically, whereas those from categories 2-14 were captured as part of the survey.

\begin{tabular}{cc} 
Time Group & Actual Time (24 hours) \\
\hline 1 & Before 2159 \\
2 & $2200-2229$ \\
3 & $2230-2259$ \\
4 & $2300-2329$ \\
5 & $2330-2359$ \\
6 & $0000-0029$ \\
7 & $0030-0059$ \\
8 & $0100-0129$ \\
9 & $0130-0159$ \\
10 & $0200-0229$ \\
11 & $0230-0259$ \\
12 & $0300-0329$ \\
13 & $0330-0359$ \\
14 & $0400-0429$ \\
\hline
\end{tabular}




\subsubsection{Site Fidelity Analysis}

Two maps of North Brother Island with different location grids were used over the period 1999-2008 when site data were collected (see Appendix). The newer map is an enlarged aerial photograph with a grid overlaid; the older map is hand drawn from an older and less centralised aerial photograph. The two maps were not to the same scale and so were overlapped using ARC GIS software (version 9.3). Features such as the lighthouse, buildings, and distinctive landforms were used to match the older map to the new one. Locations (grid squares) from the older map were then able to be overlaid on the new map (see Appendix). Animals were tracked from location to location from 1999 to 2008, with measurements made from the centre of each grid square (both older and newer). Site fidelity was estimated using two measures. The distance between the 2008 capture location and the capture location furthest away from that point was measured. The average distance travelled per year was calculated by taking the distance between sequential capture locations and dividing each distance by the number of years between captures. Distance per year was then averaged across the capture history for each individual ranging from 1999-2008, depending on the individual. Because of the lower accuracy of the older map, there is distortion in the size of some of the areas covered pre-2001 (see Appendix), particularly on the south face of the island. All animals captured in grids 25-30 on the older map were excluded from analysis, as some pre2001 grid squares were over double the size of the others. Twenty-six Duvaucel's gecko records and five tuatara records were excluded because of this. Thirty-two tuatara caught in 2008 were also caught in 1993, which is the earliest date locations were recorded on the older map. Distances between the 1993 location and 2008 location for these individuals were calculated separately from the 1999-2008 data. 


\subsection{Results}

\subsubsection{Spatial Use of Resources}

In the 2008 grid squares where animals were captured, geckos were found in $57.4 \%$ and tuatara in $68.8 \%$ of total grid squares. There is an association between vegetation type and the species composition of a location (Table 4.2). The difference between observed and expected values in the Chi squared analysis suggests that tuatara may be excluding geckos from occupying vegetated areas. Tuatara were present in more vegetated grid squares without Duvaucel's gecko present than expected, and Duvaucel's gecko were present in more grid squares without tuatara on open ground than expected. However, co-habitation is obviously occurring in some areas as 37 of the 141 grid squares (26\%) where animals occurred were occupied by both species. These areas were investigated further (see section 4.3.5)

Table 4.2 Contingency Table used for Chi Squared Tests. There is an association between vegetation type and species composition on North Brother Island $\left(\chi^{2}=15.6\right.$, $\mathrm{DF}=4, \mathrm{p}=0.0035)$

\begin{tabular}{llll|l}
\multicolumn{1}{l}{ Vegetation } & Open Ground Concrete & \\
\hline Duvaucel's Gecko/No Tuatara & 15 & 26 & 3 & 44 \\
Both Species Present & 14 & 18 & 5 & 37 \\
Tuatara/No Duvaucel's Gecko & 39 & 14 & 7 & 60 \\
\hline & 68 & 58 & 15 & 141
\end{tabular}

For areas where $H$. duvaucelii were present without tuatara, only $4.4 \%$ of vegetated locations had multiple geckos (ranging from 2-8 animals), whereas $20.7 \%$ of open ground locations contained multiple geckos. Tuatara showed the opposite pattern with $26.5 \%$ of vegetated locations having multiple S. punctatus (ranging from 2-4 animals) but no $H$. duvaucelii, compared to $6.9 \%$ of open ground locations. The same trends are evident where only one individual of either species is present at a location. Unless both 
species were sharing a concrete location, there was only one animal present at each concrete location. Tuatara were predominantly found on the northern face of the island as only 10 animals were captured on the southern face.

\subsubsection{Temporal Use of Resources}

Sphenodon punctatus and H. duvaucelii overlap in their use of time as both species were caught during all time periods when searchers were active (Figure 4.1). The best times to capture each species appeared to be different. On the first night of captures, more tuatara were caught between 10 and $11 \mathrm{pm}(43.3 \%)$, whereas more $H$. duvaucelii were caught between 2-3am (43.2\%). Numbers of new captures dropped off after the first hour, followed by another peak in captures after a break in searching from 0030-0129 due to processing individuals. This was then followed by a period of fewer captures, which could be an indication of animals responding to human disturbance, or all animals observed out had been marked earlier in the evening. Time of capture was also influenced by the pattern of searching, with captures at the end of each survey area caught later than individuals at the beginning of the survey period. 


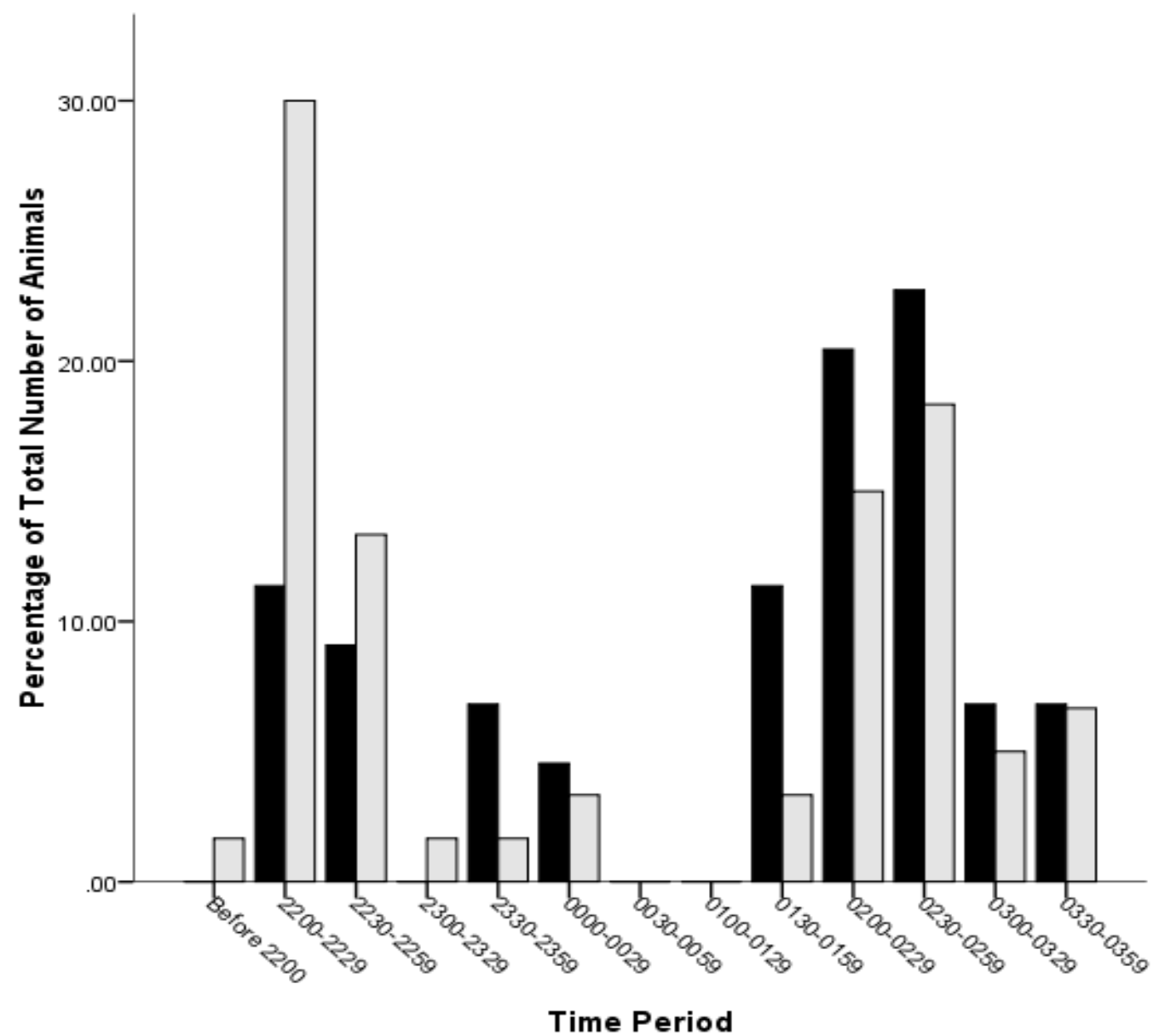

Figure 4.1 The percentage of total number of animals captured on the 26/11/2008 (₫ Tuatara; $\square$ Duvaucel's gecko). Searchers were inside assisting with processing of animals from 0030-0129 hours.

\subsubsection{Spatial and Temporal Partitioning}

A total of 71 geckos and 58 tuatara were found to be sharing 37 grid squares (Figure 4.2). At fifteen grid squares, a gecko was captured at the same time as a tuatara, which translates to $11.0 \%$ of all geckos and $10.1 \%$ of all tuatara captured over the four nights. Many of these 15 locations were either around a track or had more complex habitat than generally found. These included a site with hollow concrete blocks, one in the "picnic area" containing different vegetation types and logs, and one with a large hebe plant. All other animals were captured at either different times on the same night or at the same time but on different nights. Where both species co-occur, animals showed similar 
temporal trends to Figure 4.1. Over $50 \%$ of tuatara were captured by 2300 hours for the four nights combined; Geckos did not reach 50\% captured until 0130 hours.

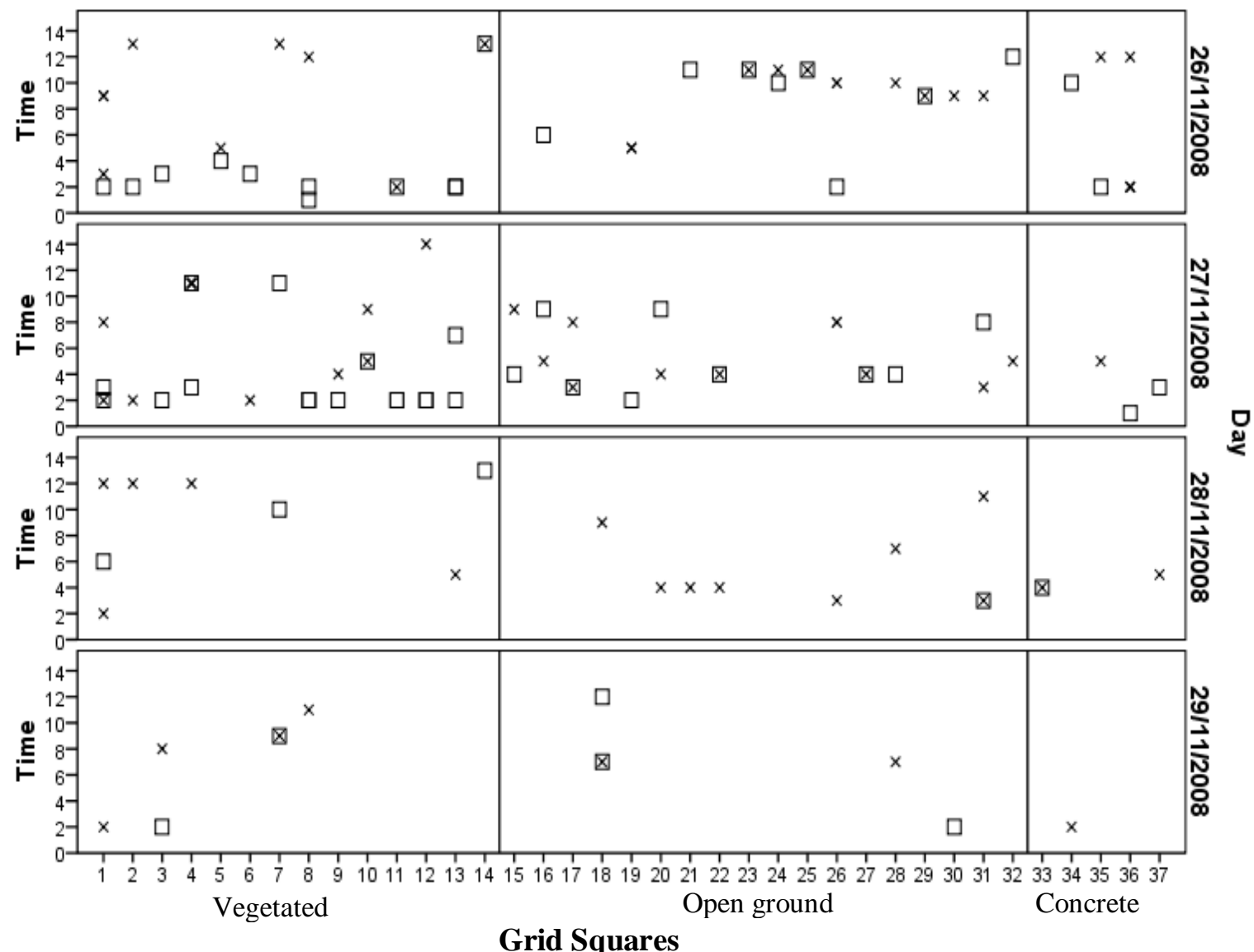

Figure 4.2 Time is allocated in half hour blocks starting at 2200 and finishing at 0429 (2-14) for four nights. Any animal allocated (1) was captured opportunistically prior to the main survey commencing at 2200 hours. Locations 1-14 are vegetated, 15-32 open ground and 33-37 concrete. $\square$ denotes a Tuatara; $\mathbf{x}$ denotes Duvaucel's Gecko. Graph does not include recaptures for these locations over the course of the trip. There is little overlap of species in space and time.

\subsubsection{Site Fidelity}

The majority of $H$. duvaucelii were previously caught within $15 \mathrm{~m}$ of their 2008 location, with a median distance of $11.7 \mathrm{~m}$ (Figure 4.3). Only two animals were located more than $35 \mathrm{~m}$ away from the 2008 capture location - one male and one female who were both adults over the period 1999-2008. The majority of $H$. duvaucelii had an average distance travelled per year of less than $2 \mathrm{~m}$, with a median distance of $1.6 \mathrm{~m}$ 
(Figure 4.4). Four individuals travelled over $5 \mathrm{~m}$ per year over the nine year period - two males and one female, all fully grown throughout the study period and one female, who was a juvenile at first capture in 2001.

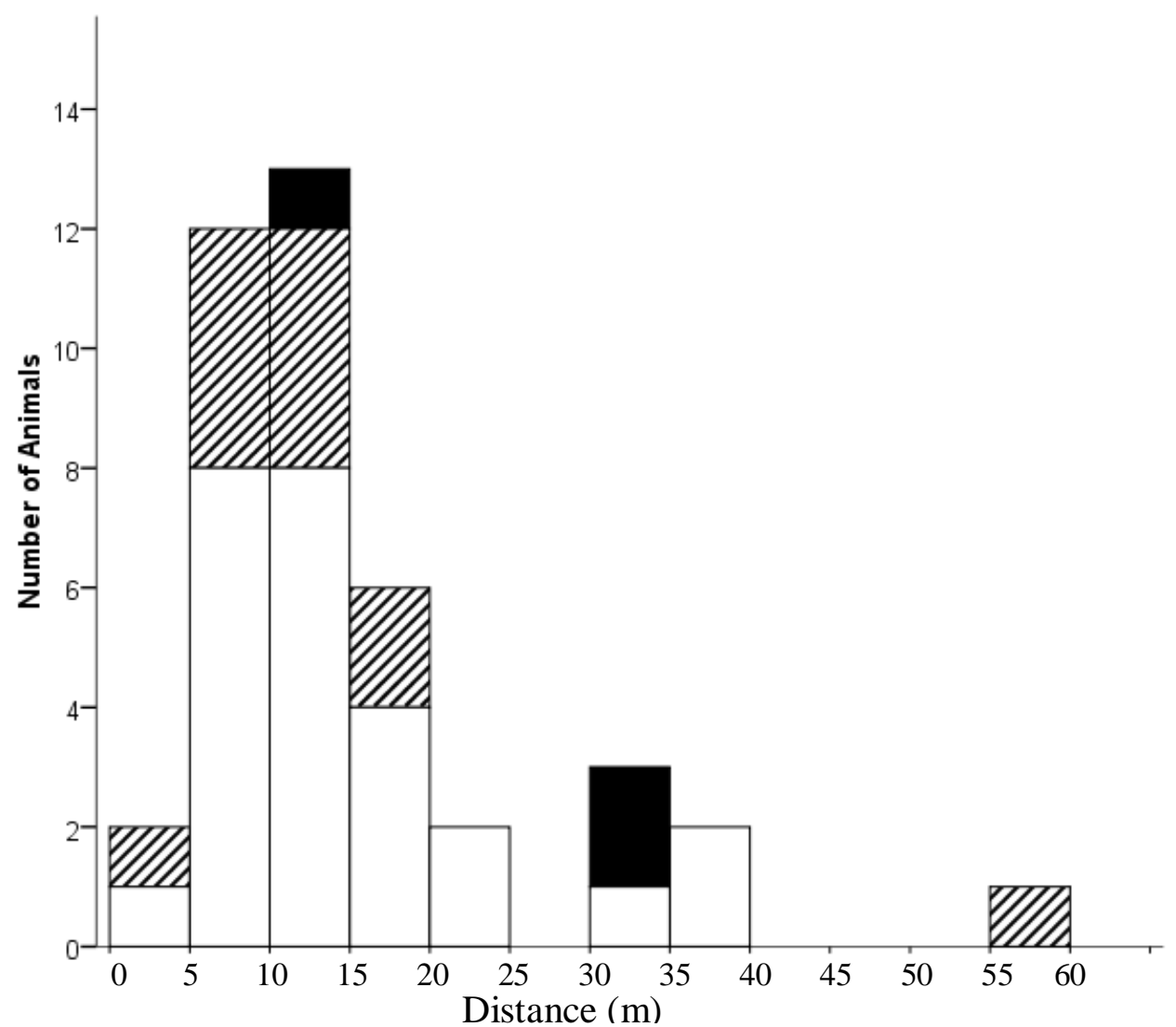

Figure 4.3 Furthest distance from 2008 grid square, encompassing all locations recorded for each $H$. duvaucelii captured in 2008 that were also captured at least once between 1999-2008. $\square$ Indicates 2 captures; $\square 3$ captures; 4 captures. The majority (63\%) of $H$. duvaucelii were captured previously within $15 \mathrm{~m}$ of their 2008 location (median $=11.7 \mathrm{~m} ; \mathrm{N}=41)$. 


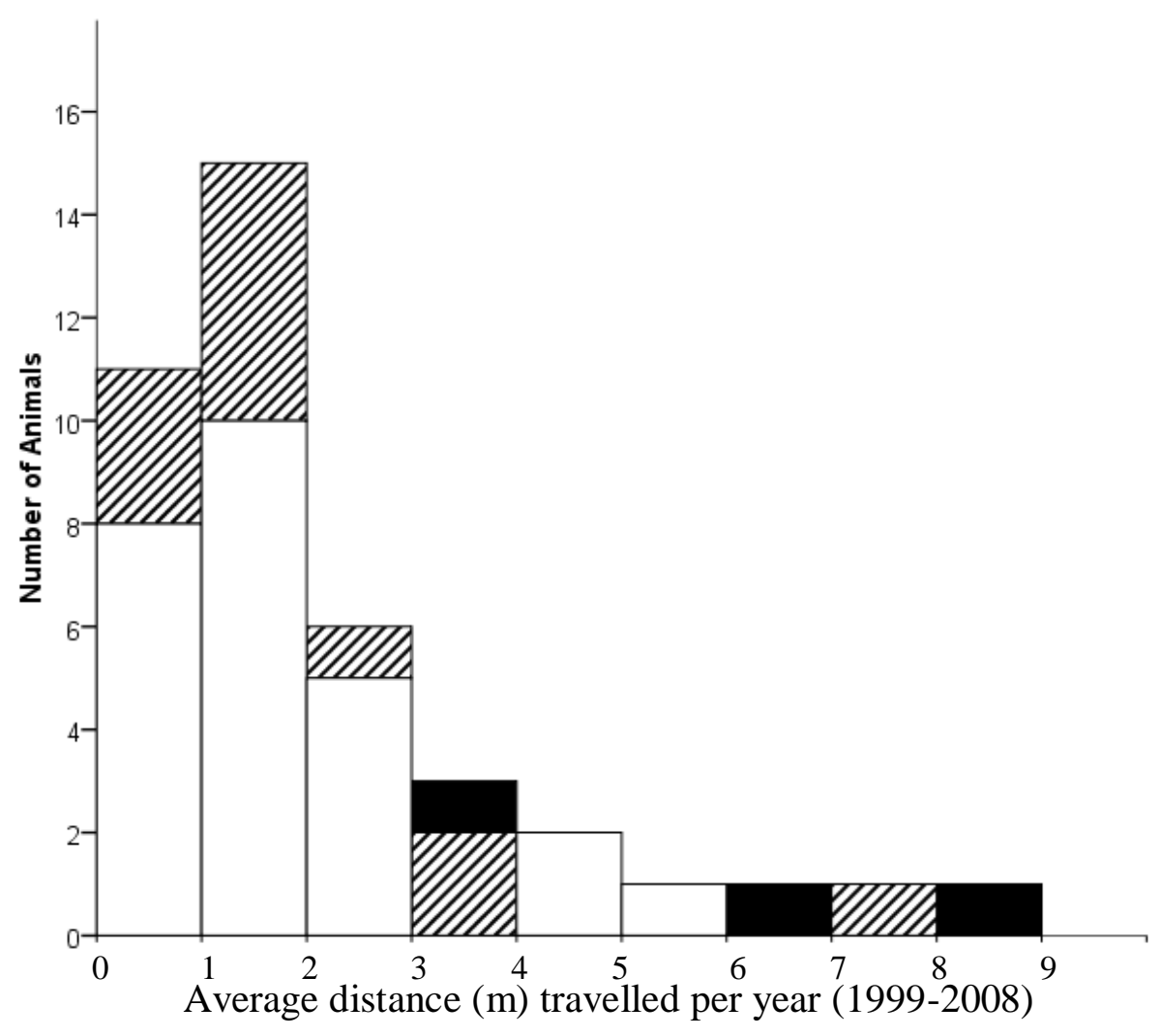

Figure 4.4 The average distance $(\mathrm{m})$ travelled per year for $H$. duvaucelii individuals who were captured in 2008 and at least once during the previous four surveys from 1999-2008. $\square$ Indicates 2 captures; $\boldsymbol{Z} 3$ captures; 4 captures. The majority (66\%) travelled less than $2 \mathrm{~m}$ per year (median $=1.6 \mathrm{~m} ; \mathrm{N}=41$ ).

The majority of $S$. punctatus were previously caught within $10 \mathrm{~m}$ of their 2008 location, with a median distance of $8.3 \mathrm{~m}$ (Figure 4.5). Only five animals had previously been captured more than $35 \mathrm{~m}$ away from the 2008 capture location - three males who were all adults over the period 2000-2008 and two females, who were not fully grown when first captured in 2000. One was a sub-adult in 2000/2001, who moved $57.5 \mathrm{~m}$ between 2001 and 2005, where she was recorded as an adult of breeding size. The other female was just of breeding size in 2000/2001 but moved $57.5 \mathrm{~m}$ to the opposite side of the island between 2001 and 2008, where she was recorded as having grown. The majority of $S$. punctatus had an average distance travelled per year of less than $2 \mathrm{~m}$, with a median distance of $1.9 \mathrm{~m}$ (Figure 4.6). Nine individuals travelled over $5 \mathrm{~m}$ per year over the eight year period - this includes the five individuals discussed above, one adult male still growing and two large fully grown males. 
For the 32 tuatara caught in 1993 and 2008, the median distance between the two locations was $8.3 \mathrm{~m}$. Only two individuals travelled more than $20 \mathrm{~m}$ - a small adult male that moved $60 \mathrm{~m}$, and a fully grown adult male that moved $25 \mathrm{~m}$.

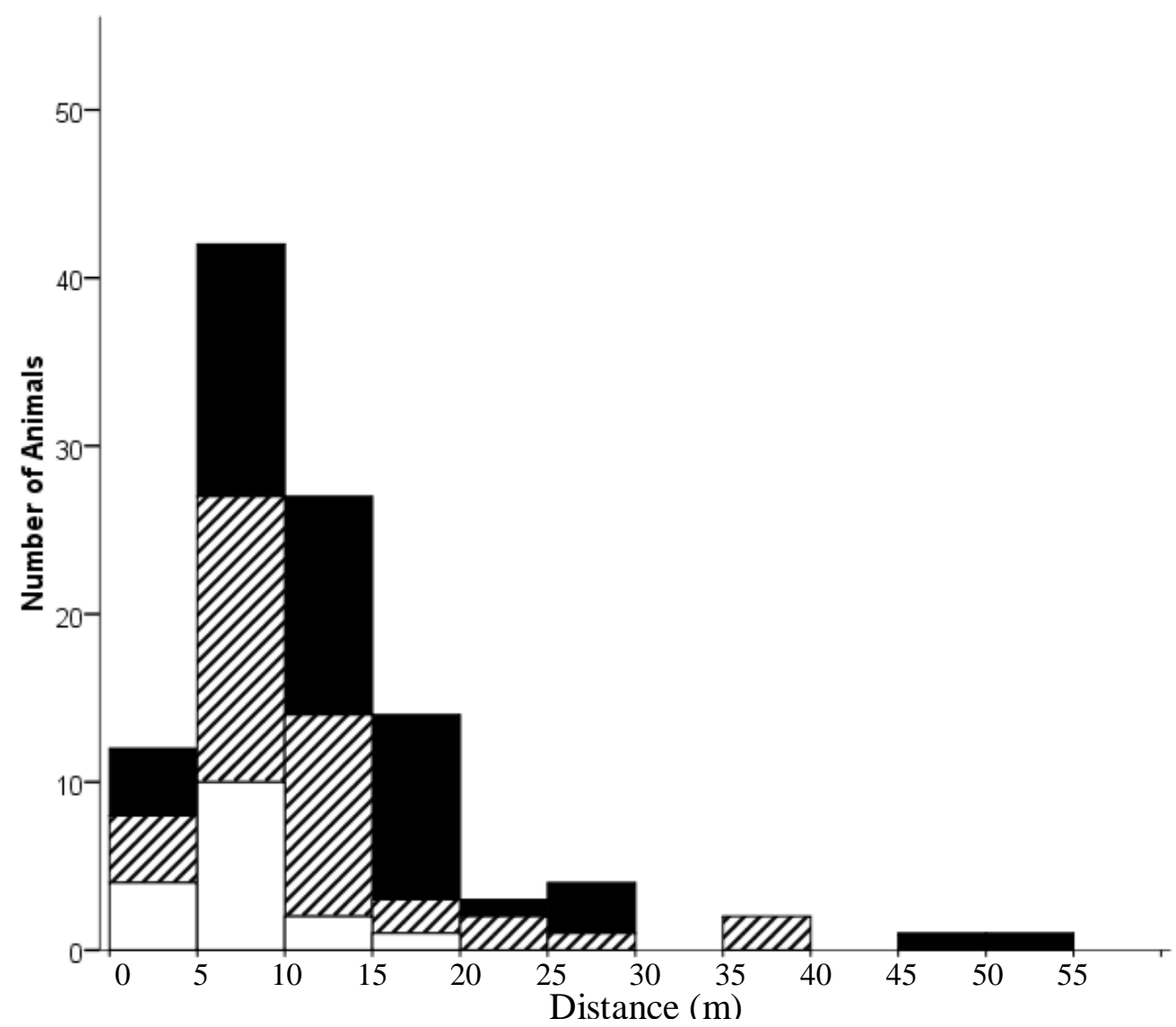

Figure 4.5 Furthest distance from 2008 grid square, encompassing all locations recorded for each $S$. punctatus captured in 2008 that were also captured at least once between 2000-2008. $\square$ Indicates 2 captures; $\square 3$ captures; 4 captures. The majority $(60 \%)$ of S. punctatus were captured previously within $10 \mathrm{~m}$ of their 2008 location (median $=8.3 \mathrm{~m} ; \mathrm{N}=106)$. 


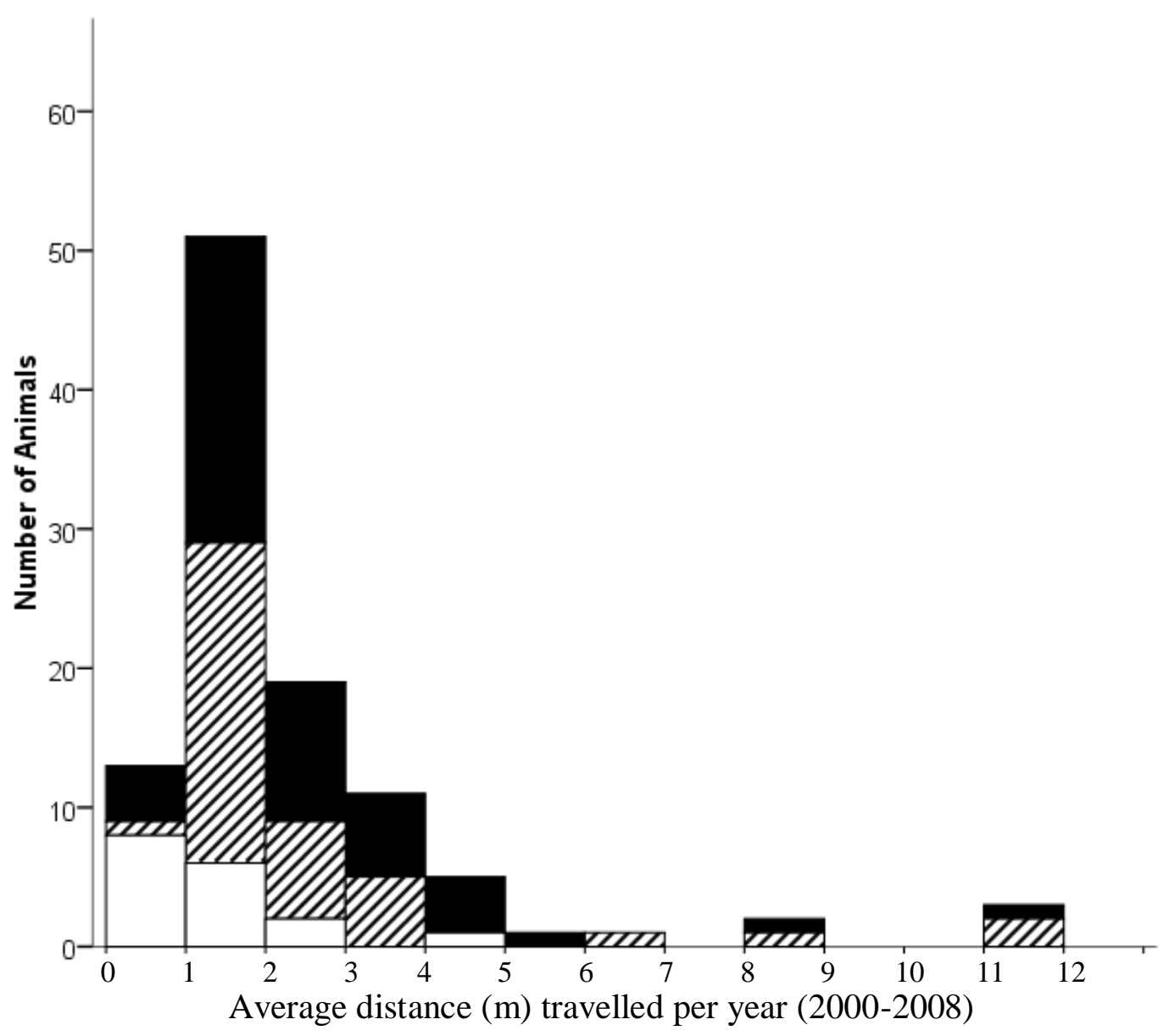

Figure 4.6 The average distance (m) travelled per year for $S$. punctatus individuals who were captured in 2008 and at least once during the previous four surveys from 20002008. $\square$ Indicates 2 captures; $\square 3$ captures; 4 captures. The majority (51\%) travelled less than $2 \mathrm{~m}$ per year (median $=1.9 \mathrm{~m} ; \mathrm{N}=106$ ).

\subsubsection{Body Condition}

Body condition (BC) for Duvaucel's gecko fluctuates over time but appears to be stable long-term (Figure 4.7). Body condition for tuatara also fluctuates but is declining over time (Figure 4.8; see Hoare et al. 2006 for more detailed analysis). Body condition for H. duvaucelii is related to rainfall levels. In the summer of 2000/2001 there was very little rain, which is likely the reason for the comparatively low BC score for $H$. duvaucelii captured during the 2001 research trip. While S. punctatus BC also fluctuates with rainfall, it does not explain the overall decline in $\mathrm{BC}$ in this species. 


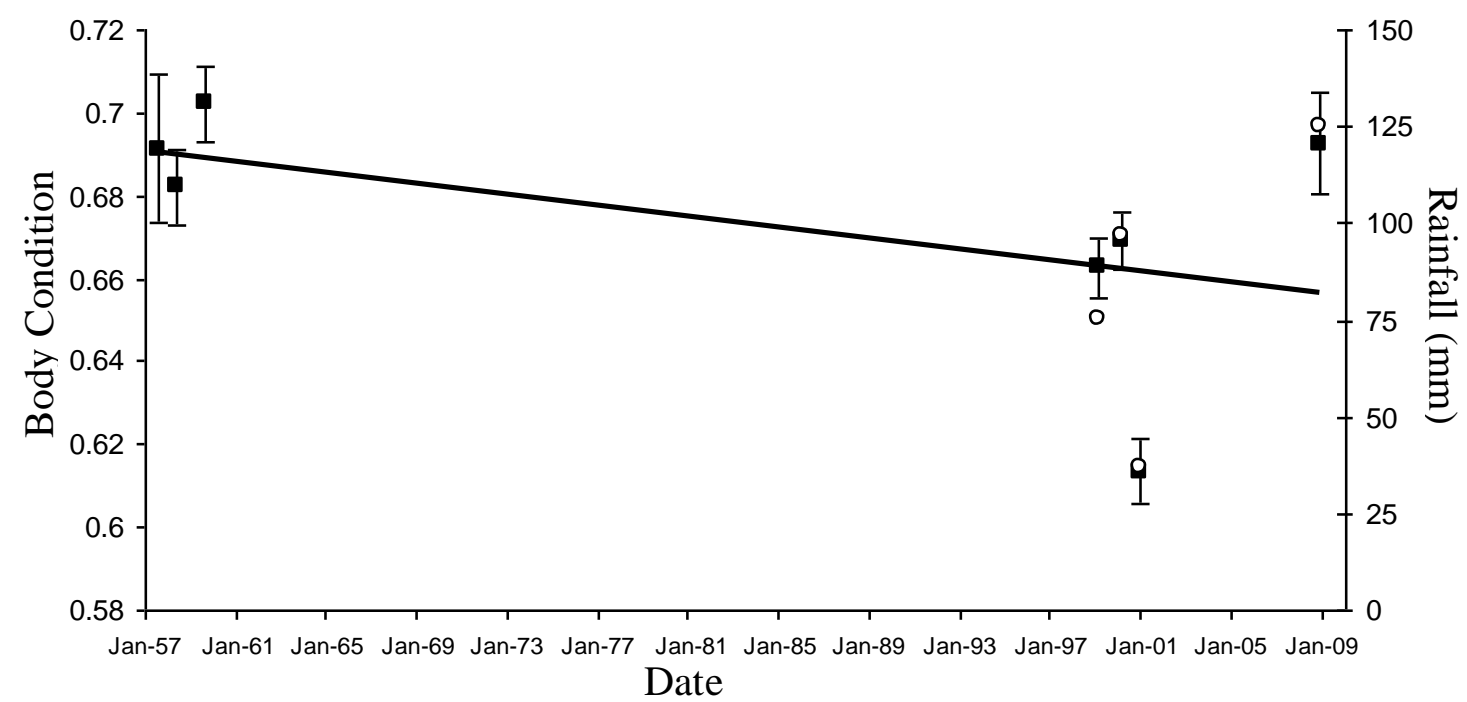

Figure 4.7 Mean body condition of Duvaucel's Gecko from 1957 - 2008 on North Brother Island. The bars indicate standard error. Body condition means include both adults and juveniles. $\mathrm{R}^{2}=0.2758$. Cumulative rainfall is for the two months prior to, but not including, the month of capture. Rainfall ( $($ ) data was unavailable for the first three trips. Body condition ( $\mathbf{a})$ rises and falls in relation to rainfall prior to capture occasion.

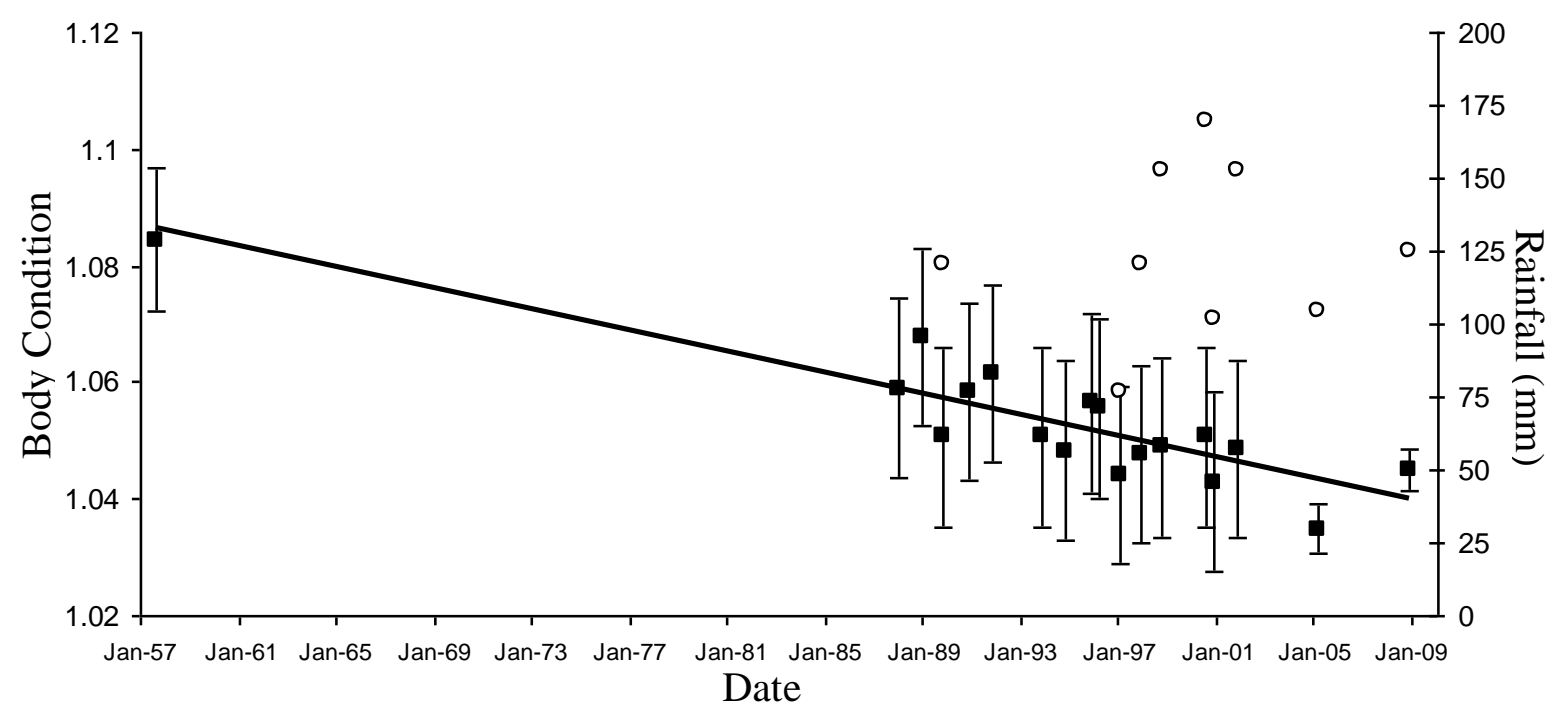

Figure 4.8 Mean body condition of adult tuatara from 1957 to 2008. The bars indicate standard error. The graph was taken from Hoare et al (2006) and adapted with data from 2005 and 2008 added. $R^{2}=0.7901$. Cumulative rainfall ( $\mathrm{O}$ ) is for the two months prior to, but not including, the month of capture. Rainfall data was unavailable for some trips. Body condition ( $\mathbf{a})$ fluctuates in the same pattern as rainfall but there is also an overall decline in condition. 


\subsection{Discussion}

Sphenodon punctatus and H. duvaucelii appear to be exhibiting a degree of partitioning, either in space, time or both. Spatially, H. duvaucelii were found in more open grid squares, where vegetation ground cover is minimal, whereas $S$. punctatus were present in more vegetated locations than open areas. Temporally, both species were caught at all times on all nights when searchers were active. Where both species occurred in the same location, the majority of animals were captured at different times or on different days, with only approximately $10 \%$ of all individuals of each species captured in the same location at the same time. Both species show site fidelity with the majority of animals previously located between 1999-2008 within 10m (tuatara) or 15m (Duvaucel's gecko) of their 2008 location. The majority of animals of both species also travelled less than $2 \mathrm{~m}$ on average per year. Body condition fluctuates over time in both species and is correlated with rainfall, but tuatara show an overall decline in condition since 1957 that is not evident in Duvaucel's gecko.

Vegetated areas are assumed to have more food resources and more habitat complexity than open areas; vegetated areas should have higher prey densities of herbivorous invertebrates and provide more shelter from the weather (Hoare et al. 2006). In a modified New Zealand grassland system, invertebrate and lizard species richness were positively correlated with vegetation cover (Norbury et al. 2009).The temporal and spatial partitioning on North Brother Island could be the result of $S$. punctatus excluding H. duvaucelii from vegetated areas. On North Brother Island, in the presence of tuatara, H. duvaucelii appeared to be out later in the night, with an optimal capture time of 23am, or were simply less conspicuous earlier in the night while tuatara were out. On islands where tuatara are not present, the optimal time to capture $H$. duvaucelii in mark- 
recapture studies is from dusk until midnight (Mana Island, Jones 2000; Korapuki Island, Van Winkel 2008). However, these studies were conducted in forested areas as opposed to the largely open ground of North Brother Island, which may affect patterns of behaviour. Disturbance using spotlighting techniques was also identified as an issue by Jones and Van Winkel, reducing capture rates later in the night. If disturbance was a factor in sightings on North Brother Island, it would be expected that fewer animals were observed later in the night, which was not the case. The contrasting results indicate Hoplodactylus duvaucelii could be avoiding S. punctatus in order to reduce competition or predation risk on North Brother Island.

Exclusion of access to resources of one species by another has been observed in several species. For example in Israel, where two gerbil species occur together, the dominant species Gerbiluis pyramidum excludes Gerbillus allenbyi, causing it to change its activity period and habitat selection from its usual behaviour in the absence of $G$. pyramidum (Ziv et al. 1993). The golden spiny mouse Acomys russatus is diurnal in the wild, where it overlaps in diet and habitat with the nocturnal common spiny mouse Acomys cahirinus, but reverts to nocturnal activity in laboratory conditions in the absence of its competitor (Kronfeld-Schor et al. 2001).

Further support for competition-induced changes has been gathered where Hoplodactylus duvaucelii occur with rats. Duvaucel's geckos overlap in diet and habitat with the introduced Pacific rat (Rattus exulans), but are observed to use preferred rat habitat when rats are removed (Hoare et al. 2007). Whitaker (1968), also suspected $H$. duvaucelii avoided larger skink species, as they became predominately arboreal in the 
presence of the ground dwelling lizards. North Brother Island does not support tall vegetation, ruling out the option of partitioning space vertically on this island.

In grid squares where species co-occurred, both spatial and temporal partitioning was evident, as only approximately $10 \%$ of each species were captured in the same place at the same time. However, the grid squares where individuals of both species were found at the same time generally had more complex habitat than other areas of the island. As individuals of both species appear to show strong site fidelity, it is likely that partitioning occurs to avoid agonistic interactions between neighbours, most likely by H. duvaucelii avoiding S. punctatus.

Of the few records where large movements were observed, the movement of adult male tuatara may be related to establishing and maintaining territories. To move territories, higher quality habitat must be available and the gains associated with moving must be higher than the costs (Switzer 1993). Switzer (1993) speculates that for long-lived species the costs of moving territories is higher than the gain in territory quality over a lifetime. The two large male tuatara (SVL 230 and 238mm), who moved over $5 \mathrm{~m}$ per year on average, but stayed within $20 \mathrm{~m}$ of their 2008 capture locations, may simply have large territories. Males on Stephens Island had an average territory size of $30.6 \pm$ $3.9 \mathrm{~m}^{2}$, although results were variable (Moore et al. 2009). The territories of large males were found to overlap those of smaller males on Stephens Island as large males always outcompeted smaller males and could easily prevent smaller males from accessing females or acquiring resources. Males may also move to guard breeding females (Moore et al. 2009). Movements by Duvaucel's gecko do not provide any substantial information on dispersal; the male and female moving large distances were both fully 
grown. In other species, juveniles generally disperse more than adults and often only one sex disperses (Greenwood 1980). The lack of information on juvenile movements due to low captures meant that in this study, age-related dispersal was unable to be determined.

There are limitations with the accuracy of site fidelity results as often searchers may not have accurately identified their location in the dark, especially for areas away from major landmarks, and could be as much as $5-10 \mathrm{~m}$ off the true location. The distortion of the older map will likely have exaggerated or underestimated distances (depending on which region of the map is being evaluated), and using the centre of each grid square will reduce accuracy further. However, in the absence of more detailed descriptions across all the surveys, the accuracy is as high as possible under the limitations described and will provide a consolidation of available information on which further studies can build.

Body condition fluctuated in both species over time, but there is a decline in tuatara body condition that cannot be explained solely by rainfall. Rainfall has been correlated with body condition in other species, including the common toad, Bufo bufo (Reading \& Clarke 1995), and desert mule deer Odocoileus homionus eremicus (Marshal et al. 2008). Body condition in Duvaucel's gecko fluctuated over time in the same pattern as rainfall totals for the two months prior to each trip, with higher body conditions occurring when rainfall was high.

According to competitive asymmetry theory, the larger tuatara should be excluding or displacing the smaller gecko and therefore be acquiring more high quality resources. 
Competitive asymmetry in favour of tuatara is supported by their domination in the use of vegetated locations and Duvaucel's gecko exhibiting contrasting activity periods compared to tuatara-free islands. However, although fluctuating, $H$. duvaucelii are maintaining body condition, whereas the condition of $S$. punctatus is declining. Although S. punctatus are much larger than $H$. duvaucelii, if resources are scarce and tuatara occupy areas of higher resources, both species should show a decline. The differences in trend suggest that tuatara are subject to environmental or biological mechanisms that do not affect geckos. Larger animals may be more vulnerable to variable environments as they generally have higher energy requirements than smaller animals. For example, large Galapagos marine iguana (Amblyrhynchus cristatus) lost more mass than their small-medium conspecifics in times of resource scarcity due to energy limitations (Wikelski et al. 1997). The foraging efficiency of the smaller Duvaucel's gecko may be higher than that of tuatara, despite the apparent resource poor locations they occupy. It is also possible that $H$. duvaucelii are exploiting plant food sources that are unavailable to $S$. punctatus. However, S. punctatus could potentially utilise the seabird and lizard populations for food that is unavailable to $H$. duvaucelii.

It is possible that the overall decline in tuatara relates to intra-specific density dependence, as suggested by Hoare et al. . (2006). A decline in body condition with higher densities of animals has been observed in other species, for example, impala Aepyceros melampus (Gaidet \& Gaillard 2008) and the common toad, Bufo bufo (Reading \& Clarke 1995). 


\subsection{Summary and Future Research}

Partitioning is occurring, both temporally and spatially, by reptiles on North Brother Island. Tuatara appear to be excluding Duvaucel's gecko, but the decline in tuatara body condition is contrary to what would be expected if they hold the favourable activity period and habitat. There may be intra-specific competition driving the decline in tuatara body condition, and this should be investigated further. Further studies are needed on partitioning across all three dimensions of diet, space, and time, to tease out the relationships among reptile species on North Brother Island. Interspecific interactions and partitioning patterns could also be investigated with the other reptile species in the community, especially Hoplodactylus maculatus, another nocturnal gecko that is smaller than H. duvaucelii. 


\section{Chapter 5: Synthesis of Results, Recommendations and}

\section{Summary.}

\subsection{Overview}

Population viability is determined by many factors, including anthropogenic influences, stochastic effects at the population and community level, and interspecific interactions. Coexistence of species in a community with similar niche requirements is determined by physiological constraints and resource partitioning through dietary, spatial and temporal means. I investigated the current population statuses and long-term trends of populations of Sphenodon punctatus and Hoplodactylus duvaucelii on North Brother Island. I aimed to determine if spatial and temporal partitioning is occurring as a result of competition between the two species on North Brother Island. This information is important as understanding population and community ecology can assist in conservation management.

Chapter 2: Sex bias in tuatara (Sphenodon punctatus) on North Brother Island. In this chapter I investigated the population structure and characteristics of tuatara on North Brother Island and explored the male sex ratio bias in this population. The tuatara population on North Brother Island has a large bias in the sex ratio with an estimated 3.24 males to 1 female. The population is recruiting, as juveniles were captured, but the group entering the breeding population has a stronger male bias than that of the adult population, with 4.1 males to 1 female. The total tuatara population for the island was estimated at 390-437 adults. Adult survival rate was high at $95 \%$ per year for both 
sexes. Body condition has declined for both sexes since 1957, but the decline is more rapid in females than males.

\section{Chapter 3: Population characteristics of Duvaucel's Gecko Hoplodactylus duvaucelii} on North Brother Island.

In this chapter I investigated the population structure and characteristics of $H$. duvaucelii on North Brother Island and investigated the potential for future translocations from this population. The population of Duvaucel's gecko (Hoplodactylus duvaucelii) on North Brother Island has an approximately even sex ratio. Recruitment is occurring, and population estimates for the island range from 583 to 677 adults. Both sexes had high annual survival rates (92\%) and long life spans with confirmed longevity of 43-50 years for one male and one female. Using this population as a translocation source is feasible, but with monitoring and restrictions for the source population (see section 5.4).

\section{Chapter 4: Potential for resource competition.}

In this chapter I investigated the potential for interspecific competition between the two species by examining spatial and temporal overlap. I also collated long-term data to evaluate site fidelity and body condition trends in both species over the past 50 years to investigate long-term trends on North Brother Island. Tuatara may be excluding Duvaucel's gecko as tuatara occurred predominantly in vegetated areas, whereas Duvaucel's gecko were found largely in areas of open ground. Tuatara were also generally captured earlier in the night than Duvaucel's gecko. In areas where both species occur, it appears that at least one species is avoiding the other, either spatially or temporally, as only approximately $10 \%$ of each species were caught at the same time in 
the same grid square as a member of the other species. Both species show site fidelity with the majority of animals previously located between 1999-2008 within 10m (tuatara) or 15m (Duvaucel's gecko) of their 2008 location. The majority of animals of both species also travelled less than $2 \mathrm{~m}$ per year from 1999-2008. Body condition fluctuates in both species and is correlated with rainfall, but tuatara show an overall decline in condition since 1957 that Duvaucel's gecko do not exhibit.

\subsection{Discussion of Results}

Both populations are likely to be at, or exceeding, carrying capacity, as individuals from North Brother Island of both species showed competitive release, gaining weight following translocation (Jones 2000; Nelson et al. 2002a). Although H. duvaucelii appears to be located largely in the open, resource poor, areas, the population has maintained a stable body condition over the past 50 years. Conversely, the $S$. punctatus population, although mainly located in high resource vegetated areas, continues to experience a decline in body condition. Moore et al. (2007) identified a similar decline in S. punctatus body condition on Stephens Island. They believed the decline was related to the population expanding rapidly after human disturbance, and reaching carrying capacity, which resulted in lower resource acquisition by individuals.

Cessation of anthropogenic interference, such as harvest of individuals and habitat modification, can lead to rapid recovery from low population numbers (Iverson et al. 2006). Long-lived species are thought to take centuries to recover from population decline due to long generation times or low reproduction, but this is not always the case. Like tuatara, the Hawaiian green turtle Chelonia mydas has a long generation time. 
Once environmental damage exploitation stopped in the 1970's, the abundance of nesting turtles in Hawaii increased dramatically over 30 years (Balazs \& Chaloupka 2004). The long-lived Allen Cays rock iguana (Cyclura cychlura inornata) were hunted to low numbers in the early 1900's but the population rapidly increased to over 500 adults by 2004 (Iverson et al. 2006). A similar effect is suspected to have occurred on North Brother Island. Many tuatara were collected from North Brother Island in the mid to late 1800 's, reducing population numbers to low levels (Newman 1878).

Construction of the lighthouse likely reduced population numbers further. Rapid population growth following the cessation of human disruption of the island could have caused carrying capacity to be met, or even exceeded. The long lifespan and low adult mortality of S. punctatus are likely to contribute to maintaining high population levels long after the conditions promoting the population explosion no longer exist.

A population at carrying capacity should show resource competition. Body size is a stronger predictor of success in acquiring food in captive juvenile $S$. punctatus than an individual's sex, in experimental dyads under semi-natural conditions (Wörner 2009). If this translates to the adult population, where males are larger than females due to sexual dimorphism, males may acquire more food than females. The same may also apply to interspecific interactions, where tuatara could outcompete the smaller H. duvaucelii. The former prediction may be valid as females show a steeper decline in body condition than males. The latter prediction does not seem to hold up under the natural conditions on North Brother Island, as H. duvaucelii body condition is holding steady while that of S. punctatus is declining. Although $H$. duvaucelii could potentially have access to plant resources that are unavailable to S. punctatus (see chapter 4), they inhabit predominantly lower resource areas and should exhibit similar patterns to $S$. punctatus 
in body condition if the decline is related to resource availability alone, as suggested by Hoare et al. (2006).

If resource acquisition is not solely responsible for the decline in tuatara body condition, other factors influencing body condition must be considered. Sex-biased densitydependent intraspecific aggression could be a factor for tuatara and may also explain why females are declining at a faster rate than males (as discussed in Chapter 2). Density-dependent aggression has been observed in this species. Juvenile tuatara housed in high densities had a higher frequency of aggressive interactions, and tail loss was evident in all animals in this group (Gruber 2007). However, tail loss may not be an accurate indicator of aggression in juveniles as young animals may mistake the tails of others for food items (Wörner 2009).

The population of $S$. punctatus on North Brother Island is also heavily male-biased, which has been observed to cause increased aggression in other species (Le Galliard et al. 2005). Increased aggression against females can result in higher stress, lower fecundity and increased mortality (Le Galliard et al. 2005). Manipulation of common lizard (Lacerta vivipara) population densities revealed that females bred less often in high-density populations (Massot et al. 1992). Female S. punctatus on North Brother Island have low reproductive rates (once every nine years) compared to females on neighbouring Stephens Island (once every three-five years). Although population densities are higher on Stephens Island, the habitat is very different, with more vegetation and forest. Resources acquisition is more likely to be an issue on North Brother Island, where animals are at lower densities than Stephens Island, but resources are scarce. Females are also less likely to breed when body condition is low. A 
combination of all these factors is possible in this population, and could potentially have a compounding effect.

If the population is at carrying capacity, low reproduction may not be detrimental to the long-term viability of the population. Fewer juveniles entering the population will mean that more space and resources are available for existing animals in the population. However, currently recruitment into the breeding population is strongly male biased, which could be due to differential juvenile mortality or more nests with temperatures producing males. This could exacerbate any male aggression and lead to further decline in body condition and reproductive output by females (See Chapter 2 for discussion), ultimately threatening population viability.

\subsection{Conservation issues and recommendations for Sphenodon punctatus on North Brother Island}

Intervention will likely be needed for this population in the near future to ensure longterm population viability. Four management options are discussed. All options have limitations and some may be difficult to implement.

\section{No Intervention}

From a scientific perspective, no intervention may provide an opportunity to study population dynamics, including population collapse and recovery, and potential for adaptation to climate change. Predictions for this population based on projected climate change for the region indicate fewer female hatchlings will be produced at even the most conservative warming estimations (Mitchell et al. 2008), and once $80 \%$ of 
hatchlings are male, population viability becomes compromised and intervention will be necessary.

Studying long-term population dynamics will also provide baseline data that will assist conservation managers in identifying viability issues in other populations of tuatara. This option runs the risk of population extinction, but will cost nothing. This option may not palatable to concerned parties such as management agencies, local iwi, and conservation scientists, who are unlikely to view any risk of extinction as a viable option.

\section{Habitat Restoration}

Moore et al. (2007) believe that on Stephens Island the decline in body condition will be reversed as natural reforestation continues, and more resources become available to tuatara. Habitat restoration, by removing unused structures and increasing vegetation cover, will increase resource availability (Hoare et al. 2006), but there is limited scope for this on North Brother Island, as there are only a few structures not currently in use that could be removed for restoration purposes.

Restoration could lead to increased resource acquisition by existing animals in the population, increasing body condition, or it may lead to a population increase as more territories become available to $S$. punctatus. If reproduction results in more males, as is expected under climate change (Mitchell et al. 2008), population viability issues surrounding male aggression and sex ratios will be exacerbated, potentially creating an extinction vortex (see Chapter 2). Habitat restoration could also damage the fragile environment in the short-term, potentially causing destabilisation of the soil, and 
mortality in many of the other species occurring on the island and allowing exotic weed species to establish instead of native vegetation. The severe climate experienced on this island will also create problems with erosion and plant establishment.

\section{Translocation or Removal of Animals}

Density-dependent effects are likely causing body condition decline in this population. For effective management, the population density needs to be decreased. Removing individuals from a population may seem counter intuitive, as it makes the population more susceptible to extinction from demographic and genetic stochasticity. However, if reducing the population can assist in long-term viability it needs to be seriously considered.

Because of the current male bias, at this stage all individuals translocated off the island should be male. This would distort the sex ratio of the recipient populations, but this could be counteracted by translocating females from another population, or by incubating eggs to produce females and releasing juvenile females into the population to balance sex ratios. Translocating females from other populations would also have the advantage of increasing genetic variation in the translocated population. Alternatively, animals removed could go to zoos or other wildlife facilities for captive breeding or educational purposes. Animals would need to be in excellent health for translocation and the risks of animals contracting diseases would need to be minimised. Several options exist for choosing animals for removal. Animals with high body condition could be removed from North Brother Island. Body condition can drop due to stress during translocation and these animals will be more likely to succeed in a new habitat, whereas animals with lower body condition may have difficulties with translocation and 
adjustment to new habitats. However, animals with higher body conditions may be fitter than other individuals in the population, so care should be taken in selecting animals for removal, so as not to compromise the North Brother Island population. Smaller males with high body condition may be the best option for translocation as they are less likely to have well-established territories. Removing animals may result in increasing body condition and reproduction in this population, if these problems are related to densitydependence. It may also result in increased recruitment, which, if male-biased, may exacerbate the current situation and have a negative impact on population viability. Any removal of animals will need to be followed up with monitoring of sex ratios and body condition on North Brother Island.

\section{Sex Ratio Manipulation}

Sex ratio manipulation can be done in two ways. Firstly, through removal of eggs, incubating them in a controlled environment to produce all females, and then returning them to the island (Mitchell et al. 2009). This option would guarantee female hatchlings and any sex bias in juvenile mortality in the wild could be counteracted through raising females separately in captivity before release. As well as technical issues around egg harvesting and incubation, biosecurity concerns would need to be addressed. Transfer of diseases and parasites are always a possibility and quarantine procedures would need to be implemented. In addition, returning animals to North Brother Island may exacerbate the density-dependent issues surrounding this population. Obtaining sufficient eggs to make this option viable may be difficult with as few as nine females, laying three to eight eggs each, nesting in any one year (Chapter 2, Mitchell et al. 2009) 
The second option is to try to manipulate sex ratios in the nest, by shading nesting sites to produce more females (Mitchell et al. 2008). However, structures could be easily damaged and uprooted due to the shallow soil and exposed nature of the island. Structures may need to be replaced often and will need to be established once eggs have been laid. As oviposition timing may differ between females, this may require yearly visits of indeterminate length, which will be time and resource consuming for an uncertain outcome, especially as the majority of females do not breed each year.

\subsection{Conservation issues and recommendations for Hoplodactylus duvaucelii on North Brother Island}

The population of $H$. duvaucelii is relatively large, has an even sex ratio and is recruiting. Although likely at carrying capacity, the population does not appear to exhibit any negative effects due to density dependence. Provided monitoring of this population continues, harvest of animals for translocation may be appropriate. Translocations should be restricted to allow the population to recover between translocation events. Given that reproduction may only be once every two years and that juveniles do not reach maturity until approximately seven years of age, this interval may need to be a minimum of ten years, and perhaps even longer. If removal of animals stimulates reproductive output, translocations may be made more often, but monitoring will need to be undertaken to ensure this is the case. As the last translocation was in 1998 and the population appears to be stable, further translocations can now be considered. Large animals, without identifying toe clips, should be harvested for translocation, as they are more likely to survive the process. The number of animals removed from the population should not exceed $10 \%$ of the total population, which 
would be approximately 60 animals. This should be comprised of 30 males and 30 females to ensure the population sex ratio on North Brother Island remains even.

Although no intervention is currently needed for H. duvaucelii on North Brother Island, monitoring should be continued. This is the only population of this species that has been studied long-term and so is important for investigating the natural history of this population, including longevity and changes in demography over time. Toe clipping is no longer being carried out on this population, but other forms of long-term identification, such as PIT tags (for larger animals), should be investigated so that longterm population modelling can continue.

\subsection{Future Research}

There are many research avenues that could be explored in the future in relation to $S$. punctatus and H. duvaucelii on North Brother Island.

\section{Monitoring}

Monitoring of both species on this island should continue, as North Brother Island is an excellent long-term study site, with 50 years of existing data. Specifically monitoring should look at:

- The current population status, including population size, sex ratio and size structure. This will provide managers with updated information on the status of the population and assist in making decisions regarding intervention. This is particularly important for $S$. punctatus, where changes in the sex ratio will have a large impact on population viability. 
- Long-term population dynamics including survival, longevity and body condition trends. Current records contain fifty years of data relating to individual animals including size, sex, location and when they were captured. By adding to these data, researchers can gain further insight into long-term trends in both species, and the processes that drive variability, as well as conduct further analyses on the current data library.

- The impact of translocations on source populations. This will be important if Duvaucel's gecko translocations go ahead. Baseline data for the species on this island have been established and any deviation from current trends following a translocation effort will be able to be measured.

\section{Intraspecific Interactions}

Intraspecific competition could be explored further in both species, but may be of more benefit in tuatara as it may be one of the reasons behind the increased loss of body condition in female tuatara. Specifically, research should focus on the following.

- Aggressive behaviours towards females by males in S. punctatus. Female body condition could be declining as a result of male harassment (See chapter 2 for discussion). Aggression among males has been documented already on Stephens Island (Moore et al. 2009), but male aggression related to density could be investigated further.

- Acquisition of food by both sexes and across size classes in a group environment for S. punctatus. Work on behaviour relating to food has already been carried out in captive juvenile dyads (Wörner 2009), but whether these results transfer to group situations containing adults should be investigated further. 
- Interactions among $H$. duvaucelii could be investigated further as little is known about their behaviour in the wild.

\section{Interspecific interactions}

Patterns of partitioning indicate that $H$. duvaucelii are avoiding $S$. punctatus either spatially or temporally. Future research should focus on the following:

- Predation on H. duvaucelii by $S$. punctatus. Are tuatara responsible for the tail loss in Duvaucel's gecko? Are H. duvaucelii contributing to the diet of $S$. punctatus and, if so, are the animals being eaten juveniles, adults or all size classes?

- Recording the number of interactions between tuatara and Duvaucel's gecko and the outcome of these interactions. Knowledge of aggressive interactions, whether Duvaucel's gecko are being chased off, injured or killed would contribute to the understanding of partitioning patterns on North Brother Island.

- Interactions with other reptile species in the community, particularly Hoplodactylus maculatus, a small, nocturnal gecko.

\section{Partitioning patterns}

There is scope for further analysis into diet, spatial and temporal partitioning. Some avenues of research are suggested here:

- Investigating the diet of S. punctatus on North Brother Island. Currently dietary preferences of $S$. punctatus on North Brother Island are inferred by isolated observations, or assumed to be similar to tuatara on neighbouring islands where diet composition is known. 
- Differences in partitioning patterns on either side of North Brother Island.

Different patterns of partitioning spatially and temporally may be evident on the south face, where tuatara are scarce, compared to the north face, where tuatara are at high densities.

- Investigating spatial partitioning at the microhabitat scale may also be beneficial, particularly for those areas where results showed both species cooccurred in space and time.

- Identifying activity period for both species. By monitoring activity over the course of a whole night for a focal group of animals, the entire activity period for both species could be estimated. This thesis only looked at the time an individual was first caught at night to give an indication of temporal sharing between the two species. Patterns of partitioning may be more, or perhaps less evident, once the entire activity period is known. Caution will be necessary in determining observation methodology, as any disturbance may affect subsequent activity. Video technology may be useful for this investigation.

\subsection{Conclusion}

Tuatara will need active intervention to prevent the population from collapsing due to sex bias and density dependent effects. Duvaucel's gecko can be harvested for translocation, but this should be restricted to allow the population time to recover between translocation events. Both populations should continue to be monitored, as North Brother Island provides a unique opportunity to study population trends and community dynamics in the long-term. 
Appendix 


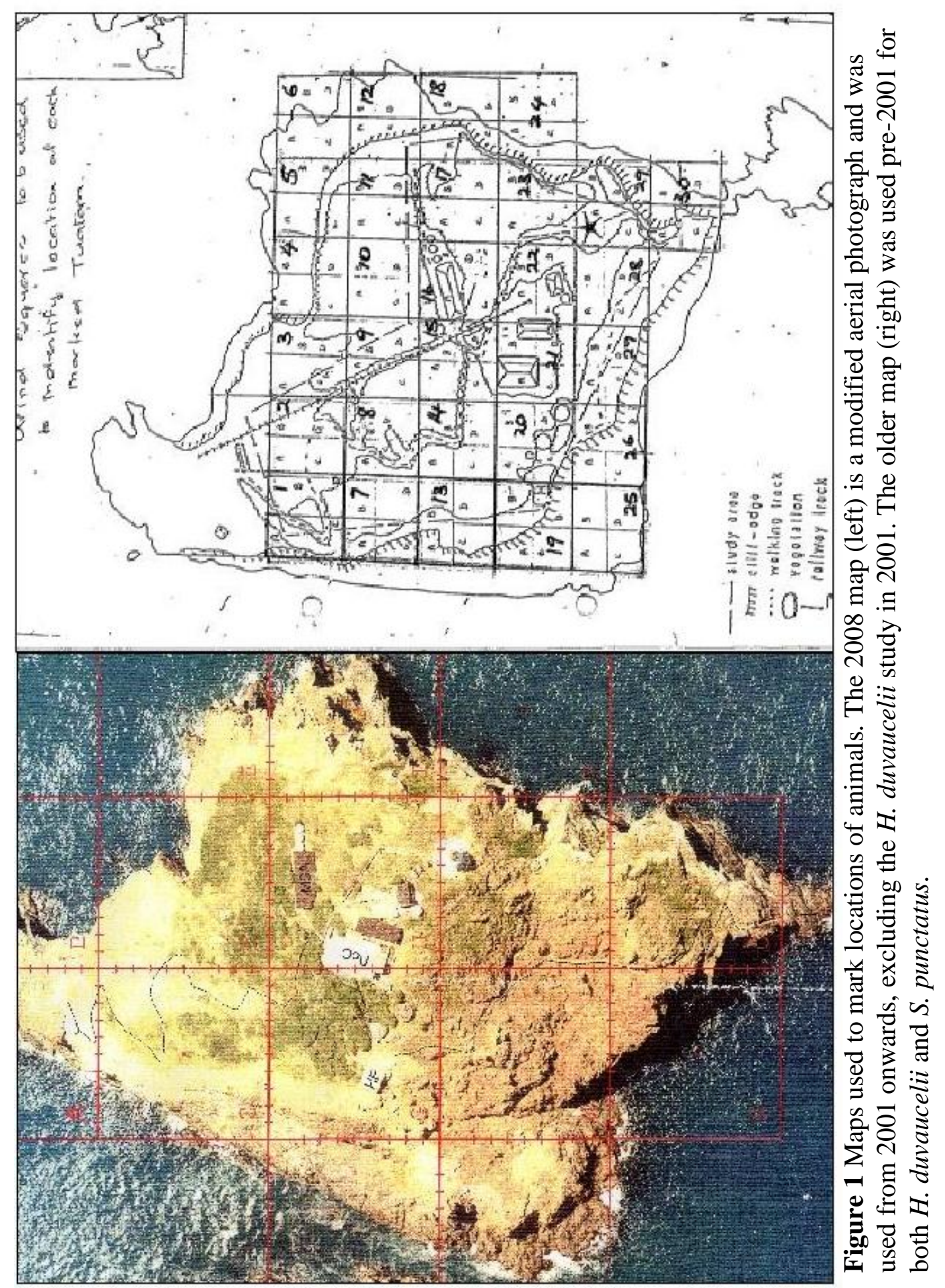




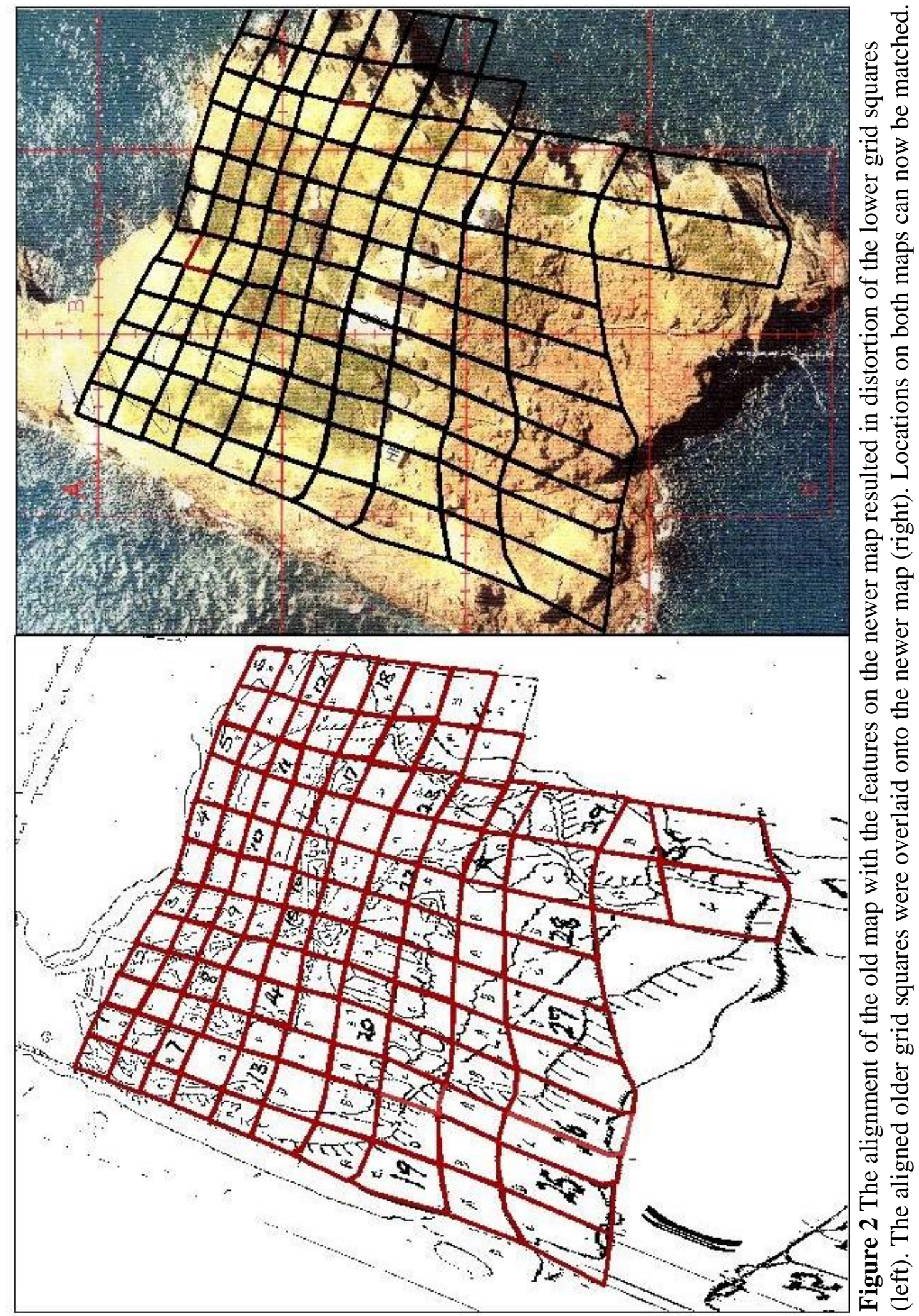




\section{References}

Adams, R. A., and K. M. Thibault. 2006. Temporal resource partitioning by bats at water holes. Journal of Zoology 270:466-472.

Anon. Lighthouses of New Zealand: The Brothers K4246. Maritime NZ.

Arjo, W. M., and D. H. Pletscher. 1999. Behavioral responses of coyotes to wolf recolonization in northwestern Montana. Canadian Journal of Zoology-Revue Canadienne De Zoologie 77:1919-1927.

Balazs, G. H., and M. Chaloupka. 2004. Thirty-year recovery trend in the once depleted Hawaiian green sea turtle stock. Biological Conservation 117:491-498.

Bannock, C. A., A. H. Whitaker, and G. J. Hickling. 1999. Extreme longevity of the common gecko (Hoplodactylus maculatus) on Motunau Island, Canterbury, New Zealand. New Zealand Journal of Ecology 23:101-103.

Barwick, R. E. 1982. The growth and ecology of the gecko Hoplodactylus duvauceli at the Brother's Island. Pages 377-391 in D. G. Newman, editor. New Zealand Herpetology. New Zealand Wildlife Service, Wellington.

Blaustein, A. R., D. B. Wake, and W. P. Sousa. 1994. Amphibian declines: Judging stability, persistence, and susceptibility of populations to local and global extinctions. Conservation Biology 8:60-71.

Blossey, B. 1999. Before, during and after: The need for long-term monitoring in invasive plant species management. Biological Invasions 1:301-311.

Both, C., S. Bouwhuis, C. M. Lessells, and M. E. Visser. 2006. Climate change and population declines in a long-distance migratory bird. Nature 441:81-83.

Boyce, M. S., C. V. Haridas, and C. T. Lee. 2006. Demography in an increasingly variable world. Trends in Ecology \& Evolution 21:141-148.

Buller, W. L. 1877. Notes on the tuatara lizard (Sphenodon punctatum), with a description of a supposed new species. Transactions and Proceedings of the New Zealand Institute 9:317-325.

Burnham, K. P., and D. J. Anderson 2002. Model selection and multimodel inference. Springer Science + Business Media, New York.

Caughley, G. 1994. Directions in conservation biology. Journal of Animal Ecology 63:215-244.

Chesson, P. 2000. Mechanisms of maintenance of species diversity. Annual Review of Ecology and Systematics 31:343-364. 
Connell, J. H. 1983. On the prevalence and relative importance of interspecific competition - evidence from field experiments. American Naturalist 122:661696.

Cree, A. 1994. Low annual reproductive output in female reptiles from New Zealand. New Zealand Journal of Zoology 21:351-372.

Cree, A., C. H. Daugherty, S. F. Schafer, and D. Brown. 1991. Nesting and clutch size of tuatara (Sphenodon guntheri) on North Brother Island, Cook Strait. Tuatara 31:9-16.

Daugherty, C. H., A. Cree, J. M. Hay, and M. B. Thompson. 1990. Neglected taxonomy and continuing extinctions of tuatara (Sphenodon). Nature 347:177-179.

Dawbin, W. H. 1982. The tuatara, Sphenodon punctatus: aspects of life history, growth and longevity. Pages 237-250 in D. G. Newman, editor. New Zealand Herpetology. New Zealand Wildlife Service, Wellington.

Dimond, W. J., and D. P. Armstrong. 2007. Adaptive harvesting of source populations for translocation: a case study with New Zealand Robins. Conservation Biology 21:114-124.

Dodd, C. K., and R. A. Seigel. 1991. Relocation, repatriation, and translocation of amphibians and reptiles - are they conservation strategies that work. Herpetologica 47:336-350.

Eldridge, M. D. B., J. M. King, A. K. Loupis, P. B. S. Spencer, A. C. Taylor, L. C. Pope, and G. P. Hall. 1999. Unprecedented low levels of genetic variation and inbreeding depression in an island population of the Black-Footed RockWallaby. Conservation Biology 13:531-541.

Fisher, R. A. 1930. The genetical theory of natural selection. Oxford University Press, London.

Flannagan, H. J. 2000. Conservation biology of the goldstripe gecko (Hoplodactylus chrysosireticus) and interactions with Duvaucel's gecko (Hoplodactylus duvaucelii) on Mana Island, Cook Strait, New Zealand. Page 92. Massey University, Palmerston North.

Gaidet, N., and J. M. Gaillard. 2008. Density-dependent body condition and recruitment in a tropical ungulate. Canadian Journal of Zoology-Revue Canadienne De Zoologie 86:24-32.

Gaston, A. J., and P. Scofield. 1995. Birds and tuatara on North Brother Island, Cook Strait, New Zealand. Notornis 42:27-41.

Gilbert, B., D. S. Srivastava, and K. R. Kirby. 2008. Niche partitioning at multiple scales facilitates coexistence among mosquito larvae. Oikos 117:944-950.

Gillam, M. E. 1960. Vegetation of Little Brother island, in relation to spray-bearing winds, soil salinity and pH. Transactions of the Royal Society of New Zealand 88:405-424. 
Gillingham, J. C., C. Carmichael, and T. Miller. 1995. Social Behavior of the Tuatara, Sphenodon punctatus. Herpetological Monographs 9:5-16.

Goldschmidt, T., F. Witte, and J. Wanink. 1993. Cascading effects of the introduced Nile perch on the detritivorous/ phytoplanktivorous species in the sublittoral areas of Lake Victoria. Conservation Biology 7:686-700.

Goodyear, S. E., and E. R. Pianka. 2008. Sympatric ecology of five species of fossorial snakes (Elapidae) in Western Australia. Journal of Herpetology 42:279-285.

Gordon, C. E. 2000. The coexistence of species. Revista Chilena De Historia Natural 73:175-198.

Greenwood, P. J. 1980. Mating systems, philopatry and dispersal in birds and mammals Animal Behaviour 28:1140-1162.

Gruber, M. A. M. 2007. Conservation of tuatara (Sphenodon): an evaluation of the survival and growth of artificially incubated, headstarted juveniles. Victoria University, Wellington.

Hay, J. M., S. D. Sarre, D. M. Lambert, F. W. Allendorf, and C. H. Daugherty. 2010. Genetic diversity and taxonomy: a reassessment of species designation in tuatara (Sphenodon: Reptilia). Conservation Genetics:1-19.

Hitchmough, R., L. Bull, and P. Cromarty. 2007. New Zealand threat classification system lists 2005. Department of Conservation, Wellington.

Hoare, J. M., S. Pledger, S. N. Keall, J. Nelson, N. J. Mitchell, and C. H. Daugherty. 2006. Conservation implications of a long-term decline in body condition of the Brothers Island tuatara (Sphenodon guntheri). Animal Conservation 9:456-462.

Hoare, J. M., S. Pledger, N. J. Nelson, and C. H. Daugherty. 2007. Avoiding aliens: Behavioural plasticity in habitat use enables large, nocturnal geckos to survive Pacific rat invasions. Biological Conservation 136:510-519.

IUCN. 2009. IUCN red list of threatened species. Version 2009.1. IUCN.

Iverson, J. B., S. J. Converse, G. R. Smith, and J. M. Valiulis. 2006. Long-term trends in the demography of the Allen Cays Rock Iguana (Cyclura cychlura inornata): Human disturbance and density-dependent effects. Biological Conservation 132:300-310.

Janzen, F. J. 1994. Climate change and temperature-dependent sex determination in reptiles. Proceedings of the National Academy of Sciences of the United States of America 91:7487-7490.

Jones, N. 2000. Establishment, dispersal and population viability of translocated Duvaucel's gecko (Hoplodactylus duvaucelii) on Mana Island. Page 87. Victoria University, Wellington. 
Kitchen, A. M., E. M. Gese, and E. R. Schauster. 1999. Resource partitioning between coyotes and swift foxes: space, time, and diet. Canadian Journal of ZoologyRevue Canadienne De Zoologie 77:1645-1656.

Kitchener, D. J., R. A. How, and J. Dell. 1988. Biology of Oedura reticulata and Gehyra variegata (Gekkonidae) in an isolated woodland of Western Australia. Journal of Herpetology 22:401-412.

Kronfeld-Schor, N., and T. Dayan. 1999. The dietary basis for temporal partitioning: food habits of coexisting Acomys species. Oecologia 121:123-128.

Kronfeld-Schor, N., and T. Dayan. 2003. Partitioning of time as an ecological resource. Annual Review of Ecology Evolution and Systematics 34:153-181.

Kronfeld-Schor, N., T. Dayan, R. Elvert, A. Haim, N. Zisapel, and G. Heldmaier. 2001. On the use of the time axis for ecological separation: Diel rhythms as an evolutionary constraint. American Naturalist 158:451-457.

Lance, V. A., R. M. Elsey, and J. W. Lang. 2000. Sex ratios of American alligators (Crocodylidae): male or female biased? Journal of Zoology 252:71-78.

Lande, R. 1993. Risks of population extinction from demographic and environmental stochasticity and random catastrophes. American Naturalist 142:911-927.

Lande, R. 1995. Mutation and conservation. Conservation Biology 9:782-791.

Lande, R. 1998. Anthropogenic, ecological and genetic factors in extinction and conservation. Researches on Population Ecology 40:259-269.

Le Galliard, J. F., J. Cote, and P. S. Fitze. 2008. Lifetime and intergenerational fitness consequences of harmful male interactions for female lizards. Ecology 89:56-64.

Le Galliard, J. F., P. S. Fitze, R. Ferriere, and J. Clobert. 2005. Sex ratio bias, male aggression, and population collapse in lizards. Proceedings of the National Academy of Sciences of the United States of America 102:18231-18236.

Lettink, M., and T. Whitaker. 2006. Hoplodactylus maculatus (common gecko). Longevity. Herpetological review 37:223-224.

Luiselli, L. 2006. Resource partitioning and interspecific competition in snakes: the search for general geographical and guild patterns. Oikos 114:193-211.

MacArthur, H., J. M. Diamond, and J. R. Karr. 1972. Density compensation in island faunas. Ecology 53:330-342.

Macarthur, R. H., and E. O. Wilson. 1963. Equilibrium-theory of insular zoogeography. Evolution 17:373-\&.

MacAvoy, E. S., L. M. McGibbon, J. P. Sainsbury, H. Lawrence, C. A. Wilson, C. H. Daugherty, and G. K. Chambers. 2007. Genetic variation in island populations of tuatara (Sphenodon spp) inferred from microsatellite markers. Conservation Genetics 8:305-318. 
Maness, T. J., M. A. Westbrock, and D. J. Anderson. 2007. Ontogenic sex ratio variation in Nazca Boobies ends in male-biased adult sex ratio. Waterbirds 30:10-16.

Marshal, J. P., P. R. Krausman, and V. C. Bleich. 2008. Body condition of mule deer in the Sonoran Desert is related to rainfall. Southwestern Naturalist 53:311-318.

Massot, M., J. Clobert, T. Pilorge, J. Lecomte, and R. Barbault. 1992. Density dependence in the common lizard - demographic consequences of a density manipulation. Ecology 73:1742-1756.

Merkle, J. A., D. R. Stahler, and D. W. Smith. 2009. Interference competition between gray wolves and coyotes in Yellowstone National Park. Canadian Journal of Zoology-Revue Canadienne De Zoologie 87:56-63.

Millar, I., and P. Gaze. 1997. Island Management: A strategy for island management in Nelson/Marlborough Conservancy. Department of Conservation, Nelson.

Miller, H. C., J. A. Moore, F. W. Allendorf, and C. H. Daugherty. 2009. The evolutionary rate of tuatara revisited. Trends in Genetics 25:13-15.

Mitchell, N. J., F. W. Allendorf, S. N. Keall, C. H. Daugherty, and N. J. Nelson. 2009. Demographic effects of temperature-dependent sex determination: will tuatara survive global warming? Global Change Biology 9999.

Mitchell, N. J., M. R. Kearney, N. J. Nelson, and W. P. Porter. 2008. Predicting the fate of a living fossil: how will global warming affect sex determination and hatching phenology in tuatara? Proceedings of the Royal Society B-Biological Sciences 275:2185-2193.

Mitchell, N. J., N. J. Nelson, A. Cree, S. Pledger, S. N. Keall, and C. H. Daugherty. 2006. Support for a rare pattern of temperature-dependent sex determination in archaic reptiles: evidence from two species of tuatara (Sphenodon). Front Zool 3:9.

Moehlman, P. D., G. Amato, and V. Runyoro. 1996. Genetic and demographic threats to the black rhinoceros population in the Ngorongoro Crater. Conservation Biology 10:1107-1114.

Moore, J. A., C. H. Daugherty, and N. J. Nelson. 2009. Large Male Advantage: Phenotypic and Genetic Correlates of Territoriality in Tuatara. Journal of Herpetology 43:570-578.

Moore, J. A., J. M. Hoare, C. H. Daugherty, and N. J. Nelson. 2007. Waiting reveals waning weight: Monitoring over 54 years shows a decline in body condition of a long-lived reptile (tuatara, Sphenodon punctatus). Biological Conservation 135:181-188.

Mullan, B., D. Wratt, S. Dean, M. Hollis, S. Allan, T. Williams, and G. Kenny. 2008. Climate change effects and impacts assessment: a guidance manual for local government in New Zealand. 2nd edition. Page xviii +149 p. Ministry for the Environment, Wellington. 
Nelson, N. J., S. N. Keall, D. Brown, and C. H. Daugherty. 2002a. Establishing a new wild population of tuatara (Sphenodon guntheri). Conservation Biology 16:887894.

Nelson, N. J., S. N. Keall, S. Pledger, and C. H. Daugherty. 2002b. Male-biased sex ratio in a small tuatara population. Journal of Biogeography 29:633-640.

Newman, A. K. 1878. Notes on the physiology and anatomy of the tuatara (Sphenodon guntheri). Transactions and Proceedings of the New Zealand Institute 10:222239.

Norbury, G., R. Heyward, and J. Parkes. 2009. Skink and invertebrate abundance in relation to vegetation, rabbits and predators in a New Zealand dryland ecosystem. New Zealand Journal of Ecology 33:24-31.

Parmesan, C., N. Ryrholm, C. Stefanescu, J. K. Hill, C. D. Thomas, H. Descimon, B. Huntley, L. Kaila, J. Kullberg, T. Tammaru, W. J. Tennent, J. A. Thomas, and M. Warren. 1999. Poleward shifts in geographical ranges of butterfly species associated with regional warming. Nature 399:579-583.

Peterson, R. O., N. J. Thomas, J. M. Thurber, J. A. Vucetich, and T. A. Waite. 1998. Population limitation and the wolves of Isle Royale. Journal of Mammalogy 79:828-841.

Pike, D. A., L. Pizzatto, B. A. Pike, and R. Shine. 2008. Estimating survival rates of uncatchable animals: The myth of high juvenile mortality in reptiles. Ecology 89:607-611.

Rankin, D. J., and H. Kokko. 2007. Do males matter? The role of males in population dynamics. Oikos 116:335-348.

Read, J. L. 1999. Longevity, reproductive effort and movements of three sympatric Australian arid-zone geckos. Australian Journal of Zoology 47:307-316.

Reading, C. J. 1997. A proposed standard method for surveying reptiles on dry lowland heath. Journal of Applied Ecology 34:1057-1069.

Reading, C. J., and R. T. Clarke. 1995. The effects of density, rainfall and environmental temperature on body condition and fecundity in the common toad, Bufo bufo. Oecologia 102:453-459.

Reale, D., P. Bousses, and J. L. Chapuis. 1996. Female-biased mortality induced by male sexual harassment in a feral sheep population. Canadian Journal of Zoology-Revue Canadienne De Zoologie 74:1812-1818.

Rodda, G. H., and K. Dean-Bradley. 2002. Excess density compensation of island herpetofaunal assemblages. Journal of Biogeography 29:623-632.

Sæther, B.-E. 1997. Environmental stochasticity and population dynamics of large herbivores: a search for mechanisms. Trends in Ecology \& Evolution 12:143149. 
Schoener, T. W. 1983. Field experiments on interspecific competition. American Naturalist 122:240-285.

Schwanz, L. E., and F. J. Janzen. 2008. Climate change and temperature-dependent sex determination: can individual plasticity in nesting phenology prevent extreme sex ratios? Physiological and Biochemical Zoology 81:826-834.

Shaffer, M. L. 1981. Minimum population sizes for species conservation. Bioscience 31:131-134.

Sparks, T. H., D. B. Roy, and R. L. H. Dennis. 2005. The influence of temperature on migration of Lepidoptera into Britain. Global Change Biology 11:507-514.

Switzer, P. V. 1993. Site fidelity in predictable and unpredictable habitats. Evolutionary Ecology 7:533-555.

Thomas, C. D., and J. J. Lennon. 1999. Birds extend their ranges northwards. Nature 399:213-213.

Thompson, M. B., C. H. Daugherty, A. Cree, D. C. French, J. C. Gillingham, and R. E. Barwick. 1992. Status and longevity of the tuatara, Sphenodon guntheri, and Duvaucel gecko, Hoplodactylus duvaucelii, on North Brother Island, New Zealand. Journal of the Royal Society of New Zealand 22:123-130.

Toft, C. A. 1985. Resource partitioning in amphibians and reptiles. Copeia:1-21.

Towns, D. R., I. A. E. Atkinson, and C. H. Daugherty. 1990. The potential for ecological restoration in the Mercury Islands. Pages 91-108 in D. R. Towns, C. H. Daugherty, and I. A. E. Atkinson, editors. Ecological Restoration of New Zealand Islands. Department of Conservation, Wellington.

Towns, D. R., and K. G. Broome. 2003. From small Maria to massive Campbell: forty years of rat eradications from New Zealand islands. New Zealand Journal of Zoology 30:377-398.

Towns, D. R., C. H. Daugherty, and D. G. Newman. 1985. An overview of the ecological biogeography of the New Zealand lizards (Gekkonidae, Scincidae). Pages 107-123 in G. Grigg, R. Shine, and H. Ehmann, editors. Biology of Australasian Frogs and Reptiles, New South Wales.

Towns, D. R., and S. M. Ferreira. 2001. Conservation of New Zealand lizards (Lacertilia : Scincidae) by translocation of small populations. Biological Conservation 98:211-222.

Tucker, J. K., C. R. Dolan, J. T. Lamer, and E. A. Dustman. 2008. Climatic warming, sex ratios, and red-eared sliders (Trachemys scripta elegans) in Illinois. Chelonian Conservation and Biology 7:60-69.

van de Merwe, J., K. Ibrahim, and J. Whittier. 2006. Effects of nest depth, shading, and metabolic heating on nest temperatures in sea turtle hatcheries. Chelonian Conservation and Biology 5:210-215. 
Van Winkel, D. 2008. Efficiency of techniques for post-translocation monitoring of the Duvaucel's gecko (Hoplodactylus duvaucelii) and evidence of native avian predation on lizards. Page 231. Massey University, Auckland.

Walls, G. Y. 1981. Feeding ecology of the tuatara (Sphenodon punctatus) on Stephens Island, Cook Strait. New Zealand Journal of Ecology 4:89-97.

Whitaker, A. H. 1968. Lizards of Poor Knights Islands New Zealand. New Zealand Journal of Science 11:623-\&.

Wikelski, M., V. Carrillo, and F. Trillmich. 1997. Energy limits to body size in a grazing reptile, the Galapagos marine iguana. Ecology 78:2204-2217.

Wooller, R. D., U. S. Bradley, and J. P. Croxall. 1992. Long-term population studies of seabirds. Trends in Ecology and Evolution 7:111-114.

Wörner, L. L. B. 2009. Aggression and competition for space and food in captive juvenile tuatara (Sphenodon punctatus). Page 111. Victoria University.

Worthy, T. H. 1987. Osteological observations on the larger species of the skink Cyclodina and the subfossil occurrence of these and the gecko Hoplodactylus duvaucelii in the North Island, New Zealand. New Zealand Journal of Zoology 14:219-229.

Worthy, T. H. 1998. Quaternary fossil faunas of Otago, South Island, New Zealand. Journal of the Royal Society of New Zealand 28:421-521.

Worthy, T. H., and R. N. Holdaway. 1995. Quaternary fossil faunas from caves on Mt Cookson, North Canterbury, South Island, New Zealand. Journal of the Royal Society of New Zealand 25:333-370.

Young, T. P. 1994. Natural die-offs of large mammals - implications for conservation. Conservation Biology 8:410-418.

Ziv, Y., Z. Abramsky, B. P. Kotler, and A. Subach. 1993. Interference competition and temporal and habitat partitioning in 2 gerbil species. Oikos 66:237-246. 